\title{
TRATAMENTO DAS LESÕES ENDO-PERIODONTAIS: UMA REVISÃO DE ESCOPO
}

\section{TREATMENT OF ENDO-PERIODONTAL LESIONS: A SCOPE REVIEW}

Belén Retamal-Valdes ${ }^{1}$, Kamila Ribeiro do Nascimento Jabur², Silvana Felisberto Monteiro ${ }^{3}$, Laryssa Macedo de Oliveira $^{4}$, Renata Queiroz Tavares ${ }^{5}$, Cristiane Gonçalves ${ }^{6}$, Magda Feres ${ }^{7}$

\author{
Submetido: 29/01/2021 \\ Aprovado: 24/02/2021
}

\begin{abstract}
RESUMO
As lesões endo-periodontais são lesões destrutivas que acometem o tecido periodontal e pulpar de um determinado dente. $\mathrm{O}$ diagnóstico e o tratamento dessas lesões representam um grande desafio na prática clínica. Logo, o objetivo desta revisão foi responder a seguinte pergunta foco: "Quais são os protocolos de tratamento para as lesões endo-periodontais? " Uma revisão de escopo foi realizada de acordo com as normas PRISMA-ScR. A base de dados MEDLINE (Pubmed) foi pesquisada até agosto de 2020. Foram procurados estudos com qualquer desenho que relataram o tratamento endodôntico e periodontal de pelo menos um dente com lesão endo-periodontal. A busca eletrônica gerou 238 títulos/resumos e 44 artigos foram incluídos nesta revisão. No total, 545 voluntários foram incluídos e 651 dentes foram diagnosticados/tratados como lesões endo-periodontais. A terapia de maior prevalência foi o tratamento endodôntico convencional antes da terapia periodontal cirúrgica, seguido pelo tratamento endodôntico cirúrgico sendo realizado ao mesmo tempo que o tratamento periodontal cirúrgico, e em menor proporção a terapia periodontal não cirúrgica antes da terapia endodôntica. Não existiram relatos de casos onde o tratamento periodontal cirúrgico ocorreu antes da endodontia convencional. Em conclusão, o tratamento das lesões endo-periodontais deve envolver tanto a terapia endodôntica quanto a periodontal. A maioria dos casos relatados iniciou o tratamento pela endodontia convencional e seguido pelo tratamento periodontal (não-cirúrgico e/ou cirúrgico). Porém, ainda existe controvérsia se deve ser aguardado um tempo de reparo entre os dois tratamentos. A maioria dos dentes diagnosticados com algum tipo de lesão endo-periodontal e tratados tem resultados positivos.
\end{abstract}

PALAVRAS-CHAVES: Lesões endo-periodontais. Tratamento. Classificação. Tratamento endodôntico. Tratamento periodontal.

\footnotetext{
ABSTRACT

Endo-periodontal lesions are destructive lesions that affect the tooth periodontal and pulp tissues. The diagnosis and treatment of these lesions represent a great challenge for clinical practice. Therefore, the aim of this review was to answer the following focused question: "Which are the treatment protocols for endo-periodontal lesions? A scoping review was conducted following the PRISMA-ScR statement. The MEDLINE database (PubMed) was searched up to August 2020. Studies with any design that reported endodontic and periodontal treatment of at least one tooth with endo-periodontal lesion were included. The electronic search generated 238 titles/abstracts and 44 articles were included in this review. In total, 545 volunteers were included and 651 teeth with endo-periodontal

${ }^{1}$ Cirurgiã dentista, mestrado em odontologia (área de concentração em periodontia), doutorado em odontologia (área de concentração em periodontia). - https://orcid.org/0000-0003-1444-991X - belen.valdes@prof.ung.br

2 Cirurgiã dentista - ka.milaribeiro@hotmail.com

3 Cirurgiã dentista - sil_m25@hotmail.com

4 Cirurgiã dentista, mēstranda em odontologia (área de concentração em periodontia). - https://orcid.org/00000002-8683-9821 - laryssa.moliveira@edu.ung.br

5 Cirurgiã dentista, especialista em periodontia, especialista em ortodontia, mestranda em odontologia (área de concentração em periodontia). - renataqtavares@yahoo.com.br

6 Cirurgiã dentista, especialista em periodontia, especialista em microbiologia oral, especialista em radiologia odontológica e imaginologia, mestrado em periodontia, doutorado em odontologia (área de concentração em periodontia). - cristianegoncalves.10@gmail.com

7 Cirurgiã dentista, especialista em periodontia, mestrado em periodontia, doutorado em ciências médicas e biologia oral. - https://orcid.org/0000-0002-2293-3392 - mferes@gmail.com
} 


\section{RECIMA21 - REVISTA CIENTÍFICA MULTIDISCIPLINAR}

TRATAMENTO DAS LESÕES ENDO-PERIODONTAIS: UMA REVISÃO DE ESCOPO Belén Retamal-Valdes, Kamila Ribeiro do Nascimento Jabur, Silvana Felisberto Monteiro, Laryssa Macedo de Oliveira, Renata Queiroz Tavares, Cristiane Gonçalves, Magda Feres

lesions were diagnosed/treated. The most prevalent therapy observed in this study was conventional endodontic treatment, conducted before surgical periodontal therapy, followed by surgical endodontic treatment at the same time as surgical periodontal treatment, and to a lesser extent non-surgical periodontal therapy before endodontic therapy. There were no reports of cases where surgical periodontal treatment occurred before conventional endodontics treatment. In conclusion, the treatment of endo-periodontal lesions must involve both endodontic and periodontal therapy. Most of the reported cases started treatment using conventional endodontic treatment, followed by periodontal treatment (non-surgical and / or surgical). However, there is still controversy as to whether or not some time should be respected between the two treatments in order to allow a better tissue repair. Most teeth diagnosed with some type of endo-periodontal lesion and treated showed positive outcomes.

KEYWORDS: Endo-perio lesions. Treatment. Classification. Endodontic treatment. Periodontal treatment.

\section{INTRODUÇÃO}

As lesões endo-periodontais são lesões destrutivas que acometem os tecidos periodontal e pulpar de um determinado dente, e podem ter apresentações agudas ou crônicas. São consideradas condições clínicas desafiadoras devido a necessidade de uma abordagem multidisciplinar para seu diagnóstico e tratamento (1). As lesões endo-periodontais apresentam baixa prevalência e são mais frequentes em pacientes com periodontite avançada (2). Entretanto, elas apresentam grande importância clínica visto que podem demandar atendimento imediato, pois muitas vezes existe dor forte associada; além de poderem comprometer seriamente o prognóstico do elemento dentário (1).

A lesão endo-periodontal estabelecida está associada a diferentes graus de contaminação microbiana da polpa dentária e dos tecidos periodontais de suporte. No entanto, a etiologia primária dessas lesões pode estar associada a processos infecciosos, como exposições pulpares, periodontite e lesões cariosas, ou não-infecciosos, como fraturas e perfurações radiculares $(1,3)$. As principais manifestações clínicas dessas lesões são: aumento na profundidade de sondagem com bolsas periodontais que podem chegar até o ápice dentário, e teste de sensibilidade pulpar negativo (necrose pulpar) ou alterado (resposta exacerbada). Além disso, outros sinais e sintomas podem estar presentes, como: reabsorção óssea, dor espontânea ou à percussão e/ou palpação, alteração da cor da coroa dentaria e/ou gengival, exsudato purulento, mobilidade dentária e fístula $(1,4,5)$.

O estabelecimento de um plano de tratamento para as lesões endo-periodontais depende de um correto diagnóstico que deve ser pautado por uma avaliação clínica minuciosa $(6,7)$. Na literatura, existem apenas duas revisões sistemática que sintetizam os achados clínicos de artigos publicados sobre o tratamento das lesões endo-periodontais. Uma primeira revisão que foi publicada em 2014 (8), e uma mais atual, divulgada em 2020, que incluiu um número reduzido de artigos (9). No entanto, ainda existem controvérsias sobre o protocolo de tratamento das lesões endo-periodontais. Sendo 


\section{RECIMA21 - REVISTA CIENTÍFICA MULTIDISCIPLINAR}

TRATAMENTO DAS LESÕES ENDO-PERIODONTAIS: UMA REVISÃO DE ESCOPO

Belén Retamal-Valdes, Kamila Ribeiro do Nascimento Jabur, Silvana Felisberto Monteiro, Laryssa Macedo de Oliveira, Renata Queiroz Tavares, Cristiane Gonçalves, Magda Feres

assim, o objetivo desta revisão de escopo foi responder a seguinte pergunta: "Quais são os protocolos de tratamento para as lesões endo-periodontais? "

\section{MÉTODOS}

Uma revisão de escopo foi realizada de acordo com as normas PRISMA-ScR (10),

\subsection{Pergunta foco}

O objetivo da revisão foi responder a seguinte pergunta foco: "Quais são os protocolos de tratamento para as lesões endo-periodontais?"

\subsection{Critério de elegibilidade}

Critérios de inclusão:

- Estudo com qualquer desenho que relatasse pelo menos um dente com diagnóstico de lesão endoperiodontal.

- Estudo que descrevesse tratamento endodôntico e periodontal de pelo menos um dente com lesão endo-periodontal.

- Pesquisa original.

- Manuscrito disponível na íntegra.

Critérios de exclusão:

- Estudo de revisão.

- Estudo com acompanhamento $<3$ meses.

\subsection{Estratégia de pesquisa}

A base de dado MEDLINE (Pubmed) foi pesquisada até agosto de 2020. A estratégia de busca utilizou como palavras-chave: (endodontic-periodontal[All Fields] OR periodontal-endodontic[All Fields] OR endo-periodontal[All Fields] OR perio-endodontic[All Fields] OR endo-perio[All Fields] OR perio-endo[All Fields]) AND (("therapy"[Subheading] OR "therapy"[All Fields] OR "treatment"[All Fields] OR "therapeutics"[MeSH Terms] OR "therapeutics"[All Fields]) OR ("therapy"[Subheading] OR "therapy"[All Fields] OR "therapeutics"[MeSH Terms] OR "therapeutics"[All Fields]) OR ("therapeutics"[MeSH Terms] OR "therapeutics"[All Fields]) OR ("therapeutics"[MeSH Terms] OR "therapeutics"[All Fields] OR "therapies"[All Fields]) OR "management"[All Fields] OR "disease management"[MeSH Terms] OR ("disease"[All Fields] AND "management"[All Fields]) OR "disease management"[All Fields]))

\subsection{Variáveis}




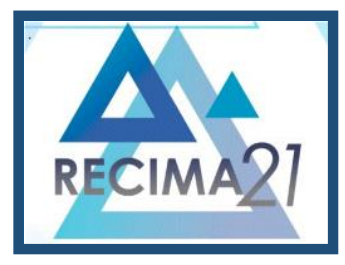

\section{RECIMA21 - REVISTA CIENTÍFICA MULTIDISCIPLINAR}

TRATAMENTO DAS LESÕES ENDO-PERIODONTAIS: UMA REVISÃO DE ESCOPO Belén Retamal-Valdes, Kamila Ribeiro do Nascimento Jabur, Silvana Felisberto Monteiro, Laryssa Macedo de Oliveira, Renata Queiroz Tavares, Cristiane Gonçalves, Magda Feres

As informações a seguir foram coletadas de cada estudo e registradas em formulários pré-definidos: referência, país, objetivo, desenho do estudo, número de voluntários, idade, gênero, fatores de risco periodontais, condição sistêmica, número de dentes com lesão endo-periodontal, diagnóstico endoperiodontal, características clínicas, diagnóstico periodontal de boca completa, fatores de risco endoperiodontais, profundidade de sondagem no início, diagnóstico pulpar no início, tratamento, acompanhamento, profundidade de sondagem após o tratamento, prognóstico, e observações.

\section{RESULTADOS}

\subsection{Artigos incluídos}

A busca eletrônica gerou 238 títulos/resumos. Desse total, 63 foram selecionados por atingir os critérios de inclusão; 15 artigos foram excluídos por não apresentar o full-text. Dos artigos que foram lidos na íntegra, 4 artigos foram excluídos devido à falta de tratamento/dados de lesões endoperiodontais (Tabela 1). Finalmente, 44 artigos foram incluídos nesta revisão.

\subsection{Características metodológicas dos artigos incluídos (Tabela 2)}

A maior parte dos estudos incluídos foi publicada entre os anos 2011-2020 (75\%), enquanto 25\% foram publicados entre 1996-2010. Em relação ao país de origem dos artigos incluídos, $52 \%$ foram oriundos do Oriente Médio (52\% do total artigos), sendo que o país que mais registrou publicações foi a Índia, somando 15 artigos. Com relação ao desenho de estudo, 86\% dos artigos selecionados foram relatos de casos, $9 \%$ foram estudos clínicos e o $5 \%$ foram ensaios clínicos aleatorizados. 545 voluntários foram tratados nesses estudos, sendo que 76,5\% foram provenientes dos estudos clínicos, $13 \%$ de ensaios clínicos aleatorizados e apenas $10,5 \%$ de relatos de caso. A idade média geral de todos os voluntários foi de 42,4 anos, e $50,5 \%$ dos sujeitos foram do gênero feminino. Do total, $56,8 \%$ não relatam informações sobre a saúde sistémica dos pacientes e o restante dos pacientes eram sistemicamente saudáveis. Sobre os fatores de risco associados à periodontite, $70,4 \%$ dos pacientes eram fumantes e/ou diabéticos e os demais artigos não apresentaram essa informação.

\subsection{Características clínicas da boca completa dos voluntários (Tabela 3)}

Metade dos artigos incluídos nesta revisão não relatou nenhuma informação sobre o diagnóstico ou características clínicas da boca completa dos voluntários. No entanto, $41 \%$ dos artigos relataram que os voluntários apresentavam periodontite, e os demais estudos (59\%) avaliaram pacientes com saúde periodontal. $77,3 \%$ não apresentaram registros das características clínicas da boca toda dos voluntários. Além disso, mobilidade dentária, cárie e sangramento gengival foram apresentados no menor percentual dos indivíduos. 


\section{RECIMA21 - REVISTA CIENTÍFICA MULTIDISCIPLINAR}

TRATAMENTO DAS LESÕES ENDO-PERIODONTAIS: UMA REVISÃO DE ESCOPO Belén Retamal-Valdes, Kamila Ribeiro do Nascimento Jabur, Silvana Felisberto Monteiro, Laryssa Macedo de Oliveira, Renata Queiroz Tavares, Cristiane Gonçalves, Magda Feres

\subsection{Lesões endo-periodontais (Tabela 4)}

651 dentes com lesão endo-periodontal foram tratados nos artigos incluídos. Com relação ao diagnóstico, 37,8\% dos dentes foram diagnosticados como tendo lesões endodônticas primárias, $21,7 \%$ lesões combinadas; $17,4 \%$ lesões periodontais primárias e $26,1 \%$ não relataram essa informação. $79,5 \%$ dos artigos não mencionaram sobre o tipo de classificação para lesões endoperiodontais que basearam seus diagnósticos; $13,6 \%$ dos artigos relatam terem utilizado a classificação de Simon et al. 1972 (11); e o restante utilizou a Classificação da AAP de 1999 (12), Al Fouzan (3) ou a Classificação de 2018 (1). A maioria dos dentes diagnosticados com lesão endoperiodontal apresentou mobilidade dentária associada a edema da região. Notou-se que, na grande maioria dos casos, a polpa já não apresentava vitalidade, e em alguns casos a perda óssea era grande.

Com relação aos indicadores de risco para lesões endo-periodontais, 38,6\% dos artigos não relataram nenhum fator; $27,3 \%$ relataram que o dente possuía sulco radicular; $18,2 \%$ informaram que houve iatrogenia no tratamento endodôntico anterior, e o restante se distribuiu entre casos com defeito ósseos ou comunicação apical. A maioria dos autores não se posicionou em relação ao prognóstico do dente envolvido, $31,8 \%$ dos casos foram considerados de prognóstico ruim e 9,1\% questionável.

\subsection{Tratamento das lesões endo-periodontais (Tabela 5)}

\section{Tipos de tratamentos instituídos}

A terapia de maior prevalência observada nesse estudo foi: "tratamento endodôntico convencional antes da terapia periodontal cirúrgica", seguido pelo "tratamento endodôntico cirúrgico ao mesmo tempo de que o tratamento periodontal cirúrgico", e em menor proporção "terapia periodontal não cirúrgica antes da terapia endodôntica". Não existiram relatos de casos onde o tratamento periodontal cirúrgico ocorreu antes da endodontia convencional. Além disso, em 27,3\% dos casos foram realizadas ressecções radiculares, e em $9 \%$ foram realizadas apicectomias.

\section{Detalhes dos protocolos terapêuticos}

Tratamento endodôntico: na grande maioria das vezes foi realizado sob anestesia, com isolamento do dente usando dique de borracha, acesso aos canais com brocas, limpeza e instrumentação dos canais radiculares realizados com limas manuais ou instrumentos rotatórios, extensão de trabalho determinado com localizador apical e confirmado radiograficamente. Para irrigação e desinfecção radicular geralmente foram utilizados hipoclorito de sódio 1\% a 5,25\% e EDTA 17\%. As substâncias foram posteriormente removidas com pontas de papel absorventes, e os canais obturados com gutapercha e cimento, utilizando a técnica de condensação lateral/compactação vertical. Em alguns casos foi utilizado selador AH26. Para confirmação da correta obturação dos canais foram realizadas radiografias. Na finalização dos procedimentos, em alguns casos foi utilizado cimentos temporários 


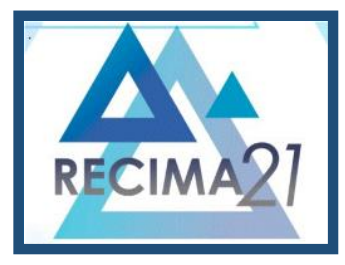

\section{RECIMA21 - REVISTA CIENTÍFICA MULTIDISCIPLINAR}

TRATAMENTO DAS LESÕES ENDO-PERIODONTAIS: UMA REVISÃO DE ESCOPO Belén Retamal-Valdes, Kamila Ribeiro do Nascimento Jabur, Silvana Felisberto Monteiro, Laryssa Macedo de Oliveira, Renata Queiroz Tavares, Cristiane Gonçalves, Magda Feres

ou resina composta com a técnica incremental. Em casos de retratamento endodôntico foram retirados as restaurações e o preenchimento de guta-percha e cimento, antes do início do novo tratamento.

Terapia periodontal não-cirúrgica: foi realizada sob anestesia, geralmente após instrução de higiene, profilaxia e a remoção do cálculo supragengival. Geralmente foi relatada a utilização de curetas Gracey e/ou ultrasson.

Terapia periodontal cirúrgica: na grande maioria das vezes foi realizada por meio de retalhos intrasulculares e mucoperiostais. Foram realizadas remoção dos tecidos patológicos granulomatosos, incluindo em alguns casos apicectomia e ressecção de raiz, e debridamento da lesão óssea. Para o ultrassom. Nos casos de presença de sulco radicular ou groove foi utilizado condicionamento químico e/ou odontoplastia. Em alguns casos foi realizada regeneração tecidual guiada. No local da perda óssea e superfícies dentinárias expostas, em alguns casos foi utilizado Emdogain ${ }^{\circledR}$ na tentativa de regenerar parte dos tecidos perdidos. Em $61,4 \%$ dos casos foram utilizados grande variedade de materiais de enxertos, tais como; enxerto aloplástico isolado ou com PRP (plasma rico em plaquetas), xenoenxerto bovino isolado ou com mistura de perioclina, EMD ${ }^{\circledR}$ Straumann ${ }^{\circledR}$ AG ou PRF (plasma rico em fibrina), DBBM, hidroxiapatita, fosfato beta-tricálcico isolados ou a mistura de ambos, osso sintético reabsorvível isolado ou com PRP, DFDBA - liofilizado isolado ou com PRF, bloco esponjoso osseocondutor e vidro bioativo com glicerina e polietilenoglicol. No entanto, a maior prevalência foi de BIO-OSS ${ }^{\circledR}$ xenoenxerto ósseo bovino (11,1\% dos casos) e DFDBA - liofilizado (11,0\% dos casos). Em 43,2\% dos casos, foram colocadas membranas sobre o enxerto. A membrana mais utilizada foi Geistlich Bio-Gide $\AA$ Perio -reabsorvível (31,7\% dos casos). Todos os casos foram suturados com fio de seda ou nylon de espessura 3-0, 4-0 ou 5-0.

\section{Tempo entre as terapias}

Em 52,3\% dos casos foi respeitado um tempo mínimo entre as terapias endodônticas e periodontais, $29,5 \%$ não forneceram essa informação, $15,9 \%$ não esperaram um tempo entre as terapias. Para os casos em que foi aguardado um tempo entra as terapias, o tempo entre 3-6 meses foi o mais prevalente $(54,2 \%$ dos casos), seguida pelo intervalo de $1-3$ meses $(33,4 \%)$ dos casos. Em $4,1 \%$ dos casos, foi respeitado um tempo de mais de 06 meses entre as terapias.

\section{Terapia medicamentosa}

$52,3 \%$ dos voluntários receberam medicamentos sistêmicos associados às terapias endodônticas e periodontais, enquanto que $47,7 \%$ não relataram essa informação. Os seguintes medicamentos foram relatados: Amoxicilina 250mg, 500gr e 1g, Nimesulida, Aspirina ${ }^{\circledR} 1 \mathrm{~g}$, Ibuprofeno $400 \mathrm{mg}$ e $600 \mathrm{mg}$, Clindamicina $300 \mathrm{mg}$, Clavulanato $125 \mathrm{mg}$, $375 \mathrm{mg}$ e $625 \mathrm{mg}$, Vouveran ${ }^{\circledR}$ SR $100 \mathrm{mg}$, 


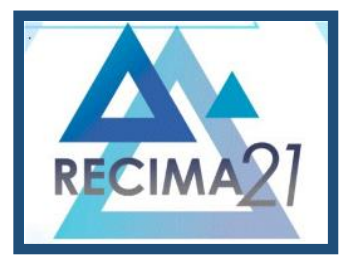

\section{RECIMA21 - REVISTA CIENTÍFICA MULTIDISCIPLINAR}

TRATAMENTO DAS LESÕES ENDO-PERIODONTAIS: UMA REVISÃO DE ESCOPO Belén Retamal-Valdes, Kamila Ribeiro do Nascimento Jabur, Silvana Felisberto Monteiro, Laryssa Macedo de Oliveira, Renata Queiroz Tavares, Cristiane Gonçalves, Magda Feres

Azitromicina $250 \mathrm{gr}$ e $500 \mathrm{mg}$, Metronidazol $500 \mathrm{mg}$, Clorexidina $0,12 \%$ e $0,2 \%$, além de outros antibióticos, analgésicos, antipiréticos e antiinflamatorios diversos. No entanto, a maior prevalência foi Amoxicilina (20,7\%), seguida de Clorexidina (22,4\%), Ibuprofeno (10,3\%), Clavulanato $(5,17 \%)$ e Metronidazol (3,4\%).

\section{Acompanhamento da evolução do tratamento}

O tempo de acompanhamento dos tratamentos variou entre os estudos incluídos. Houve acompanhamento entre 3 meses e 1 ano para 43,1\% de casos; entre 1 a 2 anos em 27,2\% dos casos e entre 2 a 3 anos em 4,5\% de casos e entre 3 a 5 anos em 11,6\% dos casos. Em 13,6\% dos casos, os tempos de acompanhamento não foram relatados.

\section{Resultados das terapias}

A maioria dos casos (95,6\%) teve resultados positivos aos tratamentos realizados, enquanto $4,4 \%$ tiveram apenas resultados positivos moderados ou mínimos. De forma geral, os dados pós-terapia mostraram melhora significativa ou uma volta à normalidade da profundidade de sondagem, redução da mobilidade dental, cura/diminuição de lesão periapical, regeneração óssea vertical e horizontal, regeneração óssea na região de furca, reparo do defeito ósseo periapical, cicatrização periodontal, redução do índice de placa, ganho de nível clinico de inserção, redução do índice periapical e desinflamação dos tecidos moles. Além disso, notou-se em alguns casos: recessão gengival, desaparecimento completo de produção purulenta do trato sinusal, diminuição do sangramento a sondagem, e melhora na função mastigatória, eliminando o desconforto e o controle da periodontite. Para os casos que não houve melhora, foi observada uma progressão da doença periodontal, sintomas de desconforto na função mastigatória, vermelhidão ou inchaço do tecido periodontal, persistência na profundidade de sondagem $\geq 5 \mathrm{~mm}$, ou menos de $2 \mathrm{~mm}$ de redução na profundidade de bolsa, índice de sangramento $\geq 3$, nível clinico de inserção aumentado, mobilidade, presença do trato sinusal e dor.

\section{DISCUSSÃO}

Este é o artigo de revisão mais atual a compilar informações sobre os protocolos de tratamento para lesões endo-periodontais. Os resultados indicaram que a terapia para esse tipo de lesão deve envolver tanto o tratamento endodôntico quanto o periodontal. Até hoje, a maioria dos casos relatados iniciou o tratamento pela endodontia convencional seguido do tratamento periodontal (nãocirúrgico e/ou cirúrgico). Ainda existe controvérsia quanto ao tempo que deve ser aguardado entre os dois tratamentos. No entanto, $95,6 \%$ dos dentes que foram tratados para lesão endo-periodontal tiveram resultados positivos. 


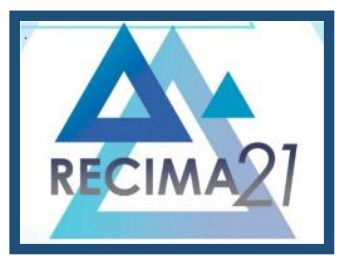

\section{RECIMA21 - REVISTA CIENTÍFICA MULTIDISCIPLINAR}

TRATAMENTO DAS LESÕES ENDO-PERIODONTAIS: UMA REVISÃO DE ESCOPO Belén Retamal-Valdes, Kamila Ribeiro do Nascimento Jabur, Silvana Felisberto Monteiro, Laryssa Macedo de Oliveira, Renata Queiroz Tavares, Cristiane Gonçalves, Magda Feres

Nossos resultados estão em concordância com uma revisão sistemática prévia, onde os autores concluíram que o tratamento do canal radicular seria a primeira etapa do tratamento das lesões endo-periodontais associadas com profundidade a sondagem aumentada e uma resposta negativa ao teste de sensibilidade pulpar (8). Essa mesma revisão sugeriu considerar um tempo razoável para o reparo da lesão endodôntica após o tratamento do canal radicular, antes de se realizar a terapia adicional ou periodontal (8). Os dados da nossa revisão mostraram que em 52,3\% dos casos foi respeitado um intervalo mínimo de 3 meses entre as terapias endodônticas e periodontais, e 47,7\% dos artigos não relataram ou não optaram por tempo entre as terapias, tendo resultados clínicos favoráveis. Mais estudos avaliando os mecanismos de reparo das terapias neste tipo de lesão são necessários para justificar definitivamente as decisões clínicas.

Outro ponto interessante de discussão foi que $79,5 \%$ dos casos não descreveram o tipo da classificação no diagnóstico da lesão endo-periodontal. Apenas $13,6 \%$ dos artigos relataram ter utilizado a classificação de Simon et al (11). Esse achado é importante e ressalta a importância do atual sistema de classificação das lesões endo-periodontais (1). Por muito tempo, houve uma grande dificuldade no uso dos sistemas de classificação das lesões endo-periodontais, porque envolvia parâmetros difíceis de serem objetivamente avaliados na clínica, como o histórico da etiologia primária da lesão (endodôntica ou periodontal). Logo, os clínicos preferiam não classificar objetivamente as lesões, o que representava uma dificuldade a mais em se estabelecer o prognóstico e tratamento. Espera-se que, com a implementação desse atual sistema de classificação, os clínicos e pesquisadores relatem de forma mais sistemática os tipos de lesões endoperiodontais. Aparentemente, essa tendência já está sendo seguida, pois após menos de dois anos após a publicação do novo sistema de classificação das lesões endo-periodontais, já existem artigos publicados citando esse sistema (20).

Um dos pontos importantes desta revisão foi identificar que $95,6 \%$ dos casos de lesões endoperiodontais tratados obtiveram resultados favoráveis e continuam em função na cavidade oral dos pacientes. Essa conclusão é relevante e motivadora para os clínicos porque, durante muitos anos, as lesões endo-periodontais estavam quase sempre associadas a prognósticos ruins e à extração dos elementos dentários envolvidos.

O presente trabalho apresenta vários pontos fortes: envolveu um número considerável de dentes diagnosticados e tratados com lesões endo-periodontais (651 dentes), abrangeu estudos utilizando diversos desenhos experimentais, e apresentou uma análise qualitativa abrangente dos tratamentos aplicados. A principal limitação desta revisão de escopo foi envolver apenas uma base de dados eletrônica na busca dos artigos. No entanto, MEDLINE/Pubmed é a maior base de dados em medicina e o resultado da busca resultou em mais de 200 títulos/resumos. 


\section{RECIMA21 - REVISTA CIENTÍFICA MULTIDISCIPLINAR}

TRATAMENTO DAS LESÕES ENDO-PERIODONTAIS: UMA REVISÃO DE ESCOPO

Belén Retamal-Valdes, Kamila Ribeiro do Nascimento Jabur, Silvana Felisberto Monteiro, Laryssa Macedo de Oliveira, Renata Queiroz Tavares, Cristiane Gonçalves, Magda Feres

\section{CONCLUSÃO}

O tratamento das lesões endo-periodontais deve envolver tanto o tratamento endodôntico quanto o periodontal. A maioria dos casos relatados iniciou o tratamento pela endodontia convencional, seguido pelo tratamento periodontal (não-cirúrgico e/ou cirúrgico). Porém, ainda existe controvérsia se deve ser aguardado um tempo de reparo mínimo entre os dois tratamentos. A maioria dos dentes diagnosticados com algum tipo de lesão endo-periodontal e tratados mostrou resultados positivos e permaneceram em função na cavidade oral dos pacientes.

\section{REFERÊNCIAS BIBLIOGRÁFICAS}

1. Herrera D, Retamal-Valdes B, Alonso B, Feres M. Acute periodontal lesions (periodontal abscesses and necrotizing periodontal diseases) and endo-periodontal lesions. J Periodontol. 2018;89 Suppl 1:S85-S102.

2. Rhee ESSPK, Boehm TK. Prevalence of periodontal disease among dental school patients. J T U Med Sci. 2014:9:126-131.

3. Al-Fouzan KS. A new classification of endodontic-periodontal lesions. Int $\mathrm{J}$ Dent. 2014:2014:919173.

4. Harrington GW. The perio-endo question: differential diagnosis. Dental Clinics of North America. 1979;23:673-90.

5. Abbott P. Endodontic management of combined endodontic-periodontal lesions. J N Z Soc Periodontol. 1998;(83):15-28.

6. Chapple IL, Lumley PJ. The periodontal-endodontic interface. Dent Update. 1999;26(8):331-341.

7. Tommasi MH. Diagnóstico em patologia bucal. 4. ed. Rio de Janeiro: Elsevier; 2013. p. 45-50.

8. Schmidt JC, Walter C, Amato M, Weiger R. Treatment of periodontal-endodontic lesions--a systematic review. J Clin Periodontol. 2014 Aug;41(8):779-90.

9. Oktawati S, Siswanto H, Mardiana, Supiaty X, Neormansyah I, Basir I. Endodonticperiodontic lesion management: A systematic review. Med Clin Pract. 2020;3(S1):100098.

10. Tricco AC, Lillie E, Zarin W, O'Brien KK, Colquhoun H, Levac D, Moher D, Peters MDJ, Horsley T, Weeks L, Hempel S, Akl EA, Chang C, McGowan J, Stewart L, Hartling L, Aldcroft A, Wilson MG, Garritty C, Lewin S, Godfrey CM, Macdonald MT, Langlois EV, Soares-Weiser K, Moriarty J, Clifford T, Tunçalp Ö, Straus SE. PRISMA Extension for Scoping Reviews (PRISMA-ScR): Checklist and Explanation. Ann Intern Med. 2018.

11. Simon JH, Glick DH, Frank AL. The relationship of endodonticperiodontic lesions. J Periodontol. 1972;43:202-208.

12. Armitage GC. Development of a classification system for periodontal diseases and conditions. Ann Periodontol. 1999;4:1-6.

13. Fan X, Xu X, Yu S, Liu P, Chen C, Pan Y, Lin L, Li C. Prognostic Factors of Grade 2-3 EndoPeriodontal Lesions Treated Nonsurgically in Patients with Periodontitis: A Retrospective Case-Control Study. Biomed Res Int. 2020 Feb; 8;2020:1592910.

14. Tseng CC, Harn WM, Chen YH, Huang CC, Yuan K, Huang PH. A new approach to the treatment of true-combined endodontic-periodontic lesions by the guided tissue regeneration technique. J Endod. 1996 Dec;22(12):693-6.

15. Kerezoudis NP, Siskos GJ, Tsatsas V. Bilateral buccal radicular groove in maxillary incisors: case report. Int Endod J. 2003 Dec;36(12):898-906.

16. Tobón-Arroyave SI, Domínguez-Mejía JS, Flórez-Moreno GA. Periosteal grafts as barriers in periradicular surgery: report of two cases. Int Endod J. 2004 Sep;37(9):632-42.

17. Vakalis SV, Whitworth JM, Ellwood RP, Preshaw PM. A pilot study of treatment of periodontal-endodontic lesions. Int Dent J. 2005 Oct;55(5):313-8.

18. Koyess E, Fares M. Referred pain: a confusing case of differential diagnosis between two teeth presenting with endo-perio problems. Int Endod J. 2006 Sep;39(9):724-9. 


\section{RECIMA21 - REVISTA CIENTÍFICA MULTIDISCIPLINAR}

TRATAMENTO DAS LESÕES ENDO-PERIODONTAIS: UMA REVISÃO DE ESCOPO

Belén Retamal-Valdes, Kamila Ribeiro do Nascimento Jabur, Silvana Felisberto Monteiro,

Laryssa Macedo de Oliveira, Renata Queiroz Tavares, Cristiane Gonçalves, Magda Feres

19. Ballal NV, Jothi V, Bhat KS, Bhat KM. Salvaging a tooth with a deep palatogingival groove: an endo-perio treatment--a case report. Int Endod J. 2007 Oct;40(10):808-17.

20. Walter C, Krastl G, Weiger R. Step-wise treatment of two periodontal-endodontic lesions in a heavy smoker. Int Endod J. 2008 Nov;41(11):1015-23.

21. Kim E, Song JS, Jung IY, Lee SJ, Kim S. Prospective clinical study evaluating endodontic microsurgery outcomes for cases with lesions of endodontic origin compared with cases with lesions of combined periodontal-endodontic origin. J Endod. 2008 May;34(5):546-51.

22. Singh S. Management of an endo perio lesion in a maxillary canine using platelet-rich plasma concentrate and an alloplastic bone substitute. J Indian Soc Periodontol. 2009 May;13(2):97100.

23. Attam K, Tiwary R, Talwar S, Lamba AK. Palatogingival groove: endodontic-periodontal management--case report. J Endod. 2010 Oct;36(10):1717-20.

24. Blanchard SB, Almasri A, Gray JL. Periodontal-endodontic lesion of a three-rooted maxillary premolar: report of a case. J Periodontol. 2010 May;81(5):783-8.

25. Mali $R$, Lele $P$, Vishakha. Guided tissue regeneration in communicating periodontal and endodontic lesions - A hope for the hopeless! J Indian Soc Periodontol. 2011 Oct;15(4):410-3.

26. Narang S, Narang A, Gupta R. A sequential approach in treatment of perio-endo lesion. J Indian Soc Periodontol. 2011 Apr;15(2):177-80. doi:10.4103/0972-124X.84390.

27. Gandhi A, Kathuria A, Gandhi T. Endodontic-periodontal management of two rooted maxillary lateral incisor associated with complex radicular lingual groove by using spiral computed tomography as a diagnostic aid: a case report. Int Endod J. 2011 Jun;44(6):574-82.

28. Oh SL. Mesiobuccal root resection in endodontic-periodontal combined lesions. Int Endod J. $2012 \mathrm{Jul} ; 45(7): 660-9$.

29. Asgary S, Fazlyab M. Management of failed periodontal surgical intervention for a furcal lesion with a nonsurgical endodontic approach. Restor Dent Endod. 2014 May;39(2):115-9.

30. Azaripour A, Willershausen I, Kämmerer P, Willershausen B. Post-endodontic treatment periodontal surgery: a case report. Quintessence Int. 2013 Feb;44(2):123-6.

31. Jivoinovici R, Suciu I, Dimitriu B, Perlea P, Bartok R, Malita M, lonescu C. Endo-periodontal lesion--endodontic approach. J Med Life. 2014 Oct-Dec;7(4):542-4. Erratum in: J Med Life. 2014 Oct-Dec;7(4):627.

32. Kambale S, Aspalli N, Munavalli A, Ajgaonkar N, Babannavar R. A sequential approach in treatment of endo-perio lesion a case report. J Clin Diagn Res. 2014 Aug;8(8):ZD22-4.

33. Fujii R, Muramatsu T, Yamaguchi Y, Asai T, Aida N, Suehara M, Morinaga K, Furusawa M. An endodontic-periodontal lesion with primary periodontal disease: a case report on its bacterial profile. Bull Tokyo Dent Coll. 2014;55(1):33-7.

34. Kishan KV, Hegde V, Ponnappa KC, Girish TN, Ponappa MC. Management of palate radicular groove in a maxillary lateral incisor. J Nat Sci Biol Med. 2014 Jan;5(1):178-81.

35. Katwal D, Fiorica JK, Bleuel J, Clark SJ. Successful Multidisciplinary Management of an Endodontic-Periodontal Lesion Associated With a Palato- Radicular Groove: A Case Report. Clin Adv Periodontics. 2020 Jun;10(2):88-93.

36. Miao H, Chen M, Otgonbayar T, Zhang SS, Hou MH, Wu Z, Wang YL, Wu LG. Papillary reconstruction and guided tissue regeneration for combined periodontal-endodontic lesions caused by palatogingival groove and additional root: a case report. Clin Case Rep. 2015 Nov 6:3(12):1042-9.

37. Castelo-Baz P, Ramos-Barbosa I, Martín-Biedma B, Dablanca-Blanco AB, Varela-Patiño P, Blanco-Carrión J. Combined Endodontic-Periodontal Treatment of a Palatogingival Groove. J Endod. 2015 Nov;41(11):1918-22.

38. Sharma S, Srivastava D, Sood V, Yadav P. Endodontic and periodontal management of a severely affected maxillary lateral incisor having combined mucosal fenestration and palatogingival groove. J Indian Soc Periodontol. 2015 May-Jun;19(3):348-51.

39. Sharma S, Deepak P, Vivek S, Ranjan Dutta S. Palatogingival Groove: Recognizing and Managing the Hidden Tract in a Maxillary Incisor: A Case Report. J Int Oral Health. 2015 Jun;7(6):110-4. 


\section{RECIMA21 - REVISTA CIENTÍFICA MULTIDISCIPLINAR}

TRATAMENTO DAS LESÕES ENDO-PERIODONTAIS: UMA REVISÃO DE ESCOPO

Belén Retamal-Valdes, Kamila Ribeiro do Nascimento Jabur, Silvana Felisberto Monteiro, Laryssa Macedo de Oliveira, Renata Queiroz Tavares, Cristiane Gonçalves, Magda Feres

40. Gupta S, Tewari S, Tewari S, Mittal S. Effect of Time Lapse between Endodontic and Periodontal Therapies on the Healing of Concurrent Endodontic- Periodontal Lesions without Communication: A Prospective Randomized Clinical Trial. J Endod. 2015 Jun;41(6):785-90.

41. Varughese V, Mahendra J, Thomas AR, Ambalavanan N. Resection and Regeneration - A Novel Approach in Treating a Perio-endo Lesion. J Clin Diagn Res. 2015 Mar;9(3):ZD08-10.

42. Inamdar MN, Khan S, Ali SA, Ahmad E. Management of Class-II Furcation Complicated with Endodontic involvement using Two Different Regenerative Materials. J Int Oral Health. 2015;7(Suppl 2):82-4.

43. Jivoinovici R, Suciu I, Dimitriu B, Perlea P, Bartok R, Malita M, Ionescu C. Endo-periodontal lesion--endodontic approach. J Med Life. 2014 Oct-Dec;7(4):542-4. Erratum in: J Med Life. 2014 Oct-Dec;7(4):627.

44. Cho YD, Lee JE, Chung Y, Lee WC, Seol YJ, Lee YM, Rhyu IC, Ku Y. Collaborative Management of Combined Periodontal-endodontic Lesions with a Palatogingival Groove: A Case Series. J Endod. 2017 Feb;43(2):332-337.

45. Pico-Blanco A, Castelo-Baz P, Caneiro-Queija L, Liñares-González A, Martin-Lancharro P, Blanco-Carrión J. Saving Single-rooted Teeth with Combined Endodontic-periodontal Lesions. J Endod. 2016 Dec;42(12):1859-1864.

46. Sooratgar A, Tabrizizade M, Nourelahi M, Asadi $Y$, Sooratgar H. Management of an Endodontic-Periodontal Lesion in a Maxillary Lateral Incisor with Palatal Radicular Groove: A Case Report. Iran Endod J. 2016 Spring;11(2):142-5.

47. Alizadeh Tabari Z, Homayouni H, Pourseyediyan T, Arvin A, Eiland D, Moradi Majd N. Treatment of a Developmental Groove and Supernumerary Root Using Guided Tissue Regeneration Technique. Case Rep Dent. 2016;2016:2738569.

48. Asgary S, Roghanizadeh L, Haeri A. Surgical Endodontics $<i>v s</ i>$ Regenerative Periodontal Surgery for Management of a Large Periradicular Lesion. Iran Endod J. 2018 Spring;13(2):271-276.

49. Betancourt $P$, Elgueta $R$, Fuentes $R$. Treatment of endo-periodontal lesion using leukocyteplatelet-rich fibrin. A case report. Colomb Med (Cali). 2017 Dec 30;48(4):204-207.

50. Al Attas MA, Edrees HY, Sammani AMN, Madarati AA. Multidisciplinary management of concomitant pulpal and periodontal lesion: A case report. J Taibah Univ Med Sci. 2017 Jun 27;12(5):455-460.

51. Wadhwa J, Gupta A, Hans S. Evaluation of Periapical Healing of Apicomarginal Defect in Mandibular First Molar Treated with Platelet Rich Fibrin: A Case Report. J Clin Diagn Res. 2017 Apr;11(4):ZD01-ZD03.

52. Alquthami H, Almalik AM, Alzahrani FF, Badawi L. Successful Management of Teeth with Different Types of Endodontic-Periodontal Lesions. Case Rep Dent. 2018 May 29;2018:7084245.

53. Dhoum S, Laslami K, Rouggani F, El Ouazzani A, Jabri M. Endo-Perio Lesion and Uncontrolled Diabetes. Case Rep Dent. 2018 May 16;2018:7478236.

54. Tewari S, Sharma G, Tewari S, Mittal S, Bansal S. Effect of immediate periodontal surgical treatment on periodontal healing in combined endodontic- periodontal lesions with communication-A randomized clinical trial. J Oral Biol Craniofac Res. 2018 MayAug;8(2):105-112.

55. Oh S, Chung SH, Han JY. Periodontal regenerative therapy in endo-periodontal lesions: a retrospective study over 5 years. J Periodontal Implant Sci. 2019 Apr 19;49(2):90-104.

56. Goyal L, Gupta N, Gupta ND. Autologous platelet-rich derivatives along with alloplastic bone substitute in the management of complex perio-endo cases. J Indian Soc Periodontol. 2020 Mar-Apr;24(2):182-185. 


\section{RECIMA21 - REVISTA CIENTÍFICA MULTIDISCIPLINAR}

TRATAMENTO DAS LESÕES ENDO-PERIODONTAIS: UMA REVISÃO DE ESCOPO

Belén Retamal-Valdes, Kamila Ribeiro do Nascimento Jabur, Silvana Felisberto Monteiro, Laryssa Macedo de Oliveira, Renata Queiroz Tavares, Cristiane Gonçalves, Magda Feres

Tabela 1. Motivo de exclusão dos artigos.

Motivo de exclusão

Ausência do full- text

Ausência do full- text

Ausência do full- text

Ausência do full- text

Ausência do full- text

Ausência do full- text

Ausência do full- text

Ausência do full- text

Ausência do full- text

Ausência do full- text

Ausência do full- text

Ausência do full- text

Ausência do full- text

Ausência do full- text

Ausência do full- text

Ausência de Análises
Western JS, Gupta VV, Ramachandra SS. Salvaging a Periodontally Compromised (2019)

Kavarthapu A, Malaiappan S. Management of periodontic-endodontic lesion in (2019).

Bansal S, Tewari S, Tewari S, Sangwan P. The effect of endodontic treatment (2018).

Lin S, Tillinger G, Zuckerman O. Endodontic-periodontic bifurcation (2008).

Adcock JE, Bright D. Surgical intervention of complex endo-perio lesions (2007).

Mauro S, Orlando L, Panzoni R, Orlando PF. Groove associated periodontitis (2005).

John V, Warner NA, Blanchard SB. Periodontal-endodontic interdisciplinar (2004).

Camargo PM, Pirih FQ, Wolinsky LE, Lekovic V, Kamrath H, White SN. Clinical (2003).

Rosenberg ES, Torosian J. Multidisciplinary approach to a combined (1991).

Collins JF, Beatty RG, Branham L. Combined endodontic-periodontal therapy (1986).

Ashara SD, Gohil KS. Management of perio-endodontic problem--a case report (1985).

Levitan LJ. Treatment of a unique perio-endo problem. Tex Dent J (1980).

Turner PS. Periodontal-endodontic lesions and their management. Dent $\mathrm{J}$ (1976).

Skidmore AE. Surgical intervention in the endo-perio complex. A case (1972).

Begin JF. Perio-endo considerations: combined therapy. R Can Dent Corps Q (1968).

Boehm TK. Case report on managing incomplete bone formation after bilateral (2017). 


\section{RECIMA21 - REVISTA CIENTÍFICA MULTIDISCIPLINAR}

TRATAMENTO DAS LESÕES ENDO-PERIODONTAIS: UMA REVISÃO DE ESCOPO

Belén Retamal-Valdes, Kamila Ribeiro do Nascimento Jabur, Silvana Felisberto Monteiro, Laryssa Macedo de Oliveira, Renata Queiroz Tavares, Cristiane Gonçalves, Magda Feres

Ausência de Análises

Ausência de Análises

Ausência de Análises
Chang H, Wei J, Wang Y, Jia J, Gao X, Li X, Feng H. Restorative treatment (2015).

Moghaddam AS, Radafshar G, Taramsari M, Darabi F. Long-term survival rate of (2014).

Taschieri S, Del Fabbro M, El Kabbaney A, Tsesis I, Rosen E, Corbella S (2016).

Tabela 2. Informações gerais dos estudos

\begin{tabular}{|c|c|c|c|c|c|c|}
\hline Referência & Ano & Pais & $\begin{array}{l}\text { Tipo do } \\
\text { Estudo }\end{array}$ & $\begin{array}{c}\mathrm{n} \text { de } \\
\text { Voluntários }\end{array}$ & $\begin{array}{l}\text { Idade } \\
\text { (anos) }\end{array}$ & $\begin{array}{l}\text { Condição } \\
\text { Sistémica }\end{array}$ \\
\hline Tseng et al (14) & 1996 & China & $\mathrm{RC}$ & 1 & 34 & Saudável \\
\hline Kerezoudis et al (15) & 2003 & Grécia & $\mathrm{RC}$ & 1 & 60 & $\begin{array}{c}\text { Neutropenia } \\
\text { Idiopática }\end{array}$ \\
\hline Tobón-Arroyave et al (16) & 2004 & Colômbia & $\mathrm{RC}$ & 2 & 41,5 & NR \\
\hline Vakalis et al (17) & 2005 & Reino Unido & PC & 9 & 49 & NR \\
\hline Koyess et al (18) & 2006 & Líbano & $\mathrm{RC}$ & 1 & 45 & NR \\
\hline Ballal et al (19) & 2007 & Índia & $\mathrm{RC}$ & 1 & 48 & NR \\
\hline Walter et al (20) & 2008 & Suíça & $\mathrm{RC}$ & 1 & 53 & Saudável \\
\hline Kim et al (21) & 2008 & EUA & PC & 227 & 41 & NR \\
\hline Singh et al (22) & 2009 & Índia & $\mathrm{RC}$ & 1 & 45 & NR \\
\hline Attam et al (23) & 2010 & Índia & $\mathrm{RC}$ & 1 & 24 & Saudável \\
\hline Blanchard et al (24) & 2010 & EUA & $\mathrm{RC}$ & 1 & 43 & NR \\
\hline
\end{tabular}


Mali et al (25)

Narang et al (26)

Gandhi et al (27)

Oh et al (28)

Asgary et al (29)

Azaripour et al (30)

Jivoinovici et al (31)

Kambale et al (32)

Fujii et al (33)

Kishan et al (34)

Katwal et al (45)

Miao et al (36)

Castelo-Baz et al (37)

Sharma et al (38)

Sharma et al (39)

Gupta et al (40)

Varughese et al (41)

Inamdar et al (42)

Jivoinovici et al (43)

Cho et al (44)

Pico-Blanco et al (45)

Sooratgar et al (46)

Alizadeh Tabari et al (47)

Asgary et al (48)

Betancourt et al (49)

Al Attas et al (50)

Wadhwa et al (51)

Alquthami et al (52)

Dhoum et al (53)

TRATAMENTO DAS LESÕES ENDO-PERIODONTAIS: UMA REVISÃO DE ESCOPO

Belén Retamal-Valdes, Kamila Ribeiro do Nascimento Jabur, Silvana Felisberto Monteiro, Laryssa Macedo de Oliveira, Renata Queiroz Tavares, Cristiane Gonçalves, Magda Feres

2011

2011

2011

2012

EUA

$\mathrm{RC}$

Irã

Alemanha

Romênia

Índia

Japão

Índia

EUA

China

Espanha

Índia

Índia

Índia

Índia

Arábia Saudita

Romênia

Coreia

Espanha

Irã

Irã

Irã

Chile

Arábia Saudita

Índia

Arábia Saudita

Marrocos

$\mathrm{RC}$

$\mathrm{RC}$

$\mathrm{RC}$

$\mathrm{RC}$

$\mathrm{RC}$

$\mathrm{RC}$

$\mathrm{RC}$

$\mathrm{RC}$

$\mathrm{RC}$

$\mathrm{RC}$

$\mathrm{RC}$

$\mathrm{RC}$

$\mathrm{RC}$

$\mathrm{RC}$

ECR

$\mathrm{RC}$

$\mathrm{RC}$

$\mathrm{RC}$

$\mathrm{RC}$

$\mathrm{RC}$

$\mathrm{RC}$

$\mathrm{RC}$

$\mathrm{RC}$

$\mathrm{RC}$

$\mathrm{RC}$

2017

2018

2018

1

C

1

1

2

2

54

42

62,5

44

32

40

18

63

23

40

25

34

45,5

40

NR

39

42

NR

27

32

30

52

31

25

37,33

50
NR

NR

Saudável

NR

Hipotireoidismos e

estenose espinhal 


\section{RECIMA21 - REVISTA CIENTÍFICA MULTIDISCIPLINAR}

TRATAMENTO DAS LESÕES ENDO-PERIODONTAIS: UMA REVISÃO DE ESCOPO

Belén Retamal-Valdes, Kamila Ribeiro do Nascimento Jabur, Silvana Felisberto Monteiro, Laryssa Macedo de Oliveira, Renata Queiroz Tavares, Cristiane Gonçalves, Magda Feres

$\begin{array}{lllllll}\text { Tewari et al (54) } & 2018 & \text { Índia } & \text { ECR } & 40 & 42,1 & \text { Excluídos } \\ \text { Oh et al (55) } & 2019 & \text { Coreia } & \text { PC } & 41 & \text { NR } & \text { Não } \\ \text { Goyal et al (56) } & 2020 & \text { Índia } & \text { RC } & 3 & 36,6 & \text { NR } \\ \text { Fan et al (13) } & 2020 & \text { China } & \text { PC } & 140 & 48,79 & \text { Excluídos }\end{array}$

$\mathrm{RC}$, relato de caso; PC, pesquisa clínica; ECR, estudo clínico randomizado; NR, não relata; NC, não conclusivo

Tabela 3. Características da boca completa dos voluntários

\begin{tabular}{lcc}
\hline \multicolumn{1}{c}{ Referência } & Ano & Diagnóstico Periodontal \\
\hline Tseng et al (14) & 1996 & NR \\
Kerezoudis et al (15) & 2003 & Periodontite Moderada e Inflamação dos tecidos moles \\
Tobón- Arroyave et al (16) & 2004 & $\begin{array}{c}\text { Periodontite com comunicação ápico-marginal; } \\
\text { Periodontite apical supurativa crônica }\end{array}$ \\
$\begin{array}{l}\text { Vakalis et al (17) } \\
\text { Koyess et al (18) }\end{array}$ & 2005 & Periodontite \\
$\begin{array}{l}\text { Ballal et al (19) } \\
\text { Walter et al (20) }\end{array}$ & 2006 & NR \\
Kim et al (21) & 2008 & Periodontite Apical Crônica \\
Singh et al (22) & 2008 & Periodontite Crônica e Abscesso Periodontal \\
Attam et al (23) & 2009 & NR \\
Blanchard et al (24) & 2010 & NR \\
Mali et al (25) & 2010 & NR \\
Narang et al (26) & 2011 & Periodontite Apical Sintomática \\
Gandhi et al (27) & 2011 & Periodontite \\
Oh et al (28) & 2011 & Pbscesso Periodontal e Periodontite Crônica
\end{tabular}

Asgary et al (29)

Azaripour et al (30)

Jivoinovici et al (31)

Kambale et al (32)
2013

2014
Paciente realizou tratamento cirúrgico periodontal (enxerto ósseo na região de furca) porém não houve a correta regeneração devido ao tratamento endodôntico anterior ser insatisfatório

NR

Defeito periodontal disto-vestibular profundo

NR 


\section{RECIMA21 - REVISTA CIENTÍFICA MULTIDISCIPLINAR}

TRATAMENTO DAS LESÕES ENDO-PERIODONTAIS: UMA REVISÃO DE ESCOPO

Belén Retamal-Valdes, Kamila Ribeiro do Nascimento Jabur, Silvana Felisberto Monteiro, Laryssa Macedo de Oliveira, Renata Queiroz Tavares, Cristiane Gonçalves, Magda Feres

Fujii et al (33)

Kishan et al (34)

Katwal et al (35)

Miao et al (36)

Castelo-Baz et al(37)

Sharma et al (38)

Sharma et al (39)

Gupta et al (40)

Varughese et al (41)

Inamdar et al (42)

Jivoinovici et al (43)

Cho et al (44)

Pico-Blanco et al (45)

Sooratgar et al (46)

Alizadeh Tabari et al (47)

Asgary et al (48)

Betancourt et al (49)

Al Attas et al (50)

Wadhwa et al (51)

Alquthami et al (52)

Dhoum et al (53)

Tewari et al (54)

Oh et al (55)

Goyal et al (56)

Fan et al (13)
2014

2014

2020

2015

2015

2015

2015

2015

2015

2015

2014

2017

2016

2016

2016

2018

2017

2017

2017

2018

2018

2018

2019

2020

2020
Periodontite Avançada

Periodontite Perirradicular Supurativa e Moderada

NR

NR

NR

NR

NR

NR

NR

NR

Periodontite Apical Crônica.

Periodontite apical Crônica Fibrosa

NR

Periodontite Crônica

NR

NR

NR

Sem Periodontite

Periodontite Agressiva Generalizada

NR

NR

Periodontite Crônica Generalizada

Periodontite Crônica

NR

Sem Periodontite

Periodontite

$N R$, não relata

Tabela 4. Características das Lesões Endo-Periodontais 


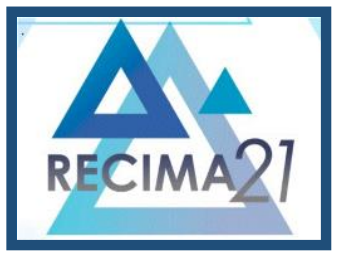

\section{RECIMA21 - REVISTA CIENTÍFICA MULTIDISCIPLINAR}

TRATAMENTO DAS LESÕES ENDO-PERIODONTAIS: UMA REVISÃO DE ESCOPO

Belén Retamal-Valdes, Kamila Ribeiro do Nascimento Jabur, Silvana Felisberto Monteiro, Laryssa Macedo de Oliveira, Renata Queiroz Tavares, Cristiane Gonçalves, Magda Feres

\begin{tabular}{|c|c|c|c|c|c|c|}
\hline Referência & Ano & $\begin{array}{l}\text { Número de } \\
\text { dentes }\end{array}$ & $\begin{array}{l}\text { Avaliação } \\
\text { Clínica }\end{array}$ & $\begin{array}{l}\text { Classificação } \\
\text { Endo- Perio }\end{array}$ & $\begin{array}{l}\text { Fatores/ } \\
\text { Indicadores } \\
\text { de Risco }\end{array}$ & $\begin{array}{c}\text { Prognóstic } \\
0\end{array}$ \\
\hline Tseng et al (14) & 1996 & 3 & $\mathrm{EC}, \mathrm{ER}$ & NR & NR & Ruim \\
\hline Kerezoudis et al (15) & 2003 & 2 & $\mathrm{EC}, \mathrm{ER}$ & Simon et. al & $\begin{array}{l}\text { Sulco Disto- } \\
\text { Lingual }\end{array}$ & NR \\
\hline Tobón-Arroyave et al (16) & 2004 & 2 & $\mathrm{EC}, \mathrm{ER}$ & NR & $\begin{array}{l}\text { Comunicação } \\
\text { Ápico Marginal }\end{array}$ & NR \\
\hline Vakalis et al (17) & 2005 & 9 & $E C, E R$ & NR & NR & Ruim \\
\hline Koyess et al (18) & 2006 & 2 & $\mathrm{EC}, \mathrm{ER}$ & NR & NR & NR \\
\hline Ballal et al (19) & 2007 & 1 & $E C, E R$ & NR & NR & Ruim \\
\hline Walter et al (20) & 2008 & 4 & EC, ER & Simon et. al & NR & NR \\
\hline Kim et al (21) & 2008 & 263 & $E C, E R$ & NR & NR & NR \\
\hline Singh et al (22) & 2009 & 1 & $\mathrm{EC}, \mathrm{ER}$ & NR & NR & NR \\
\hline Attam et al (23) & 2010 & 1 & $E C, E R$ & NR & $\begin{array}{c}\text { Sulco do } \\
\text { cíngulo até o } \\
\text { ápice da raiz }\end{array}$ & Ruim \\
\hline Blanchard et al (24) & 2010 & 5 & $E C, E R$ & Simon et. al & $\begin{array}{l}\text { latrogenia do } \\
\text { tratamento }\end{array}$ & Ruim \\
\hline Mali et al (25) & 2011 & 4 & EC, ER & NR & NR & Ruim \\
\hline Narang et al (26) & 2011 & 1 & $\mathrm{EC}, \mathrm{ER}$ & NR & NR & NR \\
\hline Gandhi et al (27) & 2011 & 1 & EC, ER, T & NR & $\begin{array}{c}\text { Sulco na } \\
\text { mesial do } \\
\text { ápice do dente }\end{array}$ & NR \\
\hline Oh et al (28) & 2012 & 2 & $E C, E R$ & NR & $\begin{array}{l}\text { latrogenia no } \\
\text { tratamento }\end{array}$ & $\begin{array}{c}\text { Questionáve } \\
\text { । }\end{array}$ \\
\hline Asgary et al (29) & 2014 & 1 & $\mathrm{EC}, \mathrm{ER}$ & NR & NR & NR \\
\hline Azaripour et al (30) & 2013 & 2 & $\begin{array}{c}\text { (1) EC, ER } \\
\text { (2) ER, T }\end{array}$ & NR & $\begin{array}{c}\text { (1) Defeito } \\
\text { Intraósseo na } \\
\text { Raiz Distal (2); } \\
\text { latroaenia }\end{array}$ & NR \\
\hline Jivoinovici et al (31) & 2014 & 3 & EC, ER & NR & NR & NR \\
\hline Kambale et al (32) & 2014 & 1 & $E C, E R$ & NR & NR & NR \\
\hline Fujii et al (33) & 2014 & 1 & $\begin{array}{l}\text { EC, ER, } \\
\text { Exame }\end{array}$ & NR & $\begin{array}{l}\text { NR } \\
\text { Sulco de }\end{array}$ & NR \\
\hline Kishan et al (34) & 2014 & 1 & EC, ER & NR & $\begin{array}{c}\text { Desenvolvimento } \\
\text { na }\end{array}$ & NR \\
\hline
\end{tabular}




\section{RECIMA21 - REVISTA CIENTÍFICA MULTIDISCIPLINAR}

TRATAMENTO DAS LESÕES ENDO-PERIODONTAIS: UMA REVISÃO DE ESCOPO

Belén Retamal-Valdes, Kamila Ribeiro do Nascimento Jabur, Silvana Felisberto Monteiro, Laryssa Macedo de Oliveira, Renata Queiroz Tavares, Cristiane Gonçalves, Magda Feres

Katwal et al (45)

Miao et al (36)

Castelo-Baz et al (37)

Sharma et al (38)

Sharma et al (39)

Gupta et al (40)

Varughese et al (41)

Inamdar et al (42)

Jivoinovici et al (43)

Cho et al (44)

Pico-Blanco et al (45)

Sooratgar et al (46)

Alizadeh Tabari et al (47)

Asgary et al (48)

Betancourt et al (49)

Al Attas et al (50)

Wadhwa et al (51)

Alquthami et al (52)
2020

1

2015

2015

2015

2015

2015

2015

2015

2014

2017

2016

2016

2016

2018

2017

2017

2017

2018

1

3
ER, T

ER, T

ER, T

ER, T

ER, T

ER, T

ER, T

EC, ER,

Hemograma

ER

ER, T

ER

ER

$E R, T$

$E R, T$

$\mathrm{ER}, \mathrm{T}$

ER, T

$E R, T$

ER

Classificação de
1999

Sulco palatogengival

Sulco palato gengival Tipo III/Trauma

Sulco palato aenaival/traum Sulco palato gengival tipo III

Sulco palato Ruim

NR

NR

NR

NR

NR

NR

NR

NR

NR

NR

latrogenia

(canal mal

NR

tratado).

Sulco Palato gengival

Ruim

NR

Ruim

NR

Simon et. al

Sulco Palato Gengival

Questionáve I

NR

Sulco Palato

Questionáve

Fonnival

latrogenia

NR

NR

Fumante

Ruim

NR

latrogenia

NR
Simon et. al

latrogenia

NR

Classificação Al Fouzan latrogenia

NR 


\section{RECIMA21 - REVISTA CIENTÍFICA MULTIDISCIPLINAR}

TRATAMENTO DAS LESÕES ENDO-PERIODONTAIS: UMA REVISÃO DE ESCOPO

Belén Retamal-Valdes, Kamila Ribeiro do Nascimento Jabur, Silvana Felisberto Monteiro, Laryssa Macedo de Oliveira, Renata Queiroz Tavares, Cristiane Gonçalves, Magda Feres

Dhoum et al (53)

Tewari et al (54)

Oh et al (55)

Goyal et al (56)

Fan et al (13)
2018

1

2018

40

2019

52

2020

4

2020
ER

ER

ER

ER

ER
Diabetes tipo

Simon et. al

NR

descompensa

NR

Não

NR

NR

Não

NR

NR

latrogenia

Ruim

Classificação

Workshop 2017
Fumantes

Ruim

EC, exame clínico; ER, exame radiográfico; T, tomografia; NR, não relata

Tabela 5. Tratamento das Lesões Endo-Periodontais

\begin{tabular}{|c|c|c|c|c|c|c|c|c|c|}
\hline $\begin{array}{l}\text { Referên } \\
\text { cia }\end{array}$ & Ano & Tratamento & $\begin{array}{l}\text { Tempo } \\
\text { entre as } \\
\text { Terapias }\end{array}$ & $\begin{array}{l}\text { Acompanham } \\
\text { ento } \\
\text { Parcial/Temp } \\
\text { o }\end{array}$ & $\begin{array}{l}\text { Medicam } \\
\text { ento }\end{array}$ & $\begin{array}{l}\text { Acompanhamen } \\
\text { to } \\
\text { total }\end{array}$ & $\begin{array}{l}\text { Resultad } \\
\text { o } \\
\text { Positivo } \\
\text { ao } \\
\text { tratamen } \\
\text { to }\end{array}$ & $\begin{array}{l}\text { Resultad } \\
\text { os }\end{array}$ & $\begin{array}{l}\text { Conflito } \\
\text { de } \\
\text { interess } \\
\text { e }\end{array}$ \\
\hline $\begin{array}{l}\text { Tseng } \\
\text { et al } \\
(14)\end{array}$ & 1996 & $\begin{array}{l}\text { Elemento } \\
\text { dentário } 12 \\
\text { 1. Tratamento } \\
\text { Endodôntico } \\
\text { Convencional; } \\
\text { 2. Tratamento } \\
\text { Periodontal } \\
\text { Cirúrgico: } \\
\text { Retalho } \\
\text { mucoperiostal foi } \\
\text { refletido usando } \\
\text { duas incisões } \\
\text { uma do lado } \\
\text { mesial do } \\
\text { elemento } 11 \text { e } \\
\text { do lado distal do } \\
\text { elemento } 13 ; \text { as } \\
\text { superfícies } \\
\text { radiculares e a } \\
\text { área apical } \\
\text { foram aplainada; } \\
\text { Para esse } \\
\text { severo defeito } \\
\text { ósseo foi } \\
\text { suturada uma } \\
\text { membrana } \\
\text { GORE-TEX }{ }^{\circledR} \text { e } \\
\text { depois refletida } \\
\text { para a } \\
\text { colocacão do }\end{array}$ & $\begin{array}{l}\text { NÄO } \\
\text { RELATA }\end{array}$ & NÄO RELATA & $\begin{array}{l}\text { Antibiótic } \\
\text { os e } \\
\text { analgésic } \\
\text { os por } 7 \\
\text { dias }\end{array}$ & 18 meses & SIM & $\begin{array}{l}\text { Mobilidad } \\
\text { e } \\
\text { reduzida } \\
\text { para < } \\
\text { que grau } \\
\text { I, OS } \\
\text { reduzida } \\
\text { para } \\
2 \mathrm{~mm}\end{array}$ & $\begin{array}{l}\text { NÄO } \\
\text { RELATA }\end{array}$ \\
\hline
\end{tabular}




\section{RECIMA21 - REVISTA CIENTÍFICA MULTIDISCIPLINAR}

TRATAMENTO DAS LESÕES ENDO-PERIODONTAIS: UMA REVISÃO DE ESCOPO Belén Retamal-Valdes, Kamila Ribeiro do Nascimento Jabur, Silvana Felisberto Monteiro, Laryssa Macedo de Oliveira, Renata Queiroz Tavares, Cristiane Gonçalves, Magda Feres

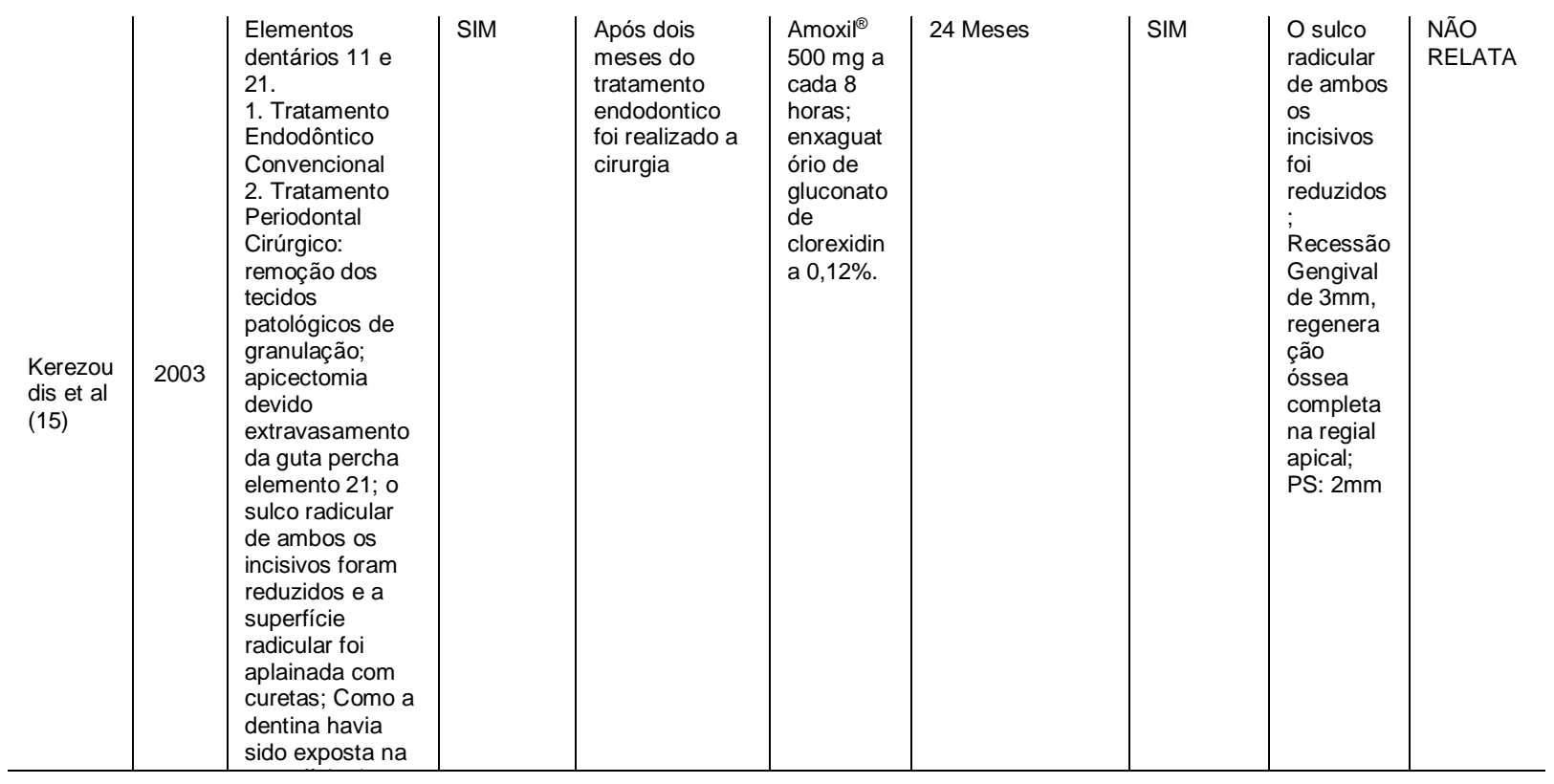




\section{RECIMA21 - REVISTA CIENTÍFICA MULTIDISCIPLINAR}

TRATAMENTO DAS LESÕES ENDO-PERIODONTAIS: UMA REVISÃO DE ESCOPO

Belén Retamal-Valdes, Kamila Ribeiro do Nascimento Jabur, Silvana Felisberto Monteiro, Laryssa Macedo de Oliveira, Renata Queiroz Tavares, Cristiane Gonçalves, Magda Feres

\begin{tabular}{|c|c|c|c|c|c|c|c|c|c|}
\hline $\begin{array}{l}\text { Tobón- } \\
\text { Arroyav } \\
\text { e et al } \\
\text { (16) }\end{array}$ & 2004 & $\begin{array}{l}\text { Caso } 1 \text { e } 2 \\
\text { (ambas } \\
\text { elemento } \\
\text { dentario 21): } \\
\text { 1. Tratamento } \\
\text { Endodontico, } \\
\text { ambos os casos } \\
\text { possuiam } \\
\text { tratamento } \\
\text { Endodontico } \\
\text { Convencional. } \\
\text { 2. Tratamento } \\
\text { periodontal } \\
\text { Cirúrgico: } \\
\text { anestesia local } \\
\text { com lidocaína } \\
2 \% \text { com } \\
\text { adrenalina } \\
1: 800.00 \\
\left.\text { (Roxycaine }{ }^{\circledR}\right) ; \\
\text { retalho de } \\
\text { espessura } \\
\text { dividida; insiçao } \\
\text { intrasulcular, } \\
\text { remoção do } \\
\text { tecido } \\
\text { granulomatoso; } \\
\text { Enxerto que } \\
\text { consistia de um } \\
\text { tecido conjuntivo } \\
\text { e incluia o } \\
\text { periósteo; } \\
\text { debridamento da } \\
\text { lesão óssea; } \\
\text { ressecção apical } \\
\text { da raiz com } \\
\text { brocas } \\
\text { cilindricas; } \\
\text { preparação da } \\
\text { cavidade } \\
\text { radicular de } \\
\text { 3mm de } \\
\text { profundidade ; } \\
\text { preenchimento } \\
\text { da raiz com IRM; } \\
\text { Irrigação com } \\
10 m g / m l \text { de } \\
\text { solucação de } \\
\text { doxiciclina por } 5 \\
\text { min para } \\
\text { remover a a } \\
\text { camada de } \\
\text { esfregaço, expor } \\
\text { a matriz de } \\
\text { colágeno e } \\
\text { imnnndir }\end{array}$ & $\begin{array}{l}\text { NÃO } \\
\text { RELATA }\end{array}$ & NÃO RELATA & $\begin{array}{l}\text { Caso1: } \\
\text { Nimesulid } \\
\text { a com } \\
\text { analgésic } \\
\text { os e } \\
\text { antipirétic } \\
\text { os, } 100 \\
\text { mg } 2 x \text { ao } \\
\text { dia por } 3 \\
\text { dias; } \\
\text { enxaguat } \\
\text { ório bucal } \\
\text { com } \\
\text { clorexidin } \\
\text { a por 2 } \\
\text { semanas. }\end{array}$ & 10 Meses & Sim & $\begin{array}{l}\text { Bem } \\
\text { sucedido }\end{array}$ & $\begin{array}{l}\text { NÃO } \\
\text { RELATA }\end{array}$ \\
\hline
\end{tabular}




\section{RECIMA21 - REVISTA CIENTÍFICA MULTIDISCIPLINAR}

TRATAMENTO DAS LESÕES ENDO-PERIODONTAIS: UMA REVISÃO DE ESCOPO Belén Retamal-Valdes, Kamila Ribeiro do Nascimento Jabur, Silvana Felisberto Monteiro, Laryssa Macedo de Oliveira, Renata Queiroz Tavares, Cristiane Gonçalves, Magda Feres

\begin{tabular}{|c|c|c|c|c|c|c|c|c|c|}
\hline $\begin{array}{l}\text { Vakalis } \\
\text { et al } \\
\text { (17) }\end{array}$ & 2005 & $\begin{array}{l}\text { Elemento quatro } \\
\text { molares, três } \\
\text { incisivos, um } \\
\text { pré-molar e um } \\
\text { canino. } \\
\text { 1. Tratamento } \\
\text { Endodontico: } \\
\text { anestesia local; } \\
\text { acesso à } \\
\text { câmara com o } \\
\text { uso de } 2 \text { brocas } \\
\text { (Dentsply }{ }^{\circledR} \text {; } \\
\text { Irrigação com } \\
\text { Hipoclorito de } \\
\text { sódio; } \\
\text { instrumentação } \\
\text { do canal com } \\
\text { limas tipo K } 25 ; \\
\text { hidróxido de } \\
\text { cálcio e } \\
\text { selamento com } \\
\text { IRM; a } \\
\text { obturação foi por } \\
\text { condensação } \\
\text { lateral a frio de } \\
\text { cones de guta } \\
\text { percha e aferidor } \\
\text { de Grossman e } \\
\text { cones } \\
\text { acessórios } \\
\text { associado a } \\
\text { tratamento } \\
\text { periodontal } \\
\text { inicial. } \\
4 \text {. Tratamento } \\
\text { periodontal } \\
\text { RAR, utilizando } \\
\text { instrumentos } \\
\text { manuais e }\end{array}$ & SIM & $\begin{array}{l}\text { Após } 30 \text { dias } \\
\text { da endodontia } \\
\text { foi realizado a } \\
\text { RAR }\end{array}$ & $\begin{array}{l}\text { NÃO } \\
\text { RELATA }\end{array}$ & 12 Meses & SIM & $\begin{array}{l}\text { O dente } \\
\text { de um } \\
\text { dos } \\
\text { pacientes } \\
\text { (fumante) } \\
\text {, com } \\
\text { mobilidad } \\
\text { e grau III } \\
\text { e perda } \\
\text { óssea } \\
\text { superior a } \\
70 \% \text { foi } \\
\text { extraído; } \\
\text { dos } \\
\text { demais } \\
\text { teve uma } \\
\text { redução } \\
\text { significati } \\
\text { va de PS; }\end{array}$ & $\begin{array}{l}\text { NÃO } \\
\text { RELATA }\end{array}$ \\
\hline
\end{tabular}




\section{RECIMA21 - REVISTA CIENTÍFICA MULTIDISCIPLINAR}

TRATAMENTO DAS LESÕES ENDO-PERIODONTAIS: UMA REVISÃO DE ESCOPO

Belén Retamal-Valdes, Kamila Ribeiro do Nascimento Jabur, Silvana Felisberto Monteiro, Laryssa Macedo de Oliveira, Renata Queiroz Tavares, Cristiane Gonçalves, Magda Feres

\begin{tabular}{|c|c|c|c|c|c|c|c|c|c|}
\hline $\begin{array}{l}\text { Koyess } \\
\text { et al } \\
\text { (18) }\end{array}$ & 2006 & $\begin{array}{l}\text { Elemento } \\
\text { dentario } 36,27 . \\
\text { 1. Tratamento } \\
\text { Endodontico } \\
\text { (36): remoção } \\
\text { do inlay, } \\
\text { modelagem } \\
\text { sistema rotativo, } \\
\text { irrigação com } \\
\text { hipoclorito de } \\
\text { sódio a } 5,25 \% \text { e } \\
\text { hidróxido de } \\
\text { cácio e cimento } \\
\text { IRM. Canais } \\
\text { preenchidos } \\
\text { com guta-percha } \\
\text { e Selador } \\
\text { usando o } \\
\text { Sistema B } \\
\text { (Analítico } \\
\text { Endodontia) } \\
\text { técnica de } \\
\text { compactação } \\
\text { quente para a } \\
\text { região apical e o } \\
\text { sistema Obtura } \\
\text { na coroa. } \\
\text { 2. Prótese: } \\
\text { núcleo e coroa. } \\
\text { 3. Exodontia: } \\
\text { extração de um } \\
\text { terceiro molar } \\
\text { impactado. } \\
\text { 4.Endodontico } \\
\text { (27): através de } \\
\text { radiografia } \\
\text { identificou um } \\
\text { volume reduzido } \\
\text { da câmara } \\
\text { pulpar e um } \\
\text { aumento do } \\
\text { ligamento } \\
\text { periodontal na } \\
\text { área apical da } \\
\text { raiz palatina - } \\
\text { necrose pulpar e } \\
\text { pus na região; } \\
\text { limpeza e } \\
\text { modelagem do } \\
\text { sistema de } \\
\text { canais } \\
\text { radiculares } \\
\text { foram realizadas } \\
\text { com abundante }\end{array}$ & $\begin{array}{l}\text { NÃO } \\
\text { RELATA }\end{array}$ & NÃO RELATA & $\begin{array}{l}1 \mathrm{~g} \mathrm{de} \\
\text { Aspirina }^{\circledR} \\
\text { por } 3 \\
\text { dias. } \\
\text { Para a } \\
\text { exodontia } \\
\text { do } \\
\text { terceiro } \\
\text { molar foi } \\
\text { admistrad } \\
\text { o } \\
\text { Amoxicilin } \\
\text { a } 1 \mathrm{~g} \text { por } 5 \\
\text { dias. }\end{array}$ & 18 Meses & SIM & $\begin{array}{l}\text { NÃO } \\
\text { RELATA }\end{array}$ & $\begin{array}{l}\text { NÃO } \\
\text { RELATA }\end{array}$ \\
\hline
\end{tabular}


TRATAMENTO DAS LESÕES ENDO-PERIODONTAIS: UMA REVISÃO DE ESCOPO Belén Retamal-Valdes, Kamila Ribeiro do Nascimento Jabur, Silvana Felisberto Monteiro, Laryssa Macedo de Oliveira, Renata Queiroz Tavares, Cristiane Gonçalves, Magda Feres

\begin{tabular}{|c|c|c|c|c|c|c|c|c|c|}
\hline $\begin{array}{l}\text { Ballal et } \\
\text { al (19) }\end{array}$ & 2007 & $\begin{array}{l}\text { Elemento } \\
\text { dentario } 22 . \\
\text { 1. Uma tala } \\
\text { composta de } \\
\text { arame foi } \\
\text { colocada para } \\
\text { estabilizar o } \\
\text { dente } 22 \text { e as } \\
\text { instruções de } \\
\text { higiene oral } \\
\text { foram passadas } \\
\text { ao paciente; } \\
\text { 2. Tratamento } \\
\text { endodôntico: o } \\
\text { acesso } \\
\text { endodôntico foi } \\
\text { preparado com } \\
\text { dique de } \\
\text { borracha; havia } \\
\text { um canal único } \\
\text { reto e sem } \\
\text { alterações } \\
\text { morfológicas } \\
\text { visíveis a olho } \\
\text { nu. Tecido } \\
\text { pulpar necrótico } \\
\text { foi extirpado, } \\
\text { comprimento de } \\
\text { trabalho } \\
\text { determinado e } \\
\text { hidróxido de } \\
\text { cálcio intracanal } \\
\text { colocado; A } \\
\text { preparação do } \\
\text { canal foi } \\
\text { realizada com } \\
\text { limas tipo K } 40 ; \\
\text { o canal radicular } \\
\text { foi preenchido } \\
\text { por } \\
\text { compactação } \\
\text { lateral fria e } \\
\text { vertical quente } \\
\text { de guta-percha } \\
\text { cones e AH mais } \\
\text { selador; foi } \\
\text { selado com } \\
\text { cimento de } \\
\text { ionômero de } \\
\text { vidro; } \\
\text { 3. Tratamento } \\
\text { Periodontal } \\
\text { Cirúrgico - Após } \\
\text { 1 semanafoi } \\
\end{array}$ & $\begin{array}{l}\text { Não } \\
\text { Relata }\end{array}$ & NÃO RELATA & $\begin{array}{l}\text { Ibuprofen } \\
\text { o } 400 \mathrm{mg} \\
3 x \text { ao dia } \\
\text { por } 3 \text { dias } \\
\text { e } \\
\text { enxaguat } \\
\text { ório bucal } \\
\text { com } \\
\text { clorexidin } \\
\text { a a } 0,2 \% \\
2 x \text { ao dia } \\
\text { por } 7 \\
\text { dias. }\end{array}$ & 18 Meses & SIM & $\begin{array}{l}\text { Resoluçã } \\
\text { o } \\
\text { substanci } \\
\text { al do } \\
\text { defeito } \\
\text { ósseo } \\
\text { com } \\
\text { ganho de } \\
\text { fixação e } \\
\text { mobilidad } \\
\text { e dentária } \\
\text { diminuída } \\
\text { PS } \\
\text { reduziu } \\
\text { para } \\
\text { 4mm, } \\
\text { sem SS e } \\
\text { sem } \\
\text { supuraçãa } \\
\text { o. }\end{array}$ & $\begin{array}{l}\text { NÃO } \\
\text { RELATA }\end{array}$ \\
\hline
\end{tabular}


TRATAMENTO DAS LESÕES ENDO-PERIODONTAIS: UMA REVISÃO DE ESCOPO Belén Retamal-Valdes, Kamila Ribeiro do Nascimento Jabur, Silvana Felisberto Monteiro, Laryssa Macedo de Oliveira, Renata Queiroz Tavares, Cristiane Gonçalves, Magda Feres

\begin{tabular}{|c|c|c|c|c|c|c|c|c|c|}
\hline $\begin{array}{l}\text { Walter } \\
\text { et al } \\
\text { (20) }\end{array}$ & 2008 & $\begin{array}{l}\text { Elemento } \\
\text { dentário } 32 \text { e } 41 . \\
\text { 1. Programa de } \\
\text { Higiene Bucal } \\
\text { Individual com a } \\
\text { técnica de Bass } \\
\text { Modificada, a } \\
\text { cessão do } \\
\text { tabagismo foi } \\
\text { recomendada } \\
\text { 2. Tratamento } \\
\text { periodontal não- } \\
\text { cirúrgico com } \\
\text { RAR (Raspagem } \\
\text { supra e sub } \\
\text { gengival) foi } \\
\text { realizado em } \\
\text { todos os dentes } \\
\text { afetados em } \\
\text { duas consultas, } \\
\text { utilizando-se da } \\
\text { forma mecânica } \\
\text { e também o } \\
\text { ultra-som } \\
\text { instrumentados } \\
\text { sob anestesia } \\
\text { local. } \\
\text { 3. Tratamento } \\
\text { Endodôntico: o } \\
\text { tratamento de } \\
\text { canal foi } \\
\text { realizado em } \\
\text { ambos os } \\
\text { dentes; a cárie } \\
\text { foi escavada } \\
\text { após retirada da } \\
\text { PPF, isolamento } \\
\text { com dique de } \\
\text { borracha a } \\
\text { anestesia; os } \\
\text { canais foram } \\
\text { instrumentados } \\
\text { até a lima } 40 \\
\text { com } \\
\text { instrumentos } \\
\text { rotativos de } \\
\text { NiTi® e também } \\
\text { utilizando-se de } \\
\text { limas manuais; a } \\
\text { determinação do } \\
\text { comprimento de } \\
\text { trabalho foi } \\
\text { realizada } \\
\text { utilizando um } \\
\text { localizador } \\
\text { apical; hidróxido } \\
\text { de cálcio foi } \\
\text { colocado nos } \\
\text { canais e as } \\
\text { cavidades foram }\end{array}$ & SIM & $\begin{array}{l}25 \text { dias após o } \\
\text { inicio do } \\
\text { tratamento } \\
\text { endodontico a } \\
\text { finalização dos } \\
\text { canais } \\
\text { radiculares } \\
\text { com guta } \\
\text { percha foi } \\
\text { realizada. } \\
\text { Após } 3 \text { meses } \\
\text { foi realizado a } \\
\text { cirurgia } \\
\text { periodontal }\end{array}$ & $\begin{array}{l}\text { Clindamin } \\
\text { cina por } 8 \\
\text { dias }\end{array}$ & 32 Meses & SIM & $\begin{array}{l}\text { Cura } \\
\text { clínica, } \\
\text { PS } \\
\text { aceitável, } \\
\text { Regenera } \\
\text { ção } \\
\text { óssea }\end{array}$ & $\begin{array}{l}\text { NÃO } \\
\text { RELATA }\end{array}$ \\
\hline
\end{tabular}


TRATAMENTO DAS LESÕES ENDO-PERIODONTAIS: UMA REVISÃO DE ESCOPO

Belén Retamal-Valdes, Kamila Ribeiro do Nascimento Jabur, Silvana Felisberto Monteiro, Laryssa Macedo de Oliveira, Renata Queiroz Tavares, Cristiane Gonçalves, Magda Feres

\begin{tabular}{|c|c|c|c|c|c|c|c|c|c|}
\hline $\begin{array}{l}\text { Kim et } \\
\text { al (21) }\end{array}$ & 2008 & $\begin{array}{l}\text { Elementos } \\
\text { dentários } \\
\text { diversos. } \\
1 \text {. Tratamento } \\
\text { Periodontal e } \\
\text { Endodôntico } \\
\text { Cirúgico } \\
\text { utilizando } \\
\text { microscópio } \\
\text { cirúrgico - Após } \\
\text { os pacientes } \\
\text { serem } \\
\text { anestesiados } \\
\text { com lidocána a } \\
\text { 2\% com 1: } \\
80.000 \\
\text { epinefrina, } \\
\text { incisões } \\
\text { sulculares ou } \\
\text { mucogengivais } \\
\text { foram } \\
\text { realizadas, } \\
\text { respeitando os } \\
\text { requisitos } \\
\text { estéticos do } \\
\text { caso. Foi } \\
\text { necessária } \\
\text { aplicação tópica } \\
\text { de algodão } \\
\text { embebidos em } \\
\text { adrenalina a } \\
0,1 \% \text { e/ou } \\
\text { sulfato férrico } \\
\text { para } \\
\text { hemostasia. Foi } \\
\text { colocado um } \\
\text { retrator KP1 e foi } \\
\text { feito um sulco } \\
\text { usando uma } \\
\text { broca } \\
\text { Lindenmann, } \\
\text { para proteger o } \\
\text { forame mentual } \\
\text { durante o } \\
\text { procedimento } \\
\text { cirúrgico } \\
\text { ancorando a } \\
\text { extremidade } \\
\text { serrilhada do } \\
\text { retrator. As } \\
\text { osteotomias } \\
\text { foram realizadas } \\
\text { com um corte } \\
\text { ósseo. Foi feita } \\
\text { curetagem } \\
\text { nnriirndinilanrn } \\
\end{array}$ & $\begin{array}{l}\text { NÃO } \\
\text { RELATA }\end{array}$ & NÃO RELATA & $\begin{array}{l}\text { Todos os } \\
\text { pacientes } \\
\text { foram } \\
\text { submetid } \\
\text { os a um } \\
\text { regime } \\
\text { pré- } \\
\text { operatório } \\
\text { de } \\
\text { antibiótico } \\
\text { s e anti- } \\
\text { inflamatór } \\
\text { ios. } \\
\text { Amoxicilin } \\
\text { a } 250 m g \\
3 \times \text { ao dia } \\
\text { prescrita } \\
\text { a partir de } \\
\text { um dia } \\
\text { antes da } \\
\text { cirurgia e } \\
\text { continuou } \\
\text { por um } \\
\text { total de } 7 \\
\text { dias. O } \\
\text { lbuprofen } \\
\text { o (400 } \\
\text { mg) foi } \\
\text { administr } \\
\text { ado } 1 \\
\text { hora } \\
\text { antes da } \\
\text { cirurgia e } \\
\text { após a } \\
\text { cirurgia } \\
\text { para } \\
\text { todos os } \\
\text { pacientes } \\
\text {. }\end{array}$ & 60 Meses & SIM & $\begin{array}{l}\text { Sucesso } \\
\text { em } 73 \% \\
\text { dos } \\
\text { Casos } \\
\text { (A) } 24 \\
\text { Casos } \\
\text { Cura } \\
\text { Cciomplet } \\
\text { a/ } 4 \\
\text { Incomplet } \\
\text { a; } \\
\text { (B) } 45 \\
\text { Casos } \\
\text { Cura } \\
\text { Completa } \\
\text { / } 7 \\
\text { Incomplet } \\
\text { a/ } 1 \\
\text { Insatisfat } \\
\text { ória; } \\
\text { (C) } 57 \\
\text { Casos } \\
\text { Cura } \\
\text { Completa } \\
\text { /4 } \\
\text { Incomplet } \\
\text { a/ } 6 \\
\text { Insatisfat } \\
\text { ória; } \\
\text { (D) 6 } \\
\text { Casos } \\
\text { Cura } \\
\text { Completa } \\
\text { /6 } 6 \\
\text { Incomplet } \\
\text { a; } \\
\text { (E) } 6 \\
\text { Casos } \\
\text { Cura } \\
\text { Completa } \\
\text { /1 } \\
\text { Incomplet } \\
\text { a/ } 1 \\
\text { Incerta/ 1 } \\
\text { Insatisfat } \\
\text { ória; } \\
\text { (F) } 11 \\
\text { Casos } \\
\text { Cura } \\
\text { Completa } \\
\text { /3 } \\
\text { Incomplet } \\
\text { a/ } 4 \\
\text { Incerta/ 1 } \\
\text { Innntinfnt }\end{array}$ & $\begin{array}{l}\text { NÃO } \\
\text { RELATA }\end{array}$ \\
\hline
\end{tabular}


TRATAMENTO DAS LESÕES ENDO-PERIODONTAIS: UMA REVISÃO DE ESCOPO Belén Retamal-Valdes, Kamila Ribeiro do Nascimento Jabur, Silvana Felisberto Monteiro, Laryssa Macedo de Oliveira, Renata Queiroz Tavares, Cristiane Gonçalves, Magda Feres

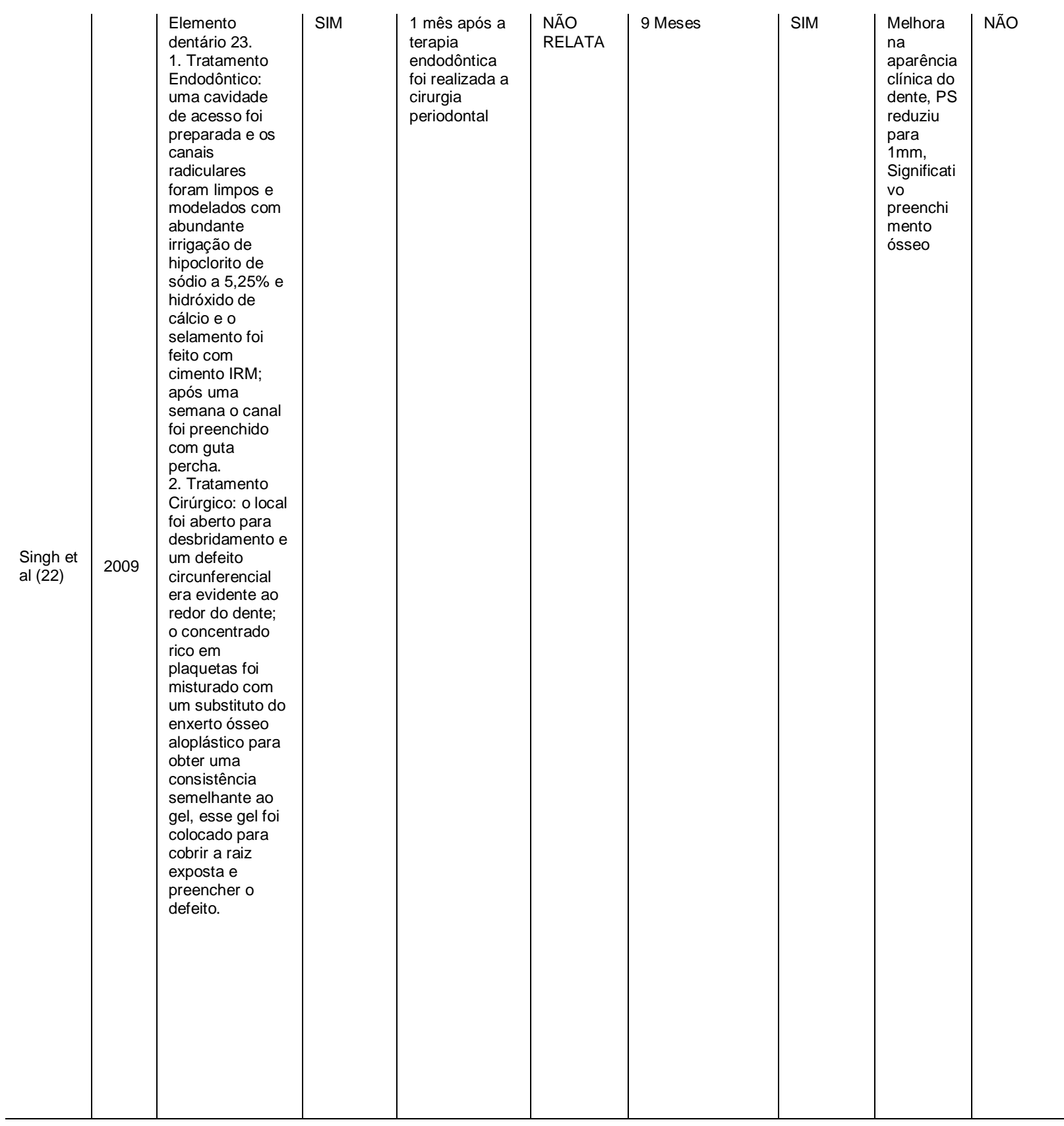


TRATAMENTO DAS LESÕES ENDO-PERIODONTAIS: UMA REVISÃO DE ESCOPO Belén Retamal-Valdes, Kamila Ribeiro do Nascimento Jabur, Silvana Felisberto Monteiro, Laryssa Macedo de Oliveira, Renata Queiroz Tavares, Cristiane Gonçalves, Magda Feres

\begin{tabular}{|c|c|c|c|c|c|c|c|c|c|}
\hline $\begin{array}{l}\text { Attam et } \\
\text { al (23) }\end{array}$ & 2010 & $\begin{array}{l}\text { Elemento } \\
\text { dentário } 22 . \\
\text { 1. Profilaxia: } \\
\text { remoção do } \\
\text { cálculo } \\
\text { localizado; } \\
\text { 2. Tratamento } \\
\text { Endodôntico: } \\
\text { Após isolamento } \\
\text { com dique de } \\
\text { borracha, foi } \\
\text { realizada técnica } \\
\text { de coroação até } \\
\text { uma lima 60; } \\
\text { irrigação } \\
\text { abundante com } \\
\text { hipoclorito de } \\
\text { sódio 1\% e } \\
\text { medicamento } \\
\text { intra canal } \\
\text { Hidróxido de } \\
\text { cálcio. Uma } \\
\text { semana depois } \\
\text { o dente foi } \\
\text { desbridado e foi } \\
\text { realizada uma } \\
\text { lavagem final } \\
\text { com etilenodia- } \\
\text { canal } 17 \% \text { e } \\
\text { ácido } \\
\text { minetetraacético } \\
\text {; o dente foi } \\
\text { obturado com } \\
\text { guta percha e } \\
\text { AH mais selante, } \\
\text { usando a técnica } \\
\text { de condensação } \\
\text { lateral. } \\
\text { 3. Tratamento } \\
\text { Periodontal } \\
\text { Cirúrgica: } \\
\text { Regeneração } \\
\text { tecidual Guiada } \\
\text { com um retalho } \\
\text { cirúrgico foi } \\
\text { levantado do } \\
\text { aspecto palatino } \\
\text { e do sulco palato } \\
\text { gengival; } \\
\text { escalonamento } \\
\text { completo e } \\
\text { aplainamento } \\
\text { foram } \\
\text { realizados, o } \\
\text { tecido de } \\
\text { granulação } \\
\text { também foi } \\
\end{array}$ & NÃO & IMEDIATO & $\begin{array}{l}\text { NÃO } \\
\text { RELATA }\end{array}$ & 3 Meses & SIM & $\begin{array}{l}\text { PS } \\
\text { reduziu } \\
\text { para } \\
2 \mathrm{~mm}, \\
\text { sem } \\
\text { aumento } \\
\text { da } \\
\text { recessão } \\
\text { gengival }\end{array}$ & NÃO \\
\hline
\end{tabular}




\section{RECIMA21 - REVISTA CIENTÍFICA MULTIDISCIPLINAR}

TRATAMENTO DAS LESÕES ENDO-PERIODONTAIS: UMA REVISÃO DE ESCOPO

Belén Retamal-Valdes, Kamila Ribeiro do Nascimento Jabur, Silvana Felisberto Monteiro, Laryssa Macedo de Oliveira, Renata Queiroz Tavares, Cristiane Gonçalves, Magda Feres

\begin{tabular}{|c|c|c|c|c|c|c|c|c|c|}
\hline $\begin{array}{l}\text { Blancha } \\
\text { rd et al } \\
\text { (24) }\end{array}$ & 2010 & \begin{tabular}{|l} 
Elemento \\
dentario 12 (24 \\
na nossa \\
classificação - \\
pré molar \\
superior \\
esquerdo). \\
1 . Tratamento \\
Endodôntico - \\
Elemento já \\
tratado com \\
endodontia. \\
2. Tratamento \\
Periodontal \\
Cirúrgico: \\
realizado retalho \\
mucoperiostal \\
para obter \\
acesso aos \\
dentes 11 (23) a \\
15 (27) para \\
tratar o \\
elemento12 (24) \\
e outros \\
problemas \\
periodontais \\
nesse sextante. \\
Constatou-se \\
que o elemento \\
12 (24) \\
tinha três raízes, \\
das quais \\
apenas duas \\
haviam recebido \\
tratamento de \\
canal. Devido as \\
invasões de \\
furca grau III, da \\
anatomia do \\
defeito \\
e o longo tronco \\
radicular no \\
elemento 12 \\
(24), foi \\
determinado \\
prognóstico \\
desfavorável e o \\
dente foi \\
extraído. O local \\
foi enxertado \\
com aloenxerto \\
ósseo seco para \\
preservar as \\
dimensões do \\
aluéono
\end{tabular} & NÃC & IMEDIATO & $\begin{array}{l}\text { NÃO } \\
\text { RELATA }\end{array}$ & 3 Meses & SIN & $\begin{array}{l}\text { Cura dos } \\
\text { dentes/te } \\
\text { cidos } \\
\text { adjacente } \\
\mathrm{s}\end{array}$ & NÃO \\
\hline
\end{tabular}


TRATAMENTO DAS LESÕES ENDO-PERIODONTAIS: UMA REVISÃO DE ESCOPO

Belén Retamal-Valdes, Kamila Ribeiro do Nascimento Jabur, Silvana Felisberto Monteiro, Laryssa Macedo de Oliveira, Renata Queiroz Tavares, Cristiane Gonçalves, Magda Feres

\begin{tabular}{|c|c|c|c|c|c|c|c|c|c|}
\hline $\begin{array}{l}\text { Mali et } \\
\text { al (25) }\end{array}$ & 2011 & 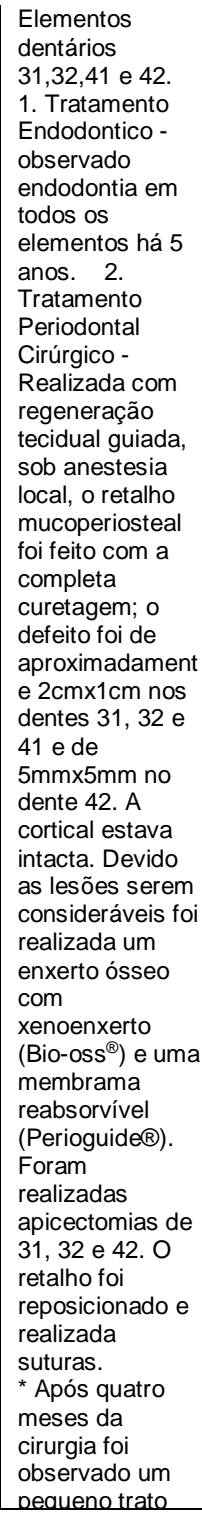 & SIM & NÃO RELATA & $\begin{array}{l}\text { Antibiótic } \\
\text { o e } \\
\text { Analgésic } \\
0\end{array}$ & NÃO RELATA & SIM & $\begin{array}{l}\text { Mobilidad } \\
\text { e } \\
\text { reduzida } \\
\text { para grau } \\
\text { I, redução } \\
\text { significati } \\
\text { va de PS, } \\
\text { cicatrizaç } \\
\text { ão } \\
\text { satisfatóri } \\
\text { a. Porém } \\
\text { após } 4 \\
\text { meses } \\
\text { um } \\
\text { pequeno } \\
\text { trato } \\
\text { sinusal foi } \\
\text { observad } \\
\text { o na } \\
\text { região do } \\
\text { dente 42 } \\
\text { e uma } \\
\text { prescriçã } \\
\text { o de } \\
\text { antibiótic } \\
\text { os foi } \\
\text { realizada; } \\
\text { mas após } \\
6 \text { meses } \\
\text { o } \\
\text { problema } \\
\text { persistiu } \\
\text { e uma } \\
\text { nova } \\
\text { cirurgia } \\
\text { foi } \\
\text { realizada } \\
\text { e o } \\
\text { paciente } \\
\text { vem } \\
\text { sendo } \\
\text { acompan } \\
\text { hado } \\
\text { regularm } \\
\text { ente. } \\
\text { É notada } \\
\text { ligeira } \\
\text { recessão } \\
\text { nos } \\
\text { dentes } 32 \\
\text { e } 42 \text { após } \\
\text { a } \\
\text { segunda } \\
\text { intervene } \\
\end{array}$ & $\begin{array}{l}\text { NÃO } \\
\text { RELATA }\end{array}$ \\
\hline
\end{tabular}


TRATAMENTO DAS LESÕES ENDO-PERIODONTAIS: UMA REVISÃO DE ESCOPO Belén Retamal-Valdes, Kamila Ribeiro do Nascimento Jabur, Silvana Felisberto Monteiro, Laryssa Macedo de Oliveira, Renata Queiroz Tavares, Cristiane Gonçalves, Magda Feres

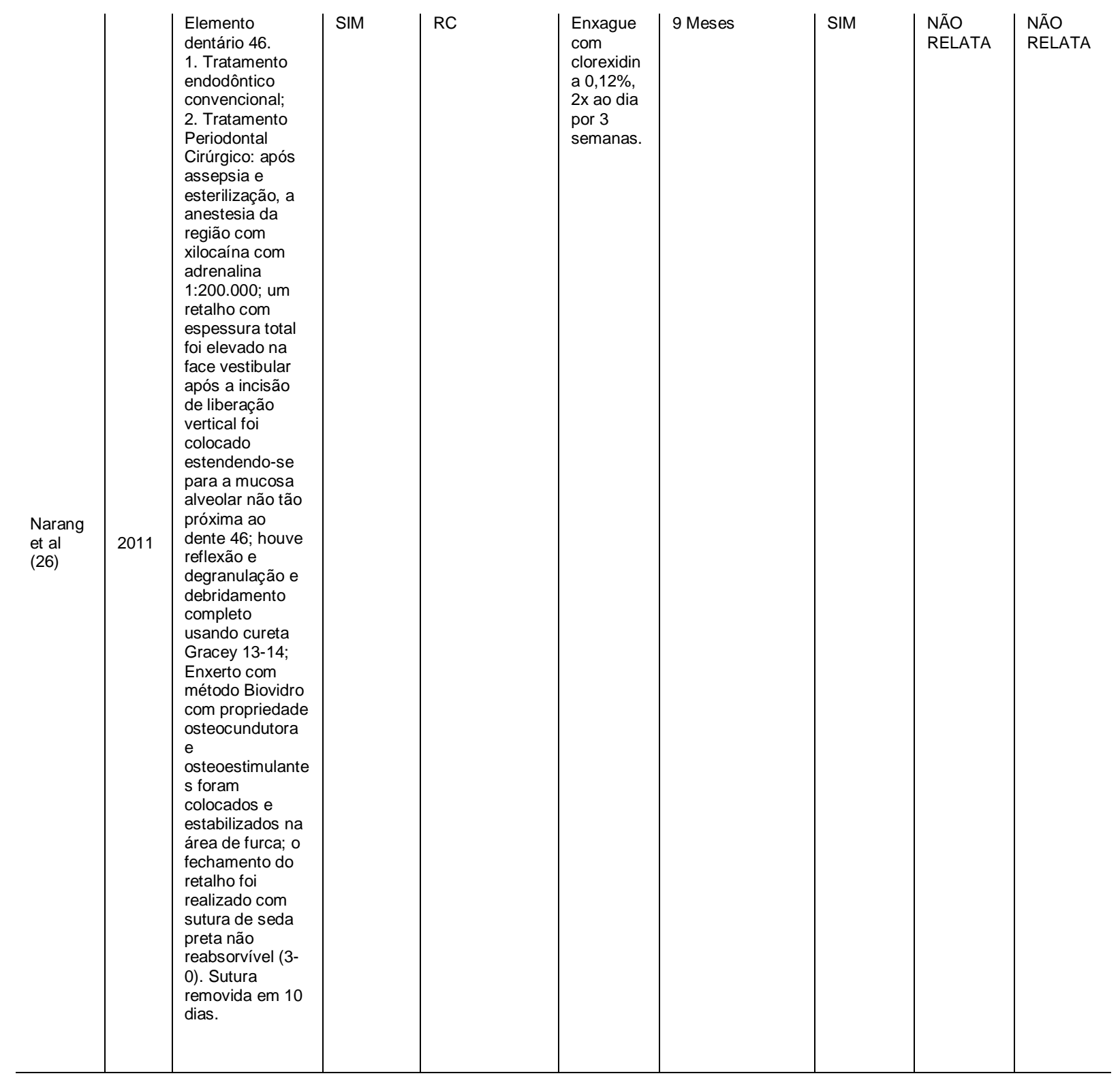


TRATAMENTO DAS LESÕES ENDO-PERIODONTAIS: UMA REVISÃO DE ESCOPO

Belén Retamal-Valdes, Kamila Ribeiro do Nascimento Jabur, Silvana Felisberto Monteiro, Laryssa Macedo de Oliveira, Renata Queiroz Tavares, Cristiane Gonçalves, Magda Feres

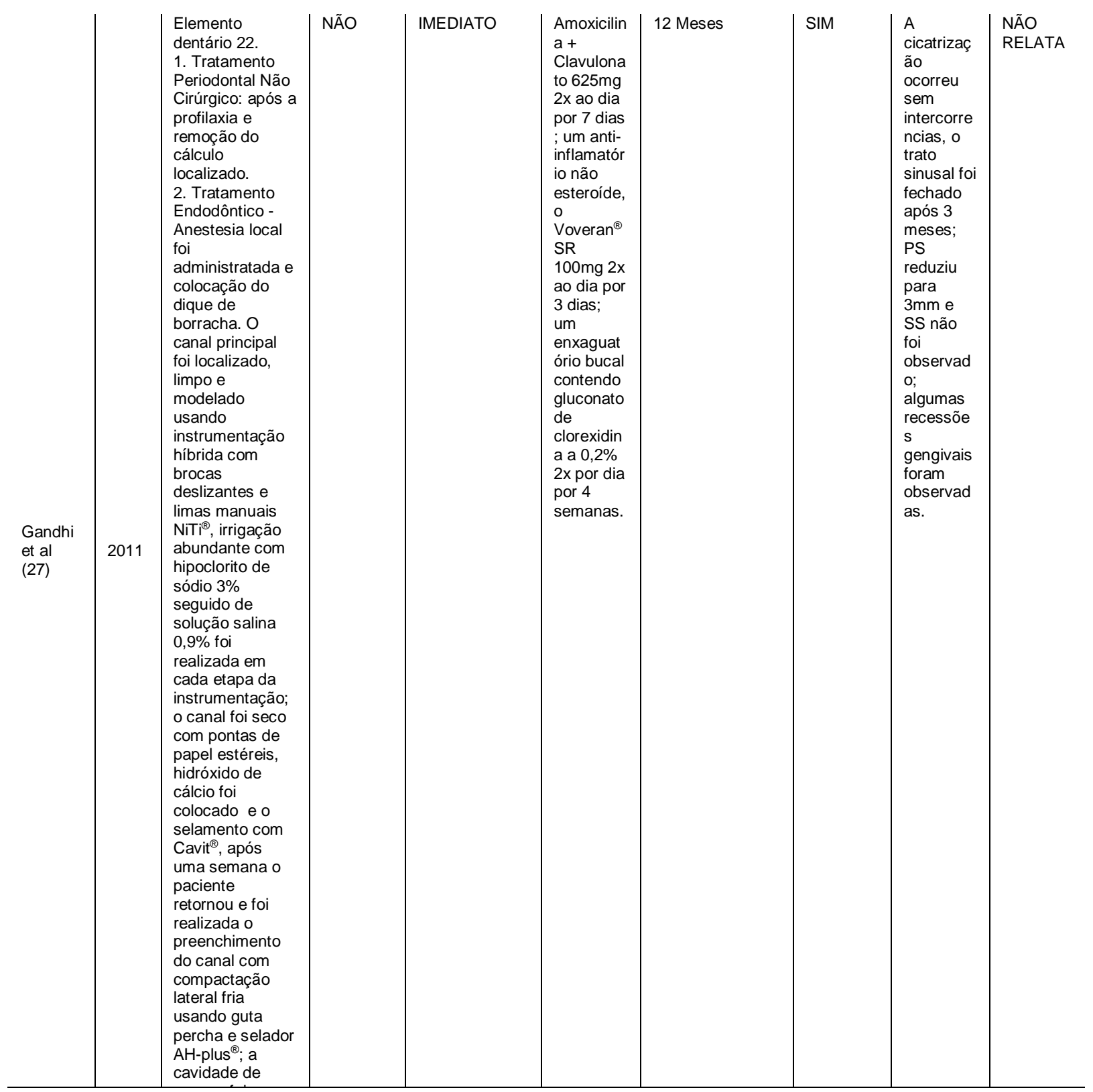


TRATAMENTO DAS LESÕES ENDO-PERIODONTAIS: UMA REVISÃO DE ESCOPO

Belén Retamal-Valdes, Kamila Ribeiro do Nascimento Jabur, Silvana Felisberto Monteiro, Laryssa Macedo de Oliveira, Renata Queiroz Tavares, Cristiane Gonçalves, Magda Feres

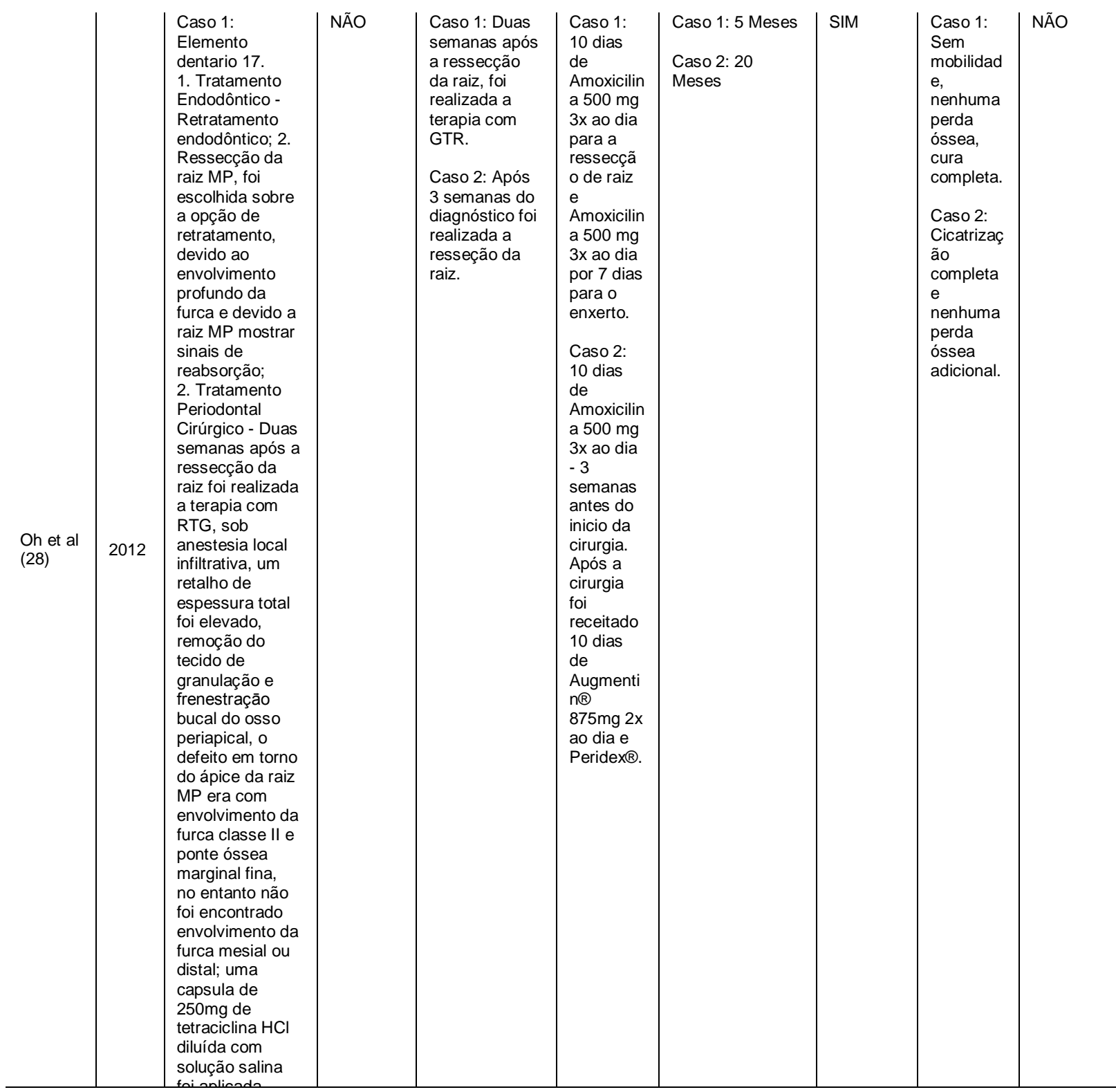




\section{RECIMA21 - REVISTA CIENTÍFICA MULTIDISCIPLINAR}

TRATAMENTO DAS LESÕES ENDO-PERIODONTAIS: UMA REVISÃO DE ESCOPO

Belén Retamal-Valdes, Kamila Ribeiro do Nascimento Jabur, Silvana Felisberto Monteiro, Laryssa Macedo de Oliveira, Renata Queiroz Tavares, Cristiane Gonçalves, Magda Feres

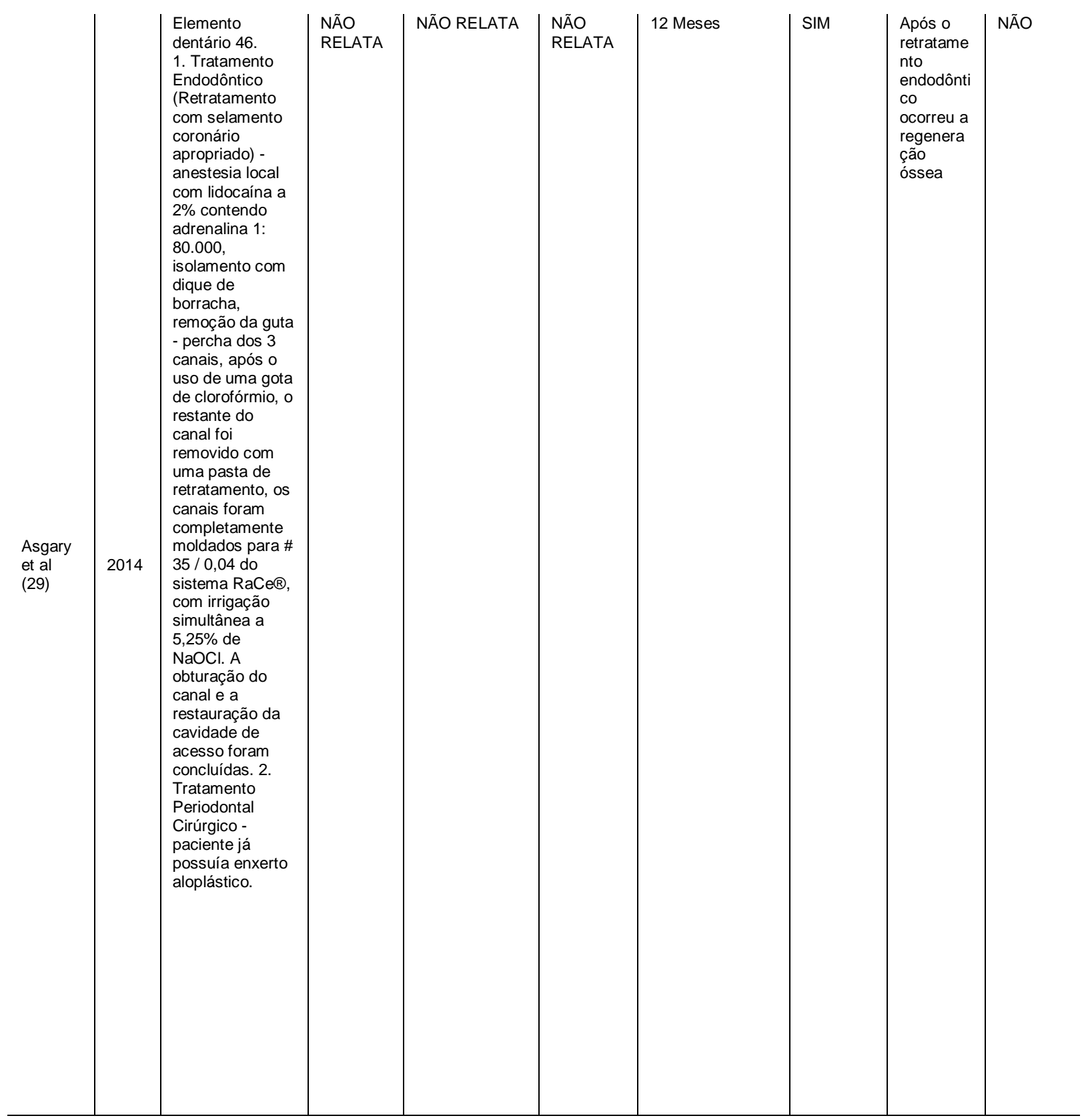




\section{RECIMA21 - REVISTA CIENTÍFICA MULTIDISCIPLINAR}

TRATAMENTO DAS LESÕES ENDO-PERIODONTAIS: UMA REVISÃO DE ESCOPO

Belén Retamal-Valdes, Kamila Ribeiro do Nascimento Jabur, Silvana Felisberto Monteiro, Laryssa Macedo de Oliveira, Renata Queiroz Tavares, Cristiane Gonçalves, Magda Feres

\begin{tabular}{|c|c|c|c|c|c|c|c|c|c|}
\hline $\begin{array}{l}\text { Azaripo } \\
\text { ur et al } \\
\text { (30) }\end{array}$ & 2013 & $\begin{array}{l}\text { Caso 1: } \\
\text { Elemento } \\
\text { dentário } 46 . \\
\text { 1. Tratamento } \\
\text { Endodôntico- } \\
\text { paciente já tinha } \\
\text { realizado } \\
\text { endodontia há } 4 \\
\text { semanas. } \\
\text { 2. Tratamento } \\
\text { Periodontal } \\
\text { Cirúrgico - } \\
\text { Retalho muco- } \\
\text { periosteal para } \\
\text { acessar a área } \\
\text { entre o segundo } \\
\text { pré-molar } \\
\text { inferior direito e } \\
\text { o segundo mola } \\
\text { inferior direito, o } \\
\text { exudato de guta } \\
\text { percha foi } \\
\text { removido. } \\
\text { CEMD } \\
\text { (Emdogain } \\
\text { Straumann) foi } \\
\text { aplicada na } \\
\text { superfície } \\
\text { radicular. } \\
\text { Caso 2: } \\
\text { Elemento } \\
\text { dentário } 34 \text { e } 35 \\
\text { 1. Endodôntico: } \\
\text { a raiz dos canais } \\
\text { foram obturadas } \\
\text { com guta percha } \\
\text { e Sealapex } \\
\text { (SybronEndo); } \\
\text { 2. Tratamento } \\
\text { Periodontal } \\
\text { Cirúrgico: } \\
\text { retalho } \\
\text { periosteal na } \\
\text { extensão do } \\
\text { defeito de três } \\
\text { paredes, CEMD } \\
\text { (Emdogain® } \\
\text { Straumanann) foi } \\
\text { aplicado na } \\
\text { superfície da } \\
\text { raiz e o retalho } \\
\text { foi } \\
\text { reposicionado. } \\
\text { 3. Tratamento } \\
\text { rnot́tico:uma }\end{array}$ & SIN & $\begin{array}{l}\text { Caso 1: } \\
\text { Cirurgia } \\
\text { ocorreu } 4 \\
\text { semanas após } \\
\text { tratamento } \\
\text { endodôntico. } \\
\text { Caso 2: A } \\
\text { cirurgia } \\
\text { ocorreu } 6 \\
\text { meses após o } \\
\text { tratamento } \\
\text { endodôntico. }\end{array}$ & $\begin{array}{l}\text { NÃO } \\
\text { RELATA }\end{array}$ & 24 Meses & SIN & $\begin{array}{l}\text { Caso 1: } \\
\text { Regenera } \\
\text { ção peri- } \\
\text { radicular; } \\
\text { redução } \\
\text { de PS } \\
\text { para } \\
5 m m \text { e } \\
\text { Envolvim } \\
\text { ento de } \\
\text { Furca de } \\
1 \text { mm. } \\
\text { Caso 2: } \\
\text { Uma } \\
\text { radiografi } \\
\text { a } 6 \\
\text { meses } \\
\text { depois } \\
\text { mostra a } \\
\text { melhora } \\
\text { das } \\
\text { lesões; } \\
\text { redução } \\
\text { de PS } \\
\text { para } \\
10 m m, \\
\text { mobilidad } \\
\text { e dentária } \\
\text { melhorou, } \\
\text { e defeito } \\
\text { circular } \\
\text { quase } \\
\text { desapare } \\
\text { ceu. }\end{array}$ & $\begin{array}{l}\text { NÃO } \\
\text { RELATA }\end{array}$ \\
\hline
\end{tabular}




\section{RECIMA21 - REVISTA CIENTÍFICA MULTIDISCIPLINAR}

TRATAMENTO DAS LESÕES ENDO-PERIODONTAIS: UMA REVISÃO DE ESCOPO

Belén Retamal-Valdes, Kamila Ribeiro do Nascimento Jabur, Silvana Felisberto Monteiro, Laryssa Macedo de Oliveira, Renata Queiroz Tavares, Cristiane Gonçalves, Magda Feres

\begin{tabular}{|c|c|c|c|c|c|c|c|c|c|}
\hline $\begin{array}{l}\text { Jivoinov } \\
\text { ici et al } \\
\text { (31) }\end{array}$ & 2014 & $\begin{array}{l}\text { Caso 1: } \\
\text { Elemento } \\
\text { dentário } 45 \text {. } \\
\text { 1. Tratamento } \\
\text { Endodôntico - } \\
\text { elemento com } \\
\text { drenagem da } \\
\text { supuração do } \\
\text { sulco. Após a } \\
\text { instrumentação, } \\
\text { foi utilizado um } \\
\text { curativo de } \\
\text { desapontamento } \\
\text { com hidróxido } \\
\text { de cálcio. Após } \\
\text { quatro semanas, } \\
\text { o dente estava } \\
\text { assintomático, } \\
\text { nenhum pus foi } \\
\text { drenado no } \\
\text { sulco, o canal foi } \\
\text { preenchido com } \\
\text { condensação } \\
\text { lateral, guta- } \\
\text { percha e selador } \\
\text { e restauração } \\
\text { coronal. } \\
\text { Caso 2: } \\
\text { Elementos } \\
\text { dentários } 36 \text { e } \\
\text { 37. } \\
\text { 1. Tratamento } \\
\text { Endodôntico - } \\
\text { instrumentação } \\
\text { rotativa de } \\
\text { níquel-titânio e o } \\
\text { hidróxido de } \\
\text { cálcio foi } \\
\text { colocado como } \\
\text { curativo. Após } \\
\text { três semanas, } \\
\text { foi preenchido } \\
\text { com uma } \\
\text { condensação } \\
\text { lateral de guta- } \\
\text { percha. } \\
2 . \text { Tratamento } \\
\text { Periodontal } \\
\text { Cirúrgico - RAR } \\
\text { superior e } \\
\text { inferior, } \\
\text { planejamento } \\
\text { radicular e } \\
\text { curetagem } \\
\text { periodontal em } \\
\text { campo aberto. }\end{array}$ & $\begin{array}{l}\text { NÃO } \\
\text { RELATA }\end{array}$ & NÃO RELATA & $\begin{array}{l}\text { NÃO } \\
\text { RELATA }\end{array}$ & 24 Meses & SIN & $\begin{array}{l}\text { Caso 1: } \\
\text { PS } \\
\text { reduzida } \\
\text { para } \\
\text { 3mm; } \\
\text { Sem } \\
\text { supuraçã } \\
\text { O; } \\
\text { Caso 2: } \\
\text { PS } \\
\text { reduzida } \\
\text { à } \\
\text { normalida } \\
\text { de }\end{array}$ & NÃO \\
\hline
\end{tabular}


TRATAMENTO DAS LESÕES ENDO-PERIODONTAIS: UMA REVISÃO DE ESCOPO Belén Retamal-Valdes, Kamila Ribeiro do Nascimento Jabur, Silvana Felisberto Monteiro, Laryssa Macedo de Oliveira, Renata Queiroz Tavares, Cristiane Gonçalves, Magda Feres

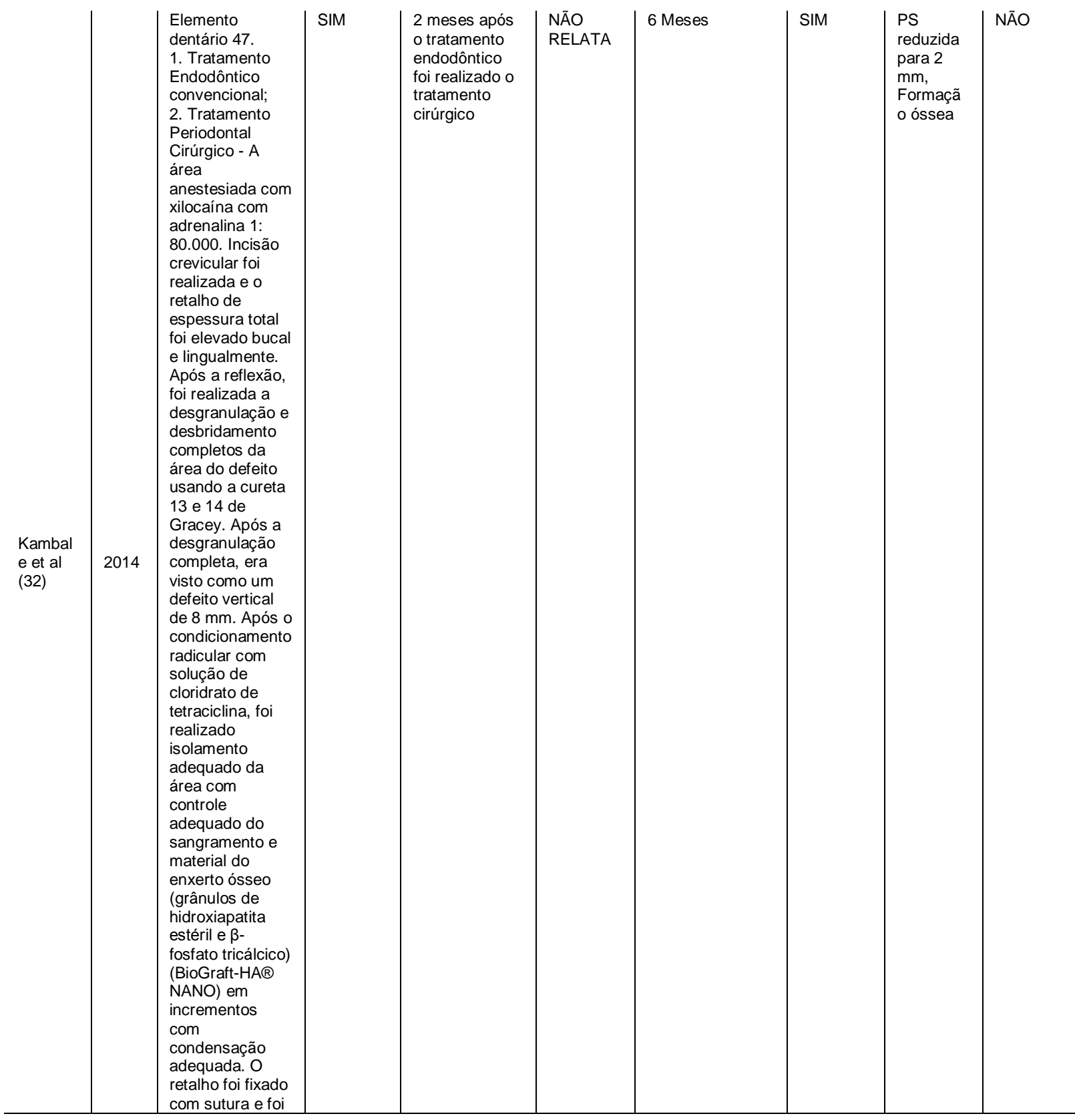


TRATAMENTO DAS LESÕES ENDO-PERIODONTAIS: UMA REVISÃO DE ESCOPO Belén Retamal-Valdes, Kamila Ribeiro do Nascimento Jabur, Silvana Felisberto Monteiro, Laryssa Macedo de Oliveira, Renata Queiroz Tavares, Cristiane Gonçalves, Magda Feres

\begin{tabular}{|c|c|c|c|c|c|c|c|c|c|}
\hline $\begin{array}{l}\text { Fujji et } \\
\text { al (33) }\end{array}$ & 2014 & 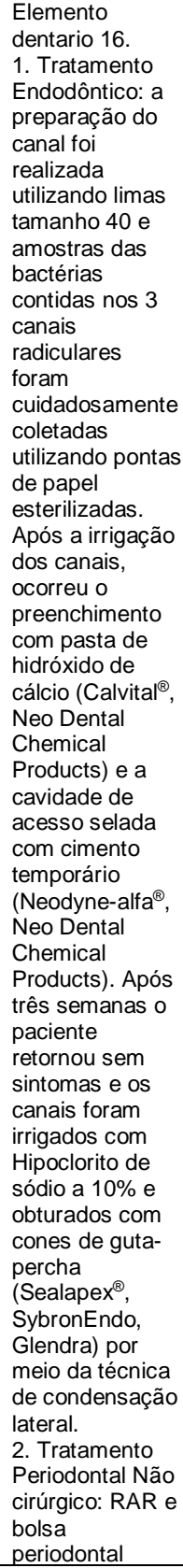 & SIM & NÃO RELATA & $\begin{array}{l}\text { NÃO } \\
\text { RELATA }\end{array}$ & NÃO RELATA & SIM & $\begin{array}{l}\mathrm{Na} \\
\text { análise } \\
\text { das } \\
\text { amostras } \\
\text { extraídas } \\
\text { dos } \\
\text { canais } \\
\text { radiculare } \\
\mathrm{s} \\
\text { constatou } \\
\text {-se a } \\
\text { presença } \\
\text { de } 10 \\
\text { espécies } \\
\text { bacterian } \\
\text { as. } \\
\text { Após a } \\
\text { restauraç } \\
\text { ão do } \\
\text { dente não } \\
\text { houveram } \\
\text { mais } \\
\text { sinais de } \\
\text { doença } \\
\text { periodont } \\
\text { al/ } \\
\text { periapical }\end{array}$ & $\begin{array}{l}\text { NÃO } \\
\text { RELATA }\end{array}$ \\
\hline
\end{tabular}


TRATAMENTO DAS LESÕES ENDO-PERIODONTAIS: UMA REVISÃO DE ESCOPO

Belén Retamal-Valdes, Kamila Ribeiro do Nascimento Jabur, Silvana Felisberto Monteiro, Laryssa Macedo de Oliveira, Renata Queiroz Tavares, Cristiane Gonçalves, Magda Feres

\begin{tabular}{|c|c|c|c|c|c|c|c|c|c|}
\hline $\begin{array}{l}\text { Kishan } \\
\text { et al } \\
\text { (34) }\end{array}$ & 2014 & $\begin{array}{l}\text { Elemento } \\
\text { Dentario } 12 . \\
\text { 1. Tratamento } \\
\text { endodôntico: } \\
\text { instrumentação } \\
\text { do canal, } \\
\text { drenagem do } \\
\text { pus, PQC foi } \\
\text { realizada } \\
\text { utilizando a } \\
\text { técnica do } \\
\text { retrocesso, foi } \\
\text { realizado um } \\
\text { curativo com } \\
\text { Hidróxido de } \\
\text { Cálcio. Na visita } \\
\text { seguinte a } \\
\text { obturação foi } \\
\text { concluída com } \\
\text { Guta Percha e } \\
\text { selador AH-26 } \\
\text { usando a técnica } \\
\text { de condensação } \\
\text { lateral fria. } \\
\text { 2. Tratamento } \\
\text { Periodontal } \\
\text { Cirúrgico - foi } \\
\text { realizada a } \\
\text { assepsia, } \\
\text { isolamento com } \\
\text { dique de } \\
\text { borracha e } \\
\text { anestesia local } \\
\text { da região. } \\
\text { incisões } \\
\text { sulculares foram } \\
\text { feitas na região } \\
\text { palatal e um } \\
\text { retalho } \\
\text { mucoperiosteal } \\
\text { de espessura } \\
\text { total elevada no } \\
\text { aspecto palativo } \\
\text { para acessar o } \\
\text { sulco palato- } \\
\text { gengival. A } \\
\text { curetagem } \\
\text { apícal e o } \\
\text { planejamento } \\
\text { radicular foram } \\
\text { realizados e o } \\
\text { sulco foi } \\
\text { restaurado com } \\
\text { cimento de } \\
\text { ionômero de } \\
\text { vidro. Uma } \\
\text { membrana de } \\
\text { colágeno } \\
\text { reabsorvível foi } \\
\text { colocada para } \\
\text { regeneração } \\
\text { tecidual auiada }\end{array}$ & NÃO & IMEDIATO & $\begin{array}{l}\text { NÃO } \\
\text { RELATA }\end{array}$ & 9 Meses & SIM & $\begin{array}{l}\text { Resultad } \\
\text { o } \\
\text { satisfatóri } \\
\text { o na } \\
\text { redução } \\
\text { da para } \\
\text { 2-3mm; a a } \\
\text { taxa de } \\
\text { cicatrizaç } \\
\text { ão do } \\
\text { local } \\
\text { cirúrgico } \\
\text { foi boa e } \\
\text { a } \\
\text { regenera } \\
\text { ção } \\
\text { óssea } \\
\text { radiográfi } \\
\text { ca foi } \\
\text { rápida e } \\
\text { impressio } \\
\text { nante, } \\
\text { sem } \\
\text { sinais de } \\
\text { reabsorçã } \\
\text { o } \\
\text { radicular } \\
\text { externa. }\end{array}$ & NÃO \\
\hline
\end{tabular}


TRATAMENTO DAS LESÕES ENDO-PERIODONTAIS: UMA REVISÃO DE ESCOPO

Belén Retamal-Valdes, Kamila Ribeiro do Nascimento Jabur, Silvana Felisberto Monteiro, Laryssa Macedo de Oliveira, Renata Queiroz Tavares, Cristiane Gonçalves, Magda Feres

\begin{tabular}{|c|c|c|c|c|c|c|c|c|c|}
\hline $\begin{array}{l}\text { Katwal } \\
\text { et al } \\
\text { (45) }\end{array}$ & 2020 & $\begin{array}{l}\text { Elemento } \\
\text { dentário } 22 . \\
1 \text {. Tratamento } \\
\text { Endodôntico - O } \\
\text { paciente já tinha } \\
\text { canal radicular } \\
\text { tratado com } \\
\text { excelencia, sem } \\
\text { a necessidade } \\
\text { de nova } \\
\text { intervenção. } \\
\text { 2. Tratamento } \\
\text { Periodontal } \\
\text { Cirúrgico - } \\
\text { Anestesia } 3,4 \\
\text { mL de lidocaína } \\
\text { a 2\% com } \\
\text { epinefrina } \\
\text { 1:100.000. O } \\
\text { retalho } \\
\text { mucoperiosteal } \\
\text { foi rebatido, } \\
\text { após curetagem } \\
\text { obtivemos local } \\
\text { em forma de } \\
\text { lágrima de } 10 \\
\text { mm x } 15 \text { mm } \\
\text { exposto, o canal } \\
\text { nasopalatino } \\
\text { ficou visível } \\
\text { durante a } \\
\text { intervenção } \\
\text { cirúrgica, mas foi } \\
\text { preservado. } \\
\text { Uma } \\
\text { regeneraçãa de } \\
\text { tecidual guiada } \\
\text { combinada foi } \\
\text { realizada para } \\
\text { prevenir o } \\
\text { crescimento } \\
\text { negativo do } \\
\text { epitélio gengival } \\
\text { e tecido } \\
\text { conjuntivo, } \\
\text { juntamente com } \\
\text { a manutenção } \\
\text { do espaço com } \\
\text { enxerto ósseo. } \\
\text { Outros materiais } \\
\text { regenerativos } \\
\text { que foram } \\
\text { relatados para } \\
\text { esse fim incluem } \\
\text { nlacuetas ricas }\end{array}$ & SIM & $\begin{array}{l}\text { Paciente já } \\
\text { havia tratado } \\
\text { endondôntico } \\
\text { há } 4 \text { meses. }\end{array}$ & $\begin{array}{l}\text { Ibuprofen } \\
\text { o } 600 \mathrm{mg}, \\
\text { alternand } \\
\text { o com } \\
\text { Acetamin } \\
\text { ofeno } 325 \\
\text { mg para } \\
\text { controle } \\
\text { da dor. } \\
\text { Um } \\
\text { analgésic } \\
\text { o } \\
\text { hidrocodo } \\
\text { na / } \\
\text { acetamin } \\
\text { ofeno (5 / } \\
\text { 325mg a } \\
\text { cada 4-6 } \\
\text { horas } \\
\text { conforme } \\
\text { necessári } \\
\text { o) foi } \\
\text { prescrito } \\
\text { em caso } \\
\text { de } \\
\text { controle } \\
\text { insuficient } \\
\text { e da dor, } \\
\text { Azitromici } \\
\text { na 500 } \\
\text { mg no dia } \\
\text { depois } \\
250 \text { mg a } \\
\text { cada 24h } \\
\text { durante } 4 \\
\text { dias e } \\
\text { instruçõe } \\
\text { s suaves } \\
\text { sobre } \\
\text { cuidados } \\
\text { de } \\
\text { higiene } \\
\text { oral. } \\
\text { Azitromici } \\
\text { na (um } \\
\text { macrolíde } \\
\text { o de } \\
\text { amplo } \\
\text { espectro) } \\
\text { foi } \\
\text { prescrito } \\
\text { porque o } \\
\text { paciente } \\
\text { era } \\
\text { aléraico a }\end{array}$ & 24 meses & SIM & $\begin{array}{l}\text { O tecido } \\
\text { gengival } \\
\text { ao redor } \\
\text { do dente } \\
10 \text { (22) } \\
\text { mostrou } \\
\text { inflamaça } \\
\text { o } \\
\text { modesra, } \\
\text { PS } 4 \text { mm } \\
\text { na face } \\
\text { disto- } \\
\text { palatina, } \\
\text { nao } \\
\text { sentia dor } \\
\text { e nem } \\
\text { relato de } \\
\text { gosto } \\
\text { ruim } \\
\text { desde a } \\
\text { realizaçã } \\
\text { o da } \\
\text { cirurgia, } \\
\text { negou } \\
\text { qualquer } \\
\text { parestesi } \\
\text { a após a } \\
\text { cirurgia. } \\
\text { A } \\
\text { tomografi } \\
\text { a pós- } \\
\text { operatóri } \\
\text { as de 2 } \\
\text { anos } \\
\text { confirmar } \\
\text { am a } \\
\text { estabilida } \\
\text { de e } \\
\text { sucesso } \\
\text { no } \\
\text { preenchi } \\
\text { mento } \\
\text { ósseo. }\end{array}$ & NÃO \\
\hline
\end{tabular}


TRATAMENTO DAS LESÕES ENDO-PERIODONTAIS: UMA REVISÃO DE ESCOPO

Belén Retamal-Valdes, Kamila Ribeiro do Nascimento Jabur, Silvana Felisberto Monteiro, Laryssa Macedo de Oliveira, Renata Queiroz Tavares, Cristiane Gonçalves, Magda Feres

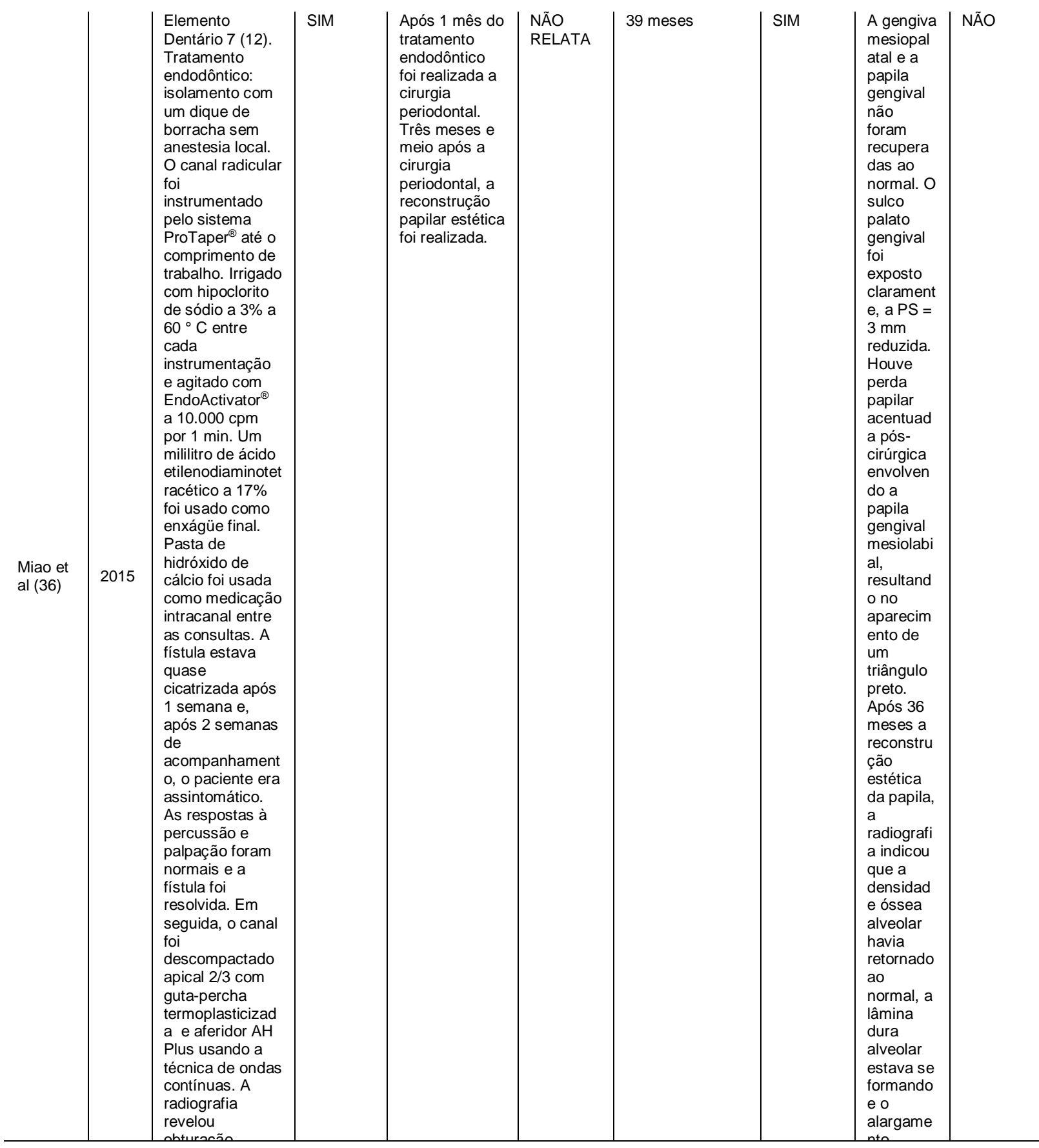


TRATAMENTO DAS LESÕES ENDO-PERIODONTAIS: UMA REVISÃO DE ESCOPO

Belén Retamal-Valdes, Kamila Ribeiro do Nascimento Jabur, Silvana Felisberto Monteiro, Laryssa Macedo de Oliveira, Renata Queiroz Tavares, Cristiane Gonçalves, Magda Feres

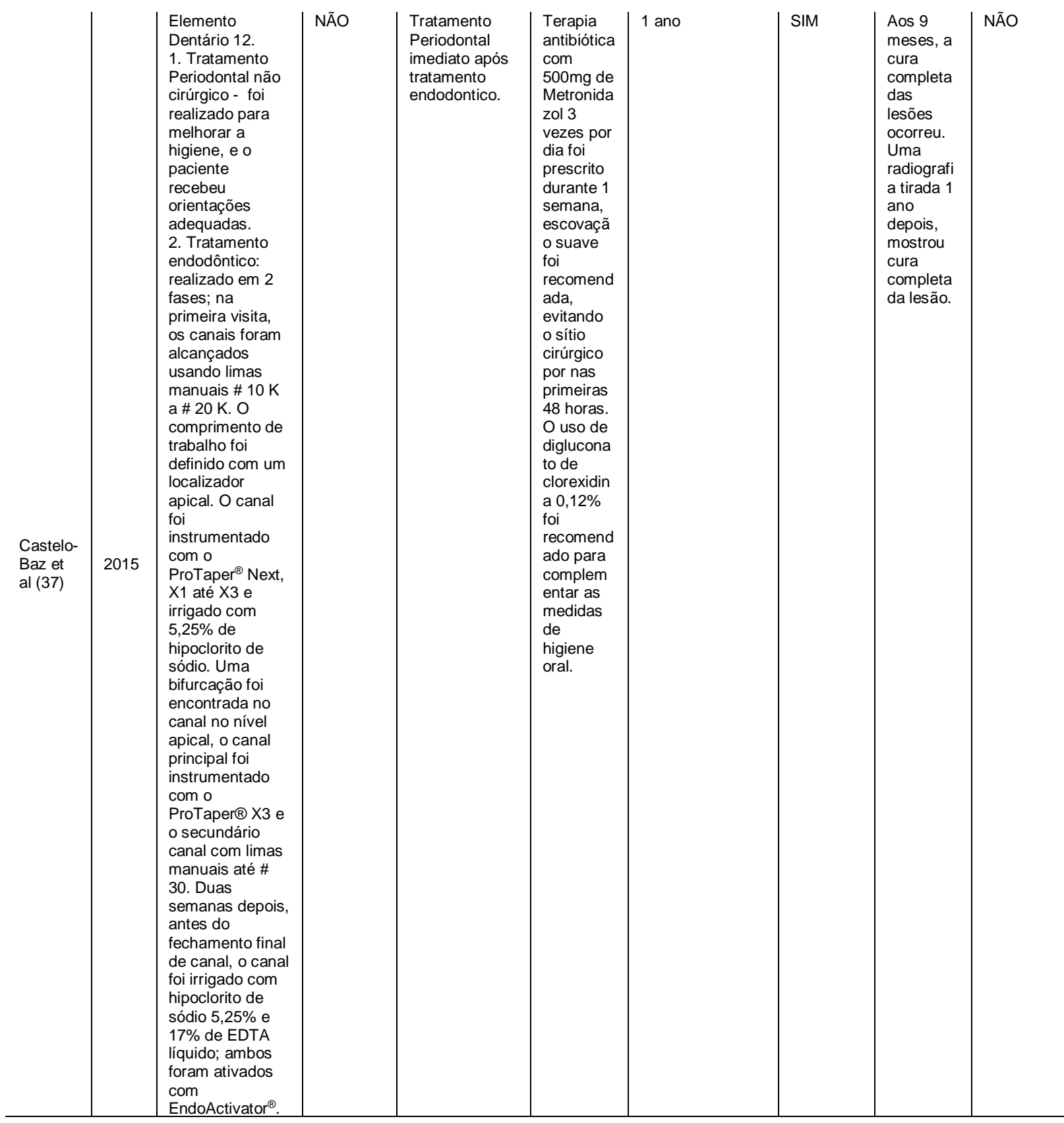


TRATAMENTO DAS LESÕES ENDO-PERIODONTAIS: UMA REVISÃO DE ESCOPO

Belén Retamal-Valdes, Kamila Ribeiro do Nascimento Jabur, Silvana Felisberto Monteiro, Laryssa Macedo de Oliveira, Renata Queiroz Tavares, Cristiane Gonçalves, Magda Feres

\begin{tabular}{|c|c|c|c|c|c|c|c|c|c|}
\hline $\begin{array}{l}\text { Sharma } \\
\text { et al } \\
\text { (38) }\end{array}$ & 2015 & $\begin{array}{l}\text { Elemento } \\
\text { Dentário } 7 \text { (12). } \\
\text { 1. Tratamento } \\
\text { endodôntico - } \\
\text { acesso sob } \\
\text { isolamento do } \\
\text { dique de } \\
\text { borracha e o } \\
\text { comprimento de } \\
\text { trabalho } \\
\text { determinado } \\
\text { usando } \\
\text { localizador } \\
\text { eletrônico de } \\
\text { apical e } \\
\text { radiografias. O } \\
\text { canal foi limpo e } \\
\text { modelado com } \\
\text { limas K de aço } \\
\text { inoxidável e } \\
\text { limas rotativas } \\
\text { de Ni-Ti®i usando } \\
\text { a técnica de } \\
\text { coroação. A } \\
\text { irrigação foi } \\
\text { realizada } \\
\text { durante todo o } \\
\text { uso de NaOCl a } \\
5,2 \% \text {. Para o } \\
\text { desbridamento } \\
\text { máximo do } \\
\text { canal, o irrigante } \\
\text { foi ativado } \\
\text { passivamente } \\
\text { com a unidade } \\
\text { ultrassônica } \\
\text { Piezon }{ }^{\circledR} \text { EMS } \\
\text { por } 1 \text { min. } \\
\text { Hidróxido de } \\
\text { cálcio foi } \\
\text { utilizado no } \\
\text { canal como } \\
\text { medicamento } \\
\text { intra-canal e a } \\
\text { cavidade de } \\
\text { acesso } \\
\text { temporariamente } \\
\text { selada com } \\
\text { material } \\
\text { restaurador } \\
\text { intermediário. } \\
\text { Na próxima } \\
\text { visita após } 1 \\
\text { semana. o } \\
\end{array}$ & $\begin{array}{l}\text { NÃO } \\
\text { RELATA }\end{array}$ & NÃO RELATA & $\begin{array}{l}\text { Analgésic } \\
\text { os e } \\
\text { antibiótico } \\
\text { s foram } \\
\text { prescritos } \\
\text {, e o } \\
\text { paciente } \\
\text { recebeu } \\
\text { instruçõe } \\
\text { s } \\
\text { regulares } \\
\text { de } \\
\text { higiene } \\
\text { bucal, } \\
\text { incluindo } \\
\text { enxaguat } \\
\text { ório bucal } \\
\text { com } \\
\text { clorexidin } \\
\text { a }(0,12 \%) \\
\text { por } 2 \\
\text { semanas. }\end{array}$ & 1 ano & SIM & $\begin{array}{l}\text { Aos } 3 \\
\text { meses, a } \\
\text { gengiva } \\
\text { parecia } \\
\text { saudável } \\
\text { e a } \\
\text { profundid } \\
\text { ade da } \\
\text { sondage } \\
\text { m foi } \\
\text { reduzida } \\
\text { para } 3 \\
\text { mm, o } \\
\text { que } \\
\text { continuou } \\
\text { a } \\
\text { permanec } \\
\text { er no } \\
\text { mesmo } \\
\text { nível, } \\
\text { mesmo } \\
\text { aos } 12 \\
\text { meses. A } \\
\text { evidência } \\
\text { radiográfi } \\
\text { ca } \\
\text { mostrou } \\
\text { excelente } \\
\text { cicatrizaç } \\
\text { ão na } \\
\text { área } \\
\text { perirradic } \\
\text { ular. }\end{array}$ & NÃO \\
\hline
\end{tabular}


TRATAMENTO DAS LESÕES ENDO-PERIODONTAIS: UMA REVISÃO DE ESCOPO

Belén Retamal-Valdes, Kamila Ribeiro do Nascimento Jabur, Silvana Felisberto Monteiro, Laryssa Macedo de Oliveira, Renata Queiroz Tavares, Cristiane Gonçalves, Magda Feres

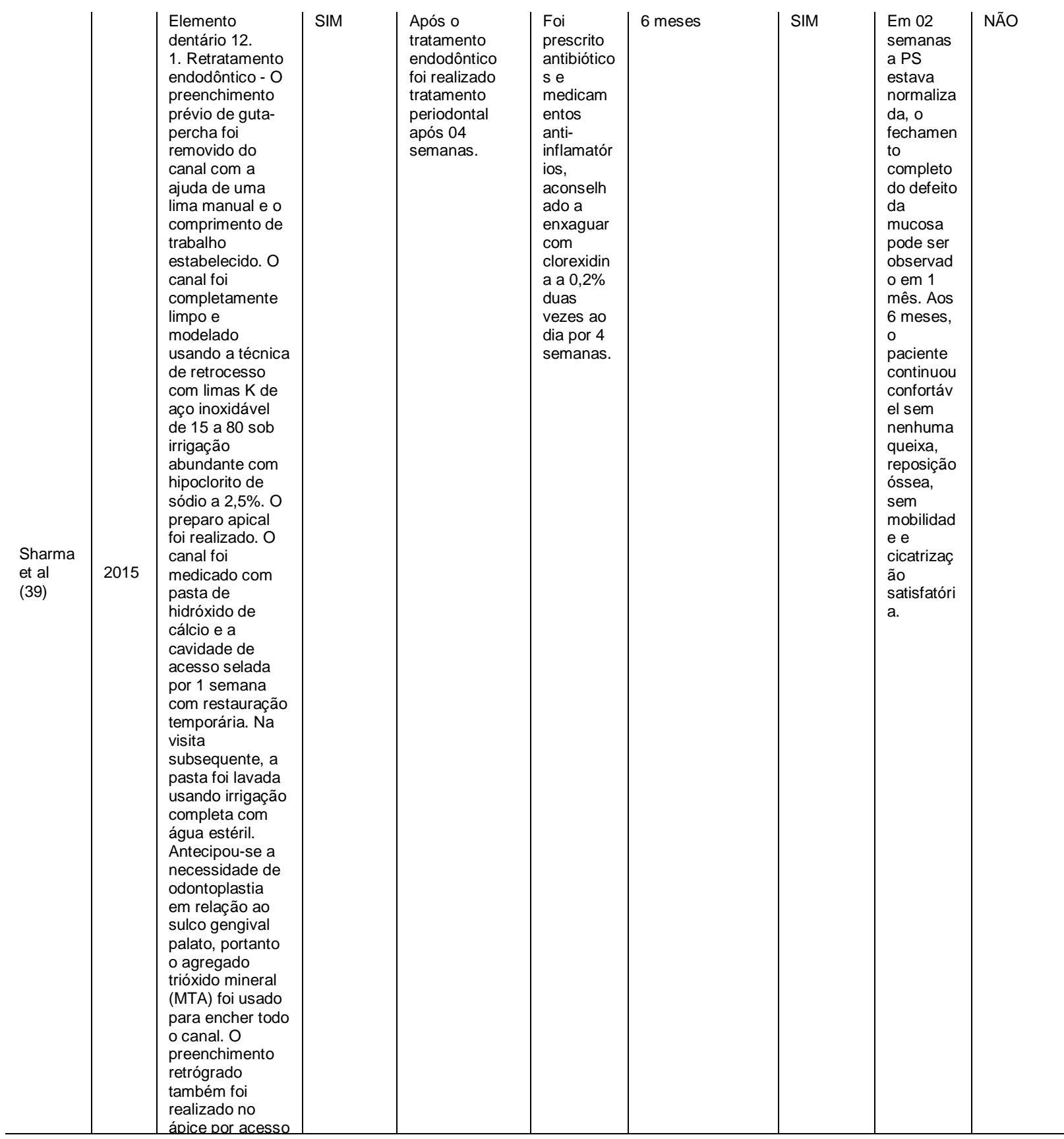


TRATAMENTO DAS LESÕES ENDO-PERIODONTAIS: UMA REVISÃO DE ESCOPO

Belén Retamal-Valdes, Kamila Ribeiro do Nascimento Jabur, Silvana Felisberto Monteiro, Laryssa Macedo de Oliveira, Renata Queiroz Tavares, Cristiane Gonçalves, Magda Feres

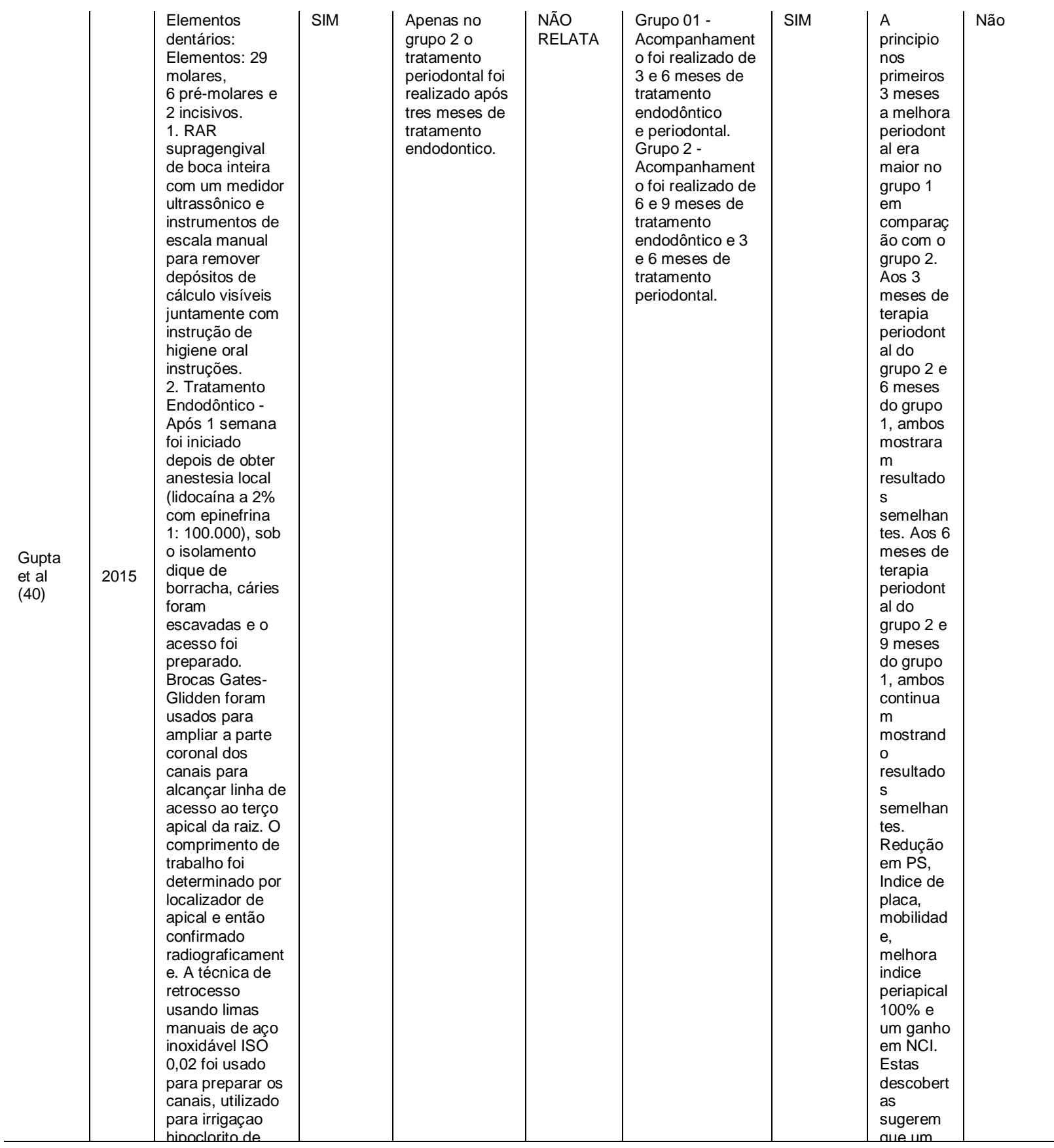


TRATAMENTO DAS LESÕES ENDO-PERIODONTAIS: UMA REVISÃO DE ESCOPO

Belén Retamal-Valdes, Kamila Ribeiro do Nascimento Jabur, Silvana Felisberto Monteiro, Laryssa Macedo de Oliveira, Renata Queiroz Tavares, Cristiane Gonçalves, Magda Feres

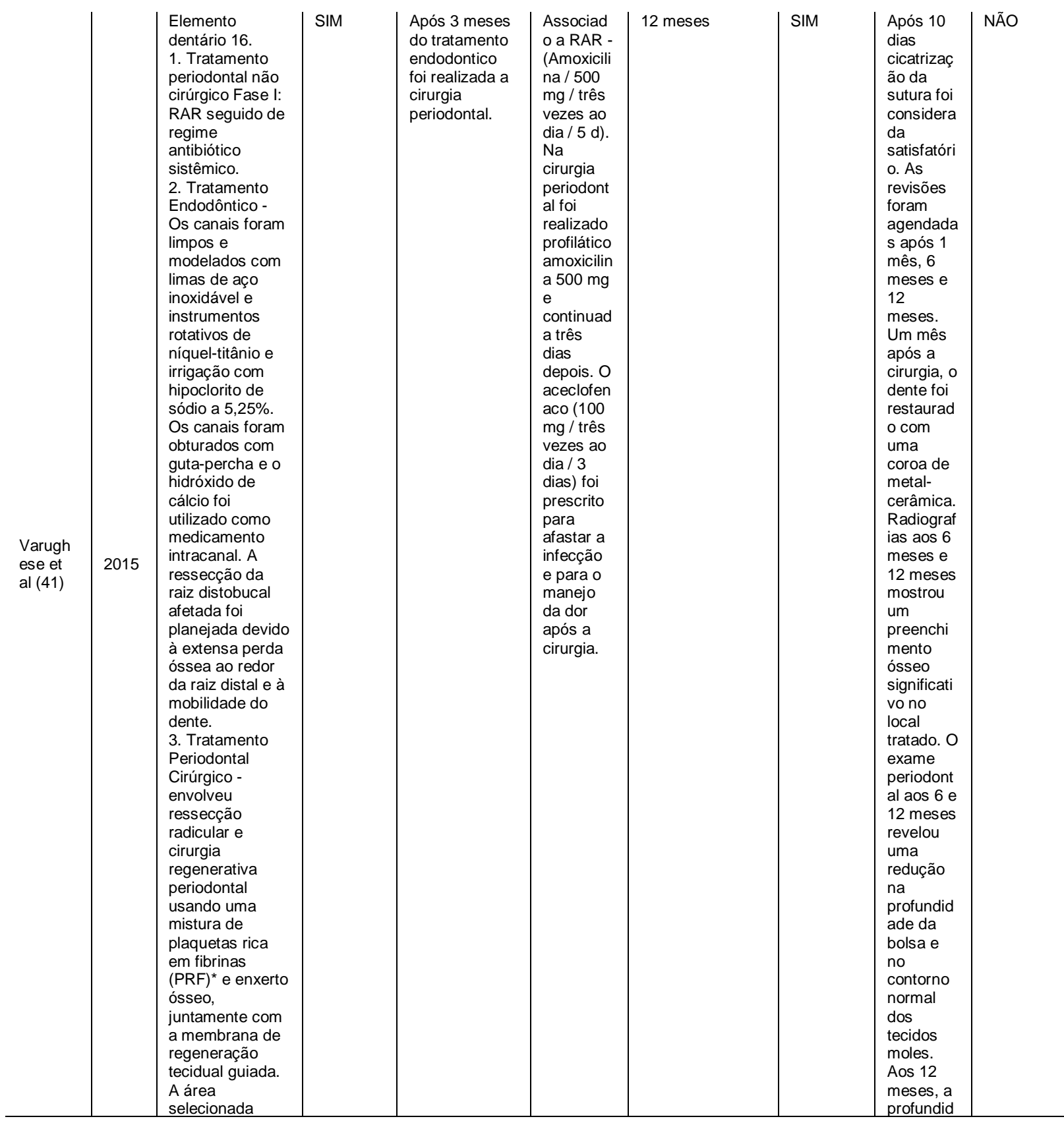




\section{RECIMA21 - REVISTA CIENTÍFICA MULTIDISCIPLINAR}

TRATAMENTO DAS LESÕES ENDO-PERIODONTAIS: UMA REVISÃO DE ESCOPO

Belén Retamal-Valdes, Kamila Ribeiro do Nascimento Jabur, Silvana Felisberto Monteiro, Laryssa Macedo de Oliveira, Renata Queiroz Tavares, Cristiane Gonçalves, Magda Feres

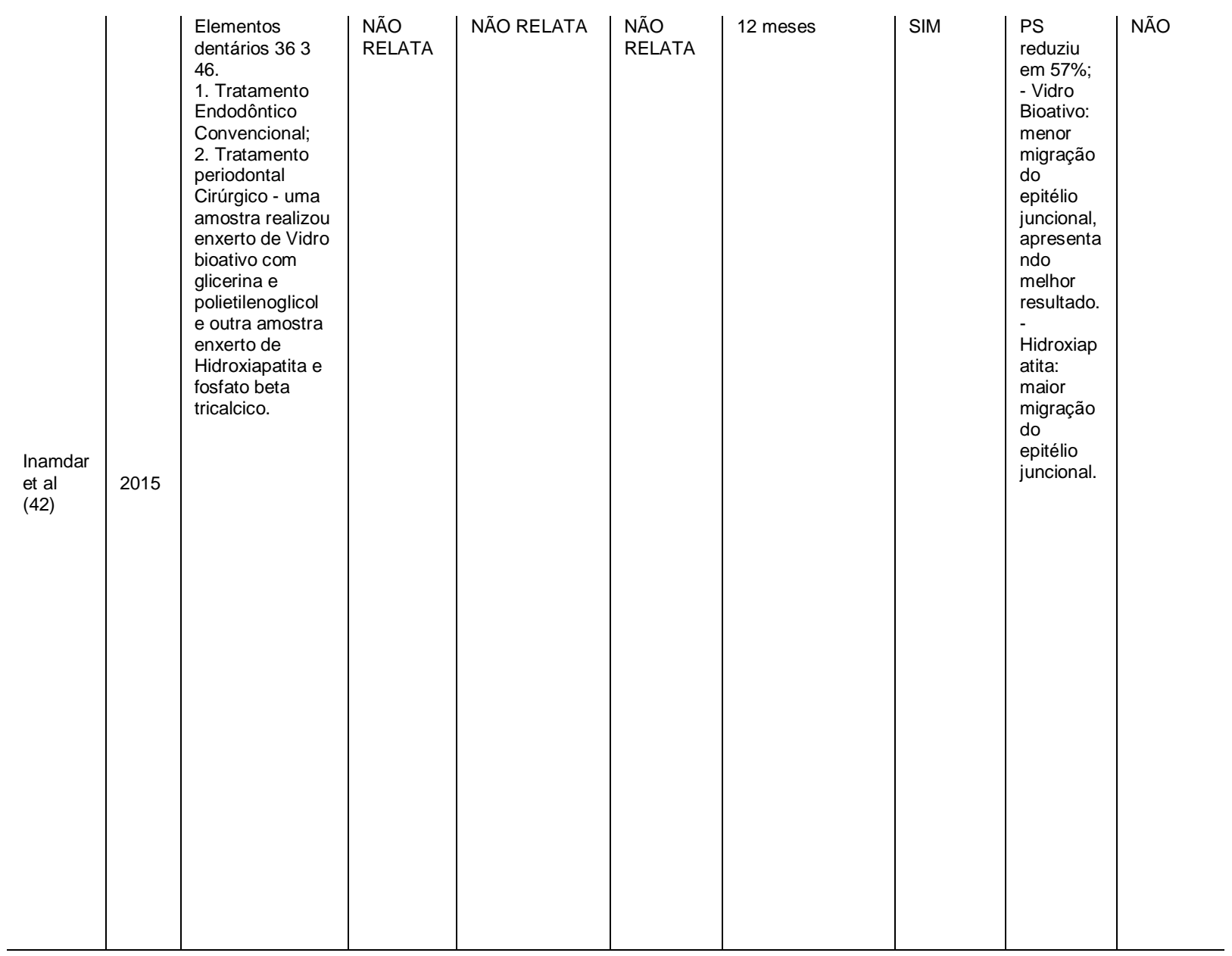


TRATAMENTO DAS LESÕES ENDO-PERIODONTAIS: UMA REVISÃO DE ESCOPO

Belén Retamal-Valdes, Kamila Ribeiro do Nascimento Jabur, Silvana Felisberto Monteiro, Laryssa Macedo de Oliveira, Renata Queiroz Tavares, Cristiane Gonçalves, Magda Feres

\begin{tabular}{|c|c|c|c|c|c|c|c|c|c|}
\hline $\begin{array}{l}\text { Jivoinov } \\
\text { ici et al } \\
\text { (43) }\end{array}$ & 2014 & $\begin{array}{l}\text { Elementos } \\
\text { dentários: CASO } \\
1=22 ; \text { CASO } 2 \\
=34 ; \text { CASO } 3= \\
47, \text { CASO } 4= \\
26 \text { CASO } 5=11 \\
\text { E } 12 . \\
\text { Todos os casos } \\
\text { utilizou-se o } \\
\text { mesmo } \\
\text { tratamento com } \\
\text { exceçao do } \\
\text { Caso } 4 \text { que foi } \\
\text { retratamento da } \\
\text { polpa radicular. } \\
1 \text {. Tratamento } \\
\text { endodôntico - } \\
\text { desbridamento, } \\
\text { instrumentação, } \\
\text { curativo de } \\
\text { Ca(OH)2 de } 2 \text { a } \\
4 \text { semanas, } \\
\text { técnica de } \\
\text { condensação } \\
\text { lateral. } \\
\text { Juntamente a } \\
\text { terapia } \\
\text { endodôntica foi } \\
\text { realizada o } \\
\text { tratamento } \\
\text { periodontal: } \\
\text { - desbridamento } \\
\text { gengival, } \\
\text { removendo a } \\
\text { placa } \\
\text { bacteriana, o } \\
\text { biofilme oral e } \\
\text { seus produtos; } \\
\text { - RAR } \\
\text { supragengival; } \\
\text { - RAR } \\
\text { subgengival } \\
\text { profissional; } \\
\text { - irrigação com } \\
\text { clorexidina a } \\
0,2 \% \text { seguida de } \\
\text { uma instilação } \\
\text { de gel de } \\
\text { clorexidina a } 1 \% \% \\
\text { - educação de } \\
\text { higiene oral ao } \\
\text { paciente } \\
\text { a }\end{array}$ & $\begin{array}{l}\text { NÃO } \\
\text { RELATA }\end{array}$ & NÃO RELATA & $\begin{array}{l}\text { NÃO } \\
\text { RELATA }\end{array}$ & $\begin{array}{l}\text { CASO } 1 \text { / CASO } \\
3 \text { / CASO } 4-12 \\
\text { MESES CASO } 2 \\
-6 \text { MESES } \\
\text { CASO } 5 \text { - } 18 \\
\text { MESES }\end{array}$ & SIM & $\begin{array}{l}\text { Caso } 1 \mathrm{E} \\
\text { 2- Notou } \\
\text { ótima } \\
\text { qualidade } \\
\text { de } \\
\text { obturação } \\
\text { do canal, } \\
\text { bem } \\
\text { como } \\
\text { ganho } \\
\text { ósseo. } \\
\text { Caso } 3 \text { - } \\
\text { Ocorreu a } \\
\text { cicatrizaç } \\
\text { ão e } \\
\text { reminerali } \\
\text { zação da } \\
\text { osteite } \\
\text { periapical } \\
\text { do septo } \\
\text { interdenta } \\
\text { I, melhora } \\
\text { na } \\
\text { reposição } \\
\text { óssea de } \\
\text { furca. } \\
\text { Caso } 4 \text { - } \\
\text { Apresent } \\
\text { ou } \\
\text { reminerali } \\
\text { zação e } \\
\text { redução } \\
\text { radiolúcid } \\
\text { a dos } \\
\text { ápices } \\
\text { circunscri } \\
\text { tos ao } \\
\text { septo } \\
\text { distal e } \\
\text { raízes } \\
\text { vestibular } \\
\text { es e } \\
\text { furca, na } \\
\text { presença } \\
\text { de uma } \\
\text { quantidad } \\
\text { e } \\
\text { moderad } \\
\text { a de } \\
\text { excesso } \\
\text { de } \\
\text { selante. } \\
\text { Caso } 5- \\
\text { breenchi } \\
\end{array}$ & NÃO \\
\hline
\end{tabular}


TRATAMENTO DAS LESÕES ENDO-PERIODONTAIS: UMA REVISÃO DE ESCOPO

Belén Retamal-Valdes, Kamila Ribeiro do Nascimento Jabur, Silvana Felisberto Monteiro, Laryssa Macedo de Oliveira, Renata Queiroz Tavares, Cristiane Gonçalves, Magda Feres

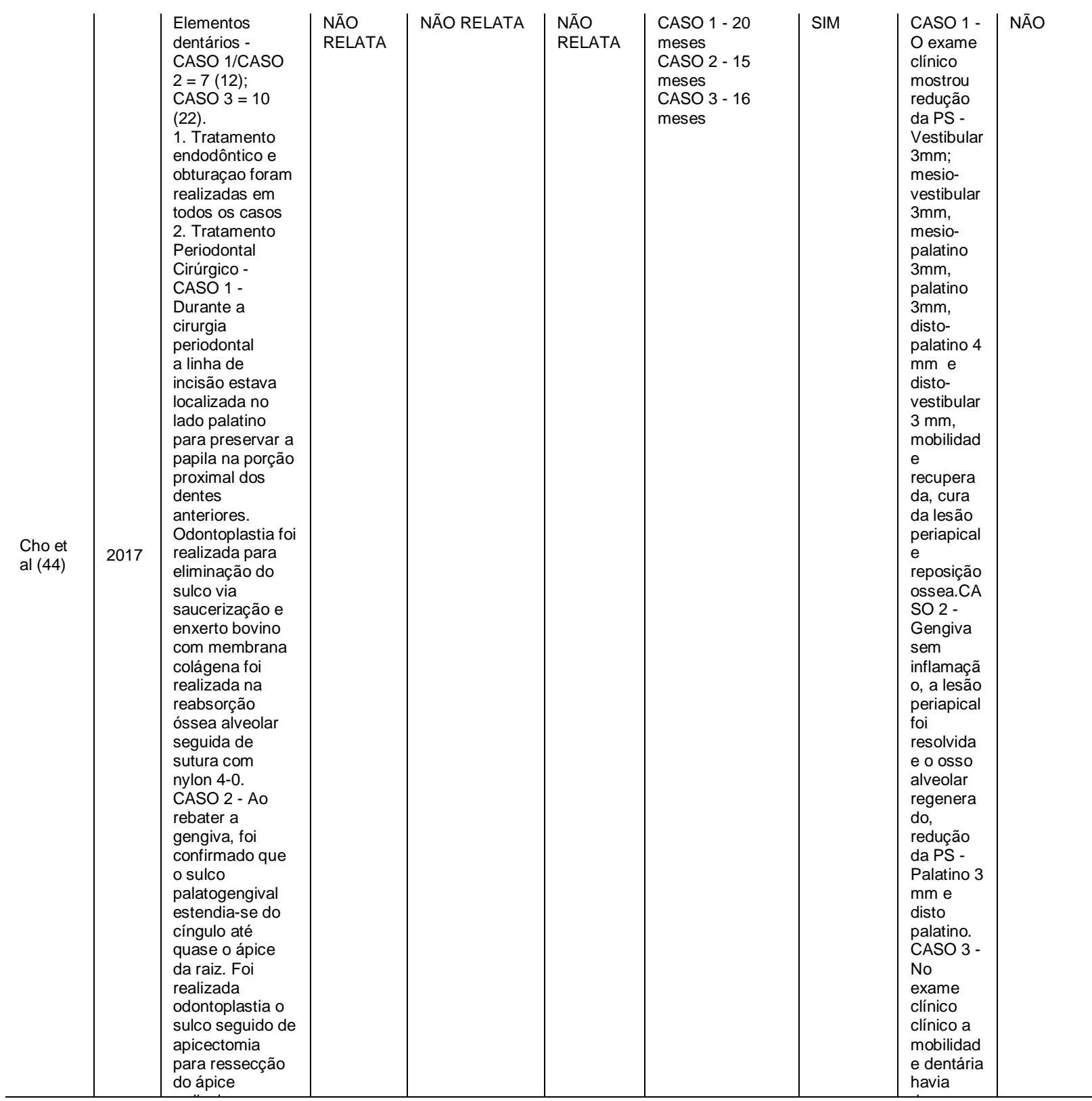


TRATAMENTO DAS LESÕES ENDO-PERIODONTAIS: UMA REVISÃO DE ESCOPO

Belén Retamal-Valdes, Kamila Ribeiro do Nascimento Jabur, Silvana Felisberto Monteiro, Laryssa Macedo de Oliveira, Renata Queiroz Tavares, Cristiane Gonçalves, Magda Feres

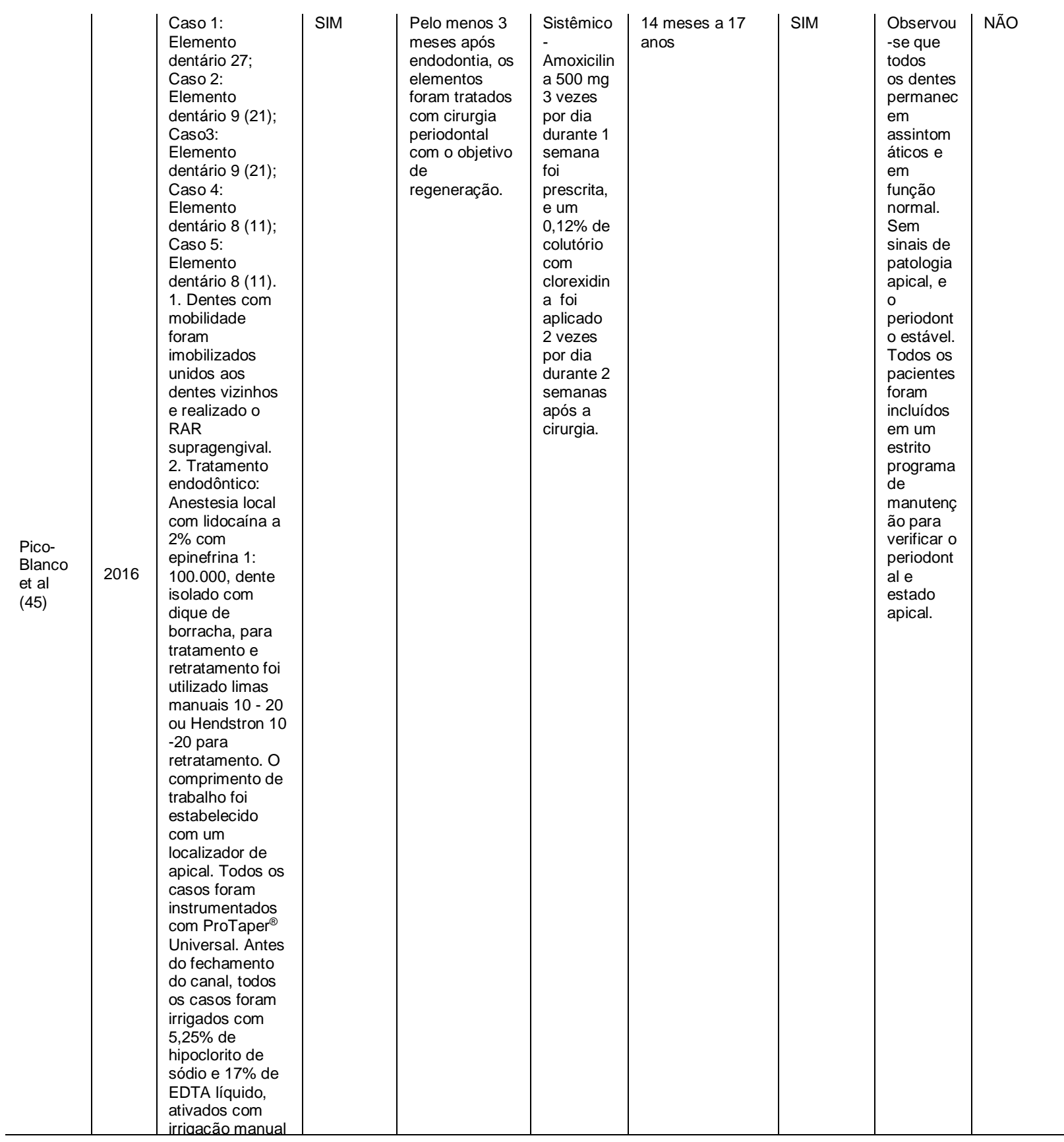




\section{RECIMA21 - REVISTA CIENTÍFICA MULTIDISCIPLINAR}

TRATAMENTO DAS LESÕES ENDO-PERIODONTAIS: UMA REVISÃO DE ESCOPO

Belén Retamal-Valdes, Kamila Ribeiro do Nascimento Jabur, Silvana Felisberto Monteiro, Laryssa Macedo de Oliveira, Renata Queiroz Tavares, Cristiane Gonçalves, Magda Feres

\begin{tabular}{|c|c|c|c|c|c|c|c|c|c|}
\hline $\begin{array}{l}\text { Sooratg } \\
\text { ar et al } \\
\text { (46) }\end{array}$ & 2016 & $\begin{array}{l}\text { Elemento } \\
\text { dentário } 10 \text { (22). } \\
\text { 1. Tratamento } \\
\text { endodôntico - } \\
\text { iniciado sob } \\
\text { isolamento do } \\
\text { dique de } \\
\text { borracha. A } \\
\text { limpeza e } \\
\text { modelagem do } \\
\text { canal foram } \\
\text { realizadas } \\
\text { instrumentação } \\
\text { usando limas K } \\
\text { manuais. O } \\
\text { canal radicular } \\
\text { foi irrigado com } \\
\text { hipoclorito de } \\
\text { sódio a 1\%. O } \\
\text { dente foi } \\
\text { obturado com } \\
\text { guta-percha e } \\
\text { aferidor AH-26 } \\
\text { usando a técnica } \\
\text { de condensação } \\
\text { lateral. Uma } \\
\text { semana depois, } \\
\text { a coroa foi } \\
\text { restaurada } \\
\text { permanentement } \\
\text { e com resina } \\
\text { composta. } \\
\text { 2. Tratamento } \\
\text { periodontal } \\
\text { Cirúrgico - uma } \\
\text { cirurgia } \\
\text { exploratória foi } \\
\text { planejada. O } \\
\text { tecido de } \\
\text { granulação do } \\
\text { defeito ósseo foi } \\
\text { curetado para } \\
\text { deixar o tecido } \\
\text { mole mais } \\
\text { propício à à } \\
\text { regeneração e } \\
\text { as superfícies } \\
\text { radiculares } \\
\text { expostas ao } \\
\text { defeito foram } \\
\text { planejadas com } \\
\text { um scaler } \\
\text { ultrassônico e } \\
\text { curetas manuais } \\
\text {. Também foram } \\
\text { ressecados } 3 \\
\text { mm do ápice } \\
\text { radicular para } \\
\text { eliminar o } \\
\text { provável biofilme } \\
\text { microbiano }\end{array}$ & SIM & $\begin{array}{l}\text { Após } 3 \text { meses } \\
\text { do tratamento } \\
\text { endodôntico } \\
\text { foi realizada a } \\
\text { cirurgia } \\
\text { periodontal. }\end{array}$ & $\begin{array}{l}\text { NÃO } \\
\text { RELATA }\end{array}$ & 2 anos & SIM & $\begin{array}{l}\mathrm{Na} \\
\text { avaliação } \\
\text { endodônti } \\
\text { ca de } \\
\text { uma } \\
\text { semana, } \\
\text { a } \\
\text { drenage } \\
\text { m do } \\
\text { trato } \\
\text { sinusal e } \\
\text { pus bucal } \\
\text { do sulco } \\
\text { palatal foi } \\
\text { eliminada } \\
\text {. Uma } \\
\text { radiografi } \\
\text { a } \\
\text { realizada } \\
6 \text { meses } \\
\text { após a } \\
\text { cirurgia } \\
\text { periodont } \\
\text { al revelou } \\
\text { desapare } \\
\text { cimento } \\
\text { parcial da } \\
\text { radiolucê } \\
\text { ncia ao } \\
\text { redor do } \\
\text { incisivo } \\
\text { lateral } \\
\text { devido a } \\
\text { enxerto } \\
\text { ósseo e } \\
\text { regenera } \\
\text { ção } \\
\text { óssea } \\
\text { simultâne } \\
\text { a. A PS } \\
\text { palatina = } \\
3 \text { mm, } \\
\text { Apos 2 } \\
\text { anos } \\
\text { observou- } \\
\text { se } \\
\text { regenera } \\
\text { ção } \\
\text { óssea e } \\
\text { cicatrizaç } \\
\text { ão de } \\
\text { defeito } \\
\text { ósseo } \\
\text { periapical } \\
\text {. } \\
\end{array}$ & NÃO \\
\hline
\end{tabular}


TRATAMENTO DAS LESÕES ENDO-PERIODONTAIS: UMA REVISÃO DE ESCOPO

Belén Retamal-Valdes, Kamila Ribeiro do Nascimento Jabur, Silvana Felisberto Monteiro, Laryssa Macedo de Oliveira, Renata Queiroz Tavares, Cristiane Gonçalves, Magda Feres

\begin{tabular}{|c|c|c|c|c|c|c|c|c|c|}
\hline $\begin{array}{l}\text { Alizade } \\
\text { h Tabari } \\
\text { et al } \\
\text { (47) }\end{array}$ & 2016 & 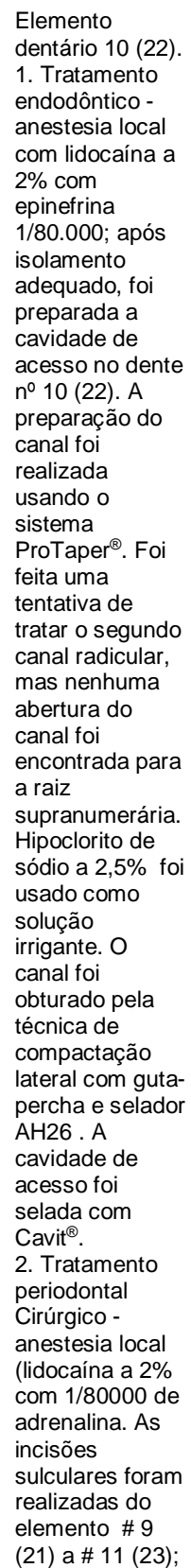 & $\begin{array}{l}\text { NÃO } \\
\text { RELATA }\end{array}$ & NÃO RELATA & $\begin{array}{l}\text { O } \\
\text { paciente } \\
\text { recebeu } \\
\text { um } \\
\text { enxaguat } \\
\text { ório bucal } \\
\text { com } \\
\text { gluconato } \\
\text { de } \\
\text { clorexidin } \\
\text { a e } 4 \times \\
400 \mathrm{mg} \\
\text { de } \\
\text { ibuprofen } \\
\text { o mais } 3 \\
\times 500 \mathrm{mg} \\
\text { de } \\
\text { Amoxicilin } \\
\text { a } \\
\text { diariamen } \\
\text { te por } \\
\text { uma } \\
\text { semana. }\end{array}$ & 2 anos & SIM & $\begin{array}{l}\text { Os } \\
\text { resultado } \\
\text { s do } \\
\text { exame } \\
\text { histológic } \\
\text { o } \\
\text { revelaram } \\
\text { que a } \\
\text { estrutura } \\
\text { da raiz } \\
\text { supranum } \\
\text { erária } \\
\text { não } \\
\text { apresenta } \\
\text { anormalid } \\
\text { ades } \\
\text { nenhuma } \\
\text { célula } \\
\text { displásica } \\
\text { é } \\
\text { detectada } \\
\text { e o tecido } \\
\text { circundan } \\
\text { te } \\
\text { consiste } \\
\text { em tecido } \\
\text { conjuntiv } \\
\text { o e } \\
\text { células } \\
\text { inflamatór } \\
\text { ias. O } \\
\text { seguimen } \\
\text { to de } \\
\text { doze } \\
\text { meses } \\
\text { revelou } \\
\text { ausência } \\
\text { de sinais } \\
\text { e } \\
\text { sintomas, } \\
\text { a } \\
\text { profundid } \\
\text { ade da } \\
\text { sondage } \\
\text { m não } \\
\text { excedeu } \\
3 \text { mm e o } \\
\text { exame } \\
\text { radiográfi } \\
\text { co } \\
\text { indicou } \\
\text { desapare } \\
\text { cimento } \\
\text { da } \\
\text { radiolucê } \\
\text { ncia ao } \\
\text { redor do } \\
\text { dente no } \\
10 \text { (22) }\end{array}$ & NÃO \\
\hline
\end{tabular}


TRATAMENTO DAS LESÕES ENDO-PERIODONTAIS: UMA REVISÃO DE ESCOPO Belén Retamal-Valdes, Kamila Ribeiro do Nascimento Jabur, Silvana Felisberto Monteiro, Laryssa Macedo de Oliveira, Renata Queiroz Tavares, Cristiane Gonçalves, Magda Feres

\begin{tabular}{|c|c|c|c|c|c|c|c|c|c|}
\hline $\begin{array}{l}\text { Asgary } \\
\text { et al } \\
\text { (48) }\end{array}$ & 2018 & $\begin{array}{l}\text { Elemento } \\
\text { dentário } 24 . \\
\text { Paciente já } \\
\text { possuia } \\
\text { Tratamento } \\
\text { endodôntico e } \\
\text { enxerto osseo. } \\
\text { 1. Tratamento } \\
\text { Endodôntico } \\
\text { Cirúrgico - } \\
\text { Anestesia com } \\
\text { lidocaína a 2\% } \\
\text { com epinefrina } \\
\text { 1: } 80.000 \text {. } \\
\text { Retalho } \\
\text { mucoperiosteal, } \\
\text { curetagem da } \\
\text { lesão para } \\
\text { remoção dos } \\
\text { tecidos } \\
\text { inflamados e } \\
\text { enxerto ósseo, } \\
\text { obtendo acesso } \\
\text { ao ápice. Uma } \\
\text { amostra da } \\
\text { curetagem foi } \\
\text { imersa em } \\
\text { solução de } \\
\text { formalina a 10\% } \\
\text { para submeter a } \\
\text { um patologista } \\
\text { oral. Após } \\
\text { retirada a } \\
\text { cavidade da raiz } \\
\text { foi preparada } \\
\text { com um retrotip } \\
\text { ultrassônico. Foi } \\
\text { inserido na } \\
\text { cavidade um } \\
\text { biomaterial } \\
\text { adquirido de } \\
\text { uma mistura } \\
\text { enriquecida com } \\
\text { cálcio pó e } \\
\text { líquido para } \\
\text { obter o } \\
\text { enchimento / } \\
\text { vedação da raiz. } \\
\text { Após fazer uma } \\
\text { radiografia de } \\
\text { confirmação o } \\
\text { retallho foi } \\
\text { recolocado e } \\
\text { suturado. } \\
\text { sudo. }\end{array}$ & $\begin{array}{l}\text { NÃO } \\
\text { RELATA }\end{array}$ & $\begin{array}{l}\text { Paciente já } \\
\text { havia tratado } \\
\text { edondôntico } \\
\text { há } 6 \text { meses. } \\
\text { Foi realizado } \\
\text { Endodontia e } \\
\text { Periodontia } \\
\text { cirúrgica } \\
\text { imediata. }\end{array}$ & $\begin{array}{l}\text { NÃO } \\
\text { RELATA }\end{array}$ & 2 anos & SIM & $\begin{array}{l}\text { Após } 7 \\
\text { dias } \\
\text { ausência } \\
\text { de sinais } \\
\text { e } \\
\text { sintomas. } \\
\text { A cura } \\
\text { da lesão } \\
\text { estava } \\
\text { em } \\
\text { progressã } \\
\text { o sem } \\
\text { intercorrê } \\
\text { ncias. } \\
\text { Apos } 2 \\
\text { anos de } \\
\text { acompan } \\
\text { hamento } \\
\text { a lesão } \\
\text { estava } \\
\text { resolvida, } \\
\text { periodont } \\
\text { o normal } \\
\text { e } \\
\text { formação } \\
\text { de osso } \\
\text { pode ser } \\
\text { observad } \\
\text { a na } \\
\text { radiografi } \\
\text { a } \\
\text { periapical }\end{array}$ & NÃO \\
\hline
\end{tabular}


TRATAMENTO DAS LESÕES ENDO-PERIODONTAIS: UMA REVISÃO DE ESCOPO

Belén Retamal-Valdes, Kamila Ribeiro do Nascimento Jabur, Silvana Felisberto Monteiro, Laryssa Macedo de Oliveira, Renata Queiroz Tavares, Cristiane Gonçalves, Magda Feres

\begin{tabular}{|c|c|c|c|c|c|c|c|c|c|}
\hline $\begin{array}{l}\text { Betanco } \\
\text { urt et al } \\
\text { (49) }\end{array}$ & 2017 & 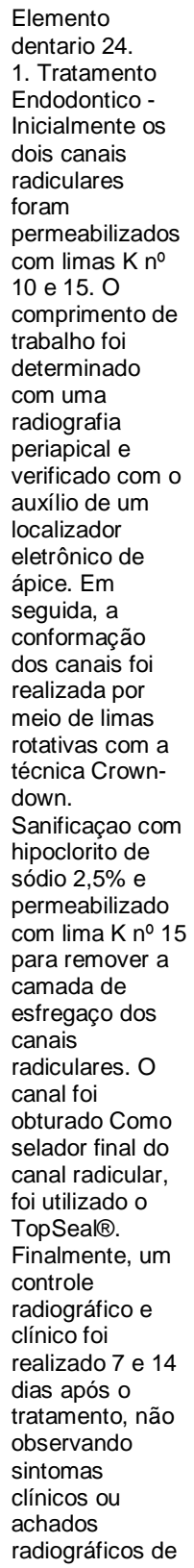 & NÃO & $\begin{array}{l}\text { O tratamento } \\
\text { periodontal e } \\
\text { regenerativo } \\
\text { foi realizado } \\
\text { em } 2 \\
\text { semanas. }\end{array}$ & $\begin{array}{l}\text { Prescriçã } \\
\text { o } \\
\text { profilática } \\
-1 \text { hora } \\
\text { antes da } \\
\text { cirurgia, } \\
\text { tomou } \\
\text { Amoxicilin } \\
\text { a } 875 \mathrm{mg} \\
\text { e } \\
\text { Cetoprofe } \\
\text { no } 200 \\
\text { mg e } \\
\text { enxaguou } \\
\text { a boca } \\
\text { com } \\
\text { clorexidin } \\
\text { a } 0,12 \% . \\
\text { Indicação } \\
\text { de } \\
\text { tratament } \\
\text { o } \\
\text { farmacoló } \\
\text { gico } \\
\text { contínuo } \\
\text { e } \\
\text { enxagua } \\
\text { mento } \\
\text { bucal } \\
\text { com } \\
\text { clorexidin } \\
\text { a a } 0,12 \% \\
\text { por } 1 \\
\text { semana } \\
\text { foram } \\
\text { indicadas. }\end{array}$ & 6 meses & $\begin{array}{l}\text { Parcialme } \\
\text { nte }\end{array}$ & $\begin{array}{l}\text { Seis } \\
\text { meses } \\
\text { após a } \\
\text { cirurgia, } \\
\text { os } \\
\text { exames } \\
\text { de } \\
\text { tomografi } \\
\text { a não } \\
\text { mostrara } \\
\text { m } \\
\text { regenera } \\
\text { ção } \\
\text { óssea em } \\
\text { nenhum } \\
\text { aspecto } \\
\text { do dente } \\
\text { e foi } \\
\text { atribuído } \\
\text { ao uso do } \\
\text { L-PRF } \\
\text { sem } \\
\text { material } \\
\text { de } \\
\text { enxerto } \\
\text { ósseo. } \\
\text { No } \\
\text { entanto, o } \\
\text { exame } \\
\text { periodont } \\
\text { al } \\
\text { mostrou } \\
\text { uma } \\
\text { melhora } \\
\text { significati } \\
\text { va na PS. } \\
\text { O } \\
\text { aspecto } \\
\text { mesioves } \\
\text { tibular } \\
\text { apresenta } \\
\text { va PS } 3 \\
\text { mm e 5 } \\
\text { mm no } \\
\text { aspecto } \\
\text { mesiopal } \\
\text { atal, } \\
\text { mostrand } \\
\text { o uma } \\
\text { redução. }\end{array}$ & NÃO \\
\hline
\end{tabular}


TRATAMENTO DAS LESÕES ENDO-PERIODONTAIS: UMA REVISÃO DE ESCOPO

Belén Retamal-Valdes, Kamila Ribeiro do Nascimento Jabur, Silvana Felisberto Monteiro, Laryssa Macedo de Oliveira, Renata Queiroz Tavares, Cristiane Gonçalves, Magda Feres

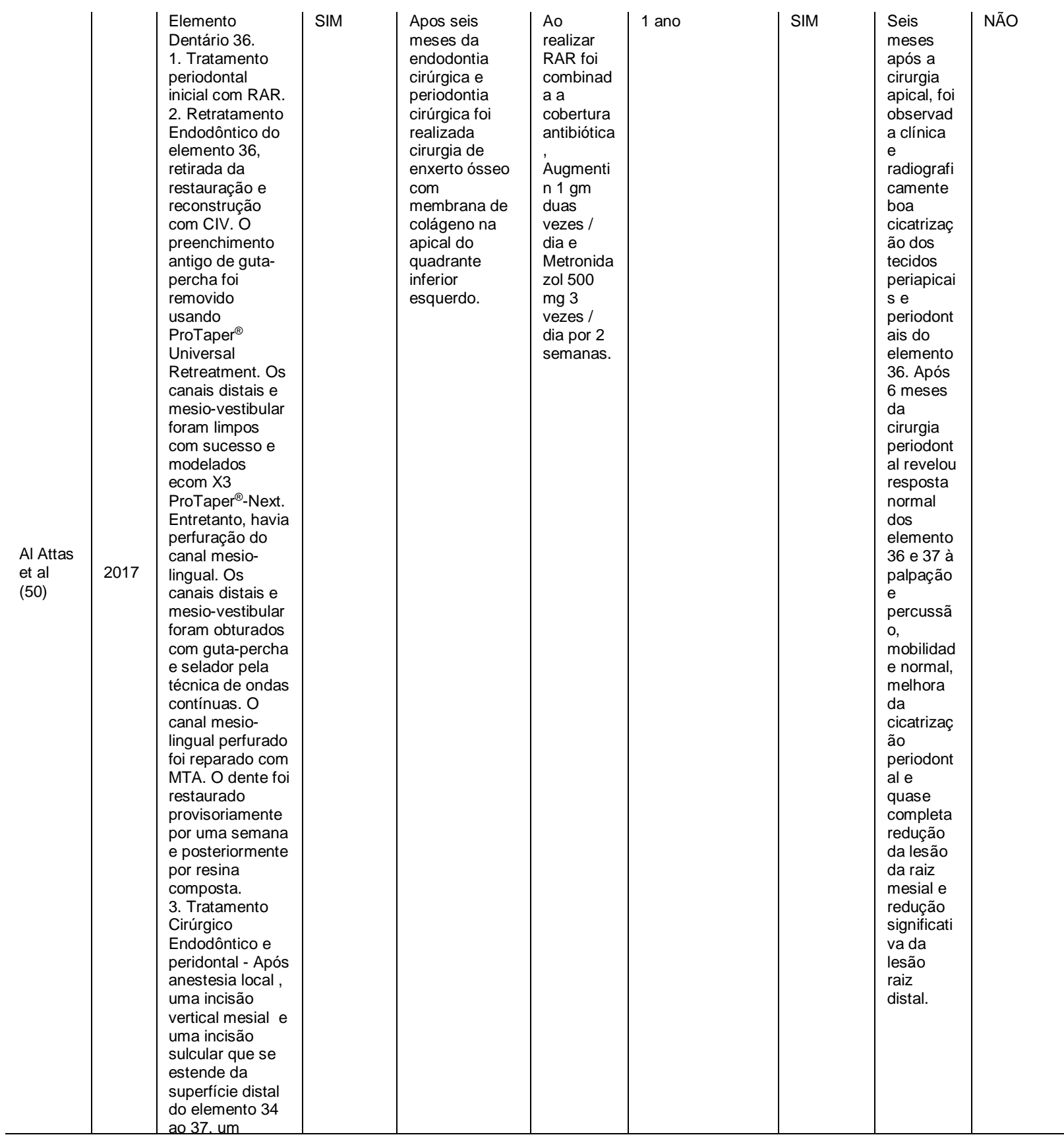


TRATAMENTO DAS LESÕES ENDO-PERIODONTAIS: UMA REVISÃO DE ESCOPO Belén Retamal-Valdes, Kamila Ribeiro do Nascimento Jabur, Silvana Felisberto Monteiro, Laryssa Macedo de Oliveira, Renata Queiroz Tavares, Cristiane Gonçalves, Magda Feres

\begin{tabular}{|c|c|c|c|c|c|c|c|c|c|}
\hline $\begin{array}{l}\text { Wadhw } \\
\text { a et al } \\
\text { (51) }\end{array}$ & 2017 & $\begin{array}{l}\text { Elemento } \\
\text { dentário } 46 . \\
1 \text {. Tratamento } \\
\text { endodôntico- } \\
\text { no entanto, } 3 \\
\text { meses após } \\
\text { paciente } \\
\text { retornou com } \\
\text { dor, exudato } \\
\text { purulento, PS } \\
\text { sem redução } \geq \\
10 \text { mm com } \\
\text { abertura sinusal } \\
\text { no aspecto bucal } \\
\text { da gengiva. } 2.2 \text {. } \\
\text { Tratamento } \\
\text { periodontal } \\
\text { cirúrgico - } \\
\text { Anestesia com } \\
\text { lidocaína a 2\% } \\
\text { com epinefrina } \\
1: 80.000 \text {. Após } \\
\text { a elevação de } \\
\text { um retalho } \\
\text { mucoperiosteal } \\
\text { de espessura } \\
\text { total, foi } \\
\text { realizada uma } \\
\text { osteotomia com } \\
\text { brocas esféricas } \\
\text { sob irrigação } \\
\text { abundante com } \\
\text { solução salina, a } \\
\text { fim de localizar a } \\
\text { extremidade } \\
\text { radicular da raiz } \\
\text { mesiall. A raiz } \\
\text { distal já estava } \\
\text { exposta até o } \\
\text { ápice. A } \\
\text { ressecção das } \\
\text { raízes foi } \\
\text { realizada a } \\
\text { aproximadament } \\
\text { e } 3 \text { mm do ápice } \\
\text { radicular. Todo o } \\
\text { tecido patológico } \\
\text { foi desbridado } \\
\text { do local da } \\
\text { cirurgia e o o } \\
\text { sangramento } \\
\text { excessivo foi } \\
\text { controlado com } \\
\text { algodão } \\
\text { embebidos em } \\
\text { adrenalina a } \\
0,1 \% \text {. } \\
\text { Preparações da } \\
\text { extremidade da } \\
\text { raiz que se } \\
\end{array}$ & SIM & $\begin{array}{l}\text { Após } 3 \text { meses } \\
\text { do tratamento } \\
\text { endodôntico } \\
\text { foi realizada a } \\
\text { cirurgia } \\
\text { periodontal. }\end{array}$ & $\begin{array}{l}\text { NÃO } \\
\text { RELATA }\end{array}$ & 18 meses & SIM & $\begin{array}{l}\text { Após } 3 \\
\text { meses } \\
\mathrm{PS}= \\
2 \mathrm{~mm}, \\
\mathrm{NCl} \\
2 \mathrm{~mm}, \\
\text { promoção } \\
\text { do tecido } \\
\text { conjuntiv } \\
\text { o e } \\
\text { ósseo. }\end{array}$ & NÃO \\
\hline
\end{tabular}


TRATAMENTO DAS LESÕES ENDO-PERIODONTAIS: UMA REVISÃO DE ESCOPO

Belén Retamal-Valdes, Kamila Ribeiro do Nascimento Jabur, Silvana Felisberto Monteiro, Laryssa Macedo de Oliveira, Renata Queiroz Tavares, Cristiane Gonçalves, Magda Feres

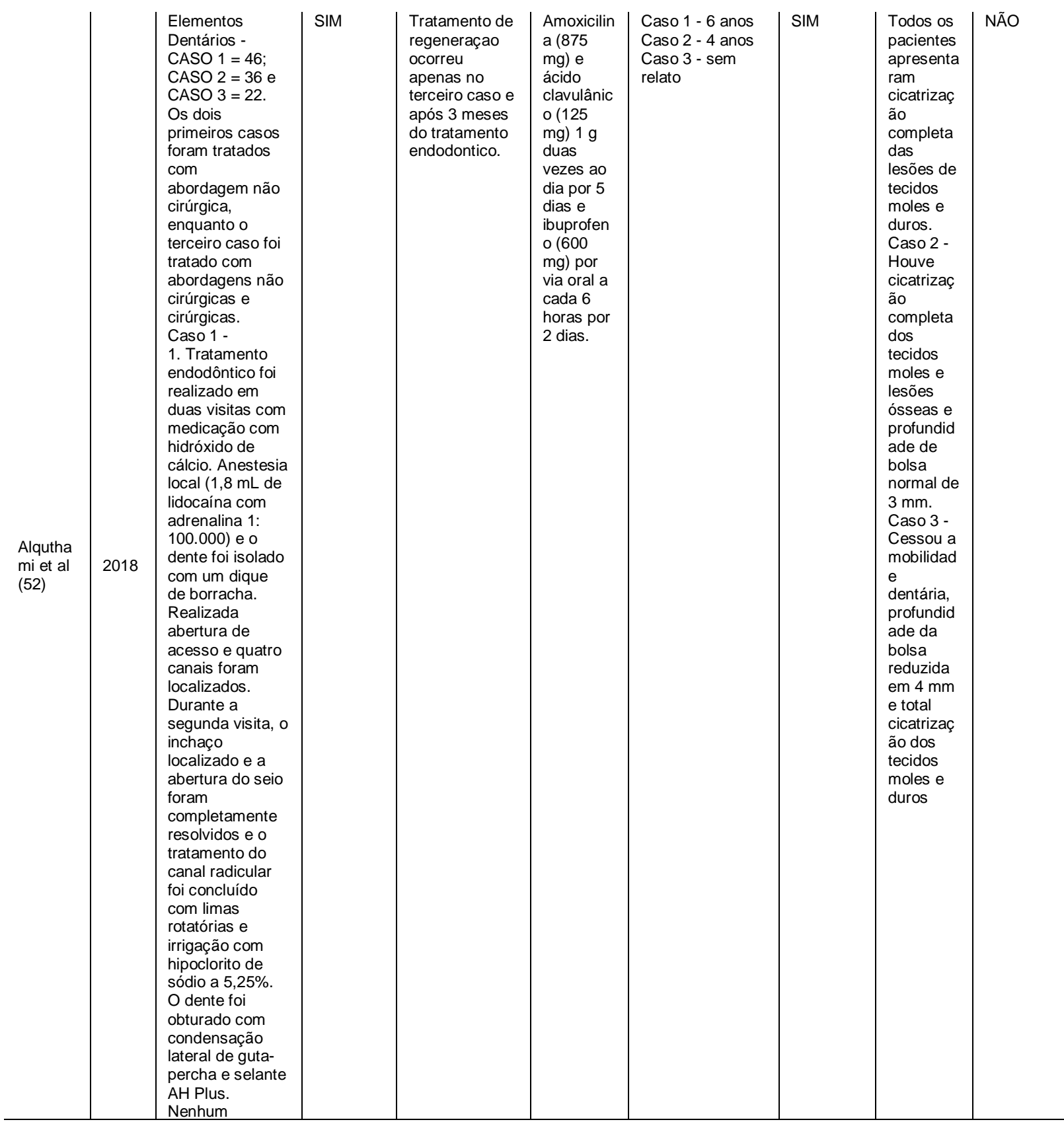


TRATAMENTO DAS LESÕES ENDO-PERIODONTAIS: UMA REVISÃO DE ESCOPO

Belén Retamal-Valdes, Kamila Ribeiro do Nascimento Jabur, Silvana Felisberto Monteiro, Laryssa Macedo de Oliveira, Renata Queiroz Tavares, Cristiane Gonçalves, Magda Feres

\begin{tabular}{|c|c|c|c|c|c|c|c|c|c|}
\hline $\begin{array}{l}\text { Dhoum } \\
\text { et al } \\
\text { (53) }\end{array}$ & 2018 & $\begin{array}{l}\text { Elemento } \\
\text { dentário } 13 . \\
1 \text {. RAR e } \\
\text { planejamento } \\
\text { radicular, } \\
\text { educação do } \\
\text { paciente e um } \\
\text { programa de } \\
\text { manutenção da } \\
\text { higiene } \\
\text { periodontal. } \\
\text { 2. O tratamento } \\
\text { endodôntico foi } \\
\text { administrado em } \\
\text { duas visitas: } \\
\text { Primeira } \\
\text { consulta } \\
\text { Paciente sob } \\
\text { medicação } \\
\text { amoxicilina dois } \\
\text { dias antes do } \\
\text { tratamento e na } \\
\text { semana } \\
\text { seguinte ao } \\
\text { procedimento. } \\
\text { Realização da } \\
\text { cavidade de } \\
\text { acesso sob uma } \\
\text { barragem } \\
\text { dentária e sem } \\
\text { anestesia local. } \\
\text { Preparação } \\
\text { mecânca do } \\
\text { sistema de } \\
\text { canais } \\
\text { radiculares } \\
\text { usando o } \\
\text { sistema } \\
\text { rotatório, } \\
\text { desinfecção } \\
\text { química com } \\
\text { hipoclorito de } \\
\text { sódio a 2,5\%, } \\
\text { preenchimento } \\
\text { temporário do } \\
\text { canal radicular } \\
\text { com hidróxido } \\
\text { de cálcio, } \\
\text { fechamento } \\
\text { coronal } \\
\text { temporário. } \\
\text { Segunda } \\
\text { consulta, } \\
\text { desbridamento } \\
\text { mecânico } \\
\text { adequado do } \\
\text { canal radicular } \\
\text { usando limas K } \\
\text { de aço } \\
\text { inoxidável } \\
\text { combinadas com } \\
\text { limas rotatórias. }\end{array}$ & SIM & $\begin{array}{l}\text { Duas semanas } \\
\text { - Início da } \\
\text { reorganização } \\
\text { óssea, } \\
\text { diminuição do } \\
\text { exudato } \\
\text { purulento, } \\
\text { diminuição da } \\
\text { mobilidade } \\
\text { dentária. } \\
\text { Dois meses - } \\
\text { Estabilização } \\
\text { da imagem } \\
\text { radiolúcida } \\
\text { revelada pelo } \\
\text { exame } \\
\text { radiográfico, } \\
\text { início da } \\
\text { reorganização } \\
\text { óssea, } \\
\text { diminuição do } \\
\text { exudato } \\
\text { purulento. } \\
\text { Seis meses - } \\
\text { Observou-se a } \\
\text { persistência do } \\
\text { exudato } \\
\text { purulento. Foi } \\
\text { realizado } \\
\text { então, um } \\
\text { retalho aberto } \\
\text { para limpeza } \\
\text { periodontal } \\
\text { com um } \\
\text { desbridamento } \\
\text { da superf́cie } \\
\text { radicular e foi } \\
\text { estabelecida } \\
\text { uma terapia } \\
\text { periodontal } \\
\text { completa para } \\
\text { concluir o } \\
\text { tratamento e } \\
\text { obter um } \\
\text { reparo } \\
\text { periodontal da } \\
\text { fixação. Foi } \\
\text { feita } \\
\text { imobilização } \\
\text { periodontal } \\
\text { para reforçar e } \\
\text { melhorar o } \\
\text { potencial de } \\
\text { cicatrizaçãa do } \\
\text { dente. } \\
\end{array}$ & $\begin{array}{l}\text { Paciente } \\
\text { sob } \\
\text { medicaçãa } \\
\text { o } \\
\text { profilática } \\
\text { de } \\
\text { amoxicilin } \\
\text { a dois } \\
\text { dias } \\
\text { antes do } \\
\text { tratament } \\
\text { o } \\
\text { endodônti } \\
\text { co e na } \\
\text { semana } \\
\text { seguinte } \\
\text { ao } \\
\text { procedim } \\
\text { ento. }\end{array}$ & 3 anos & SIM & $\begin{array}{l}\text { Cicatrizaç } \\
\text { ão de } \\
\text { tecidos } \\
\text { moles } \\
\text { com } \\
\text { recessão } \\
\text { gengival } \\
\text { localizada } \\
\text { no } \\
\text { elemento } \\
13, \\
\text { desapare } \\
\text { cimento } \\
\text { completo } \\
\text { da } \\
\text { produção } \\
\text { purulenta, } \\
\text { regenera } \\
\text { ção } \\
\text { óssea. }\end{array}$ & NÃO \\
\hline
\end{tabular}


TRATAMENTO DAS LESÕES ENDO-PERIODONTAIS: UMA REVISÃO DE ESCOPO

Belén Retamal-Valdes, Kamila Ribeiro do Nascimento Jabur, Silvana Felisberto Monteiro, Laryssa Macedo de Oliveira, Renata Queiroz Tavares, Cristiane Gonçalves, Magda Feres

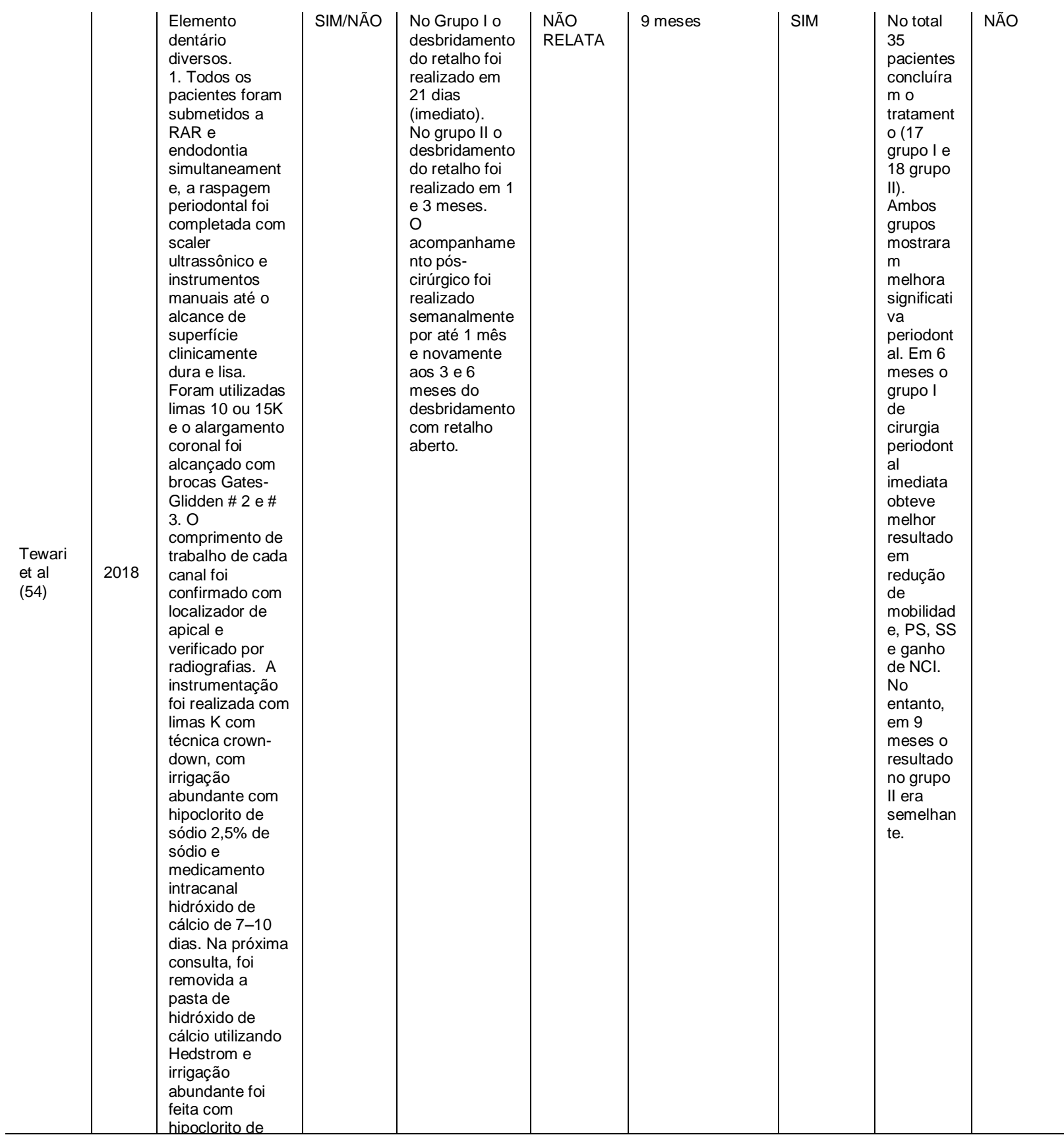


TRATAMENTO DAS LESÕES ENDO-PERIODONTAIS: UMA REVISÃO DE ESCOPO

Belén Retamal-Valdes, Kamila Ribeiro do Nascimento Jabur, Silvana Felisberto Monteiro, Laryssa Macedo de Oliveira, Renata Queiroz Tavares, Cristiane Gonçalves, Magda Feres

\begin{tabular}{|c|c|c|c|c|c|c|c|c|c|}
\hline $\begin{array}{l}\text { Oh et al } \\
\text { (55) }\end{array}$ & 2019 & \begin{tabular}{|l} 
Elementos \\
dentários \\
diversos. \\
1 . RAR seguido \\
de instruçōes de \\
higiene Oral. \\
2. Tratamento \\
Endodôntico: \\
Caso a polpa \\
não \\
respondesse ao \\
teste de \\
vitalidade foi \\
realizada a \\
endodontia, os \\
canais foram \\
limpos e \\
modelados com \\
instrumentos \\
rotativos de \\
níquel-titânio e \\
irrigados com \\
hipoclorito de \\
sódio a 5,25\%, \\
foram obturados \\
com guta-percha \\
e selante AH \\
Plus. \\
Posteriormente, \\
os dentes que \\
apresentaram \\
mobilidade \\
maior que o grau \\
1 foram \\
imobilizados nos \\
dentes \\
adjacentes \\
usando resina \\
composta e fio \\
de aço \\
inoxidável. A tala \\
foi utilizada para \\
estabilizar os \\
dentes móveis \\
durante a fase \\
cirúrgica a a \\
manutenção. 3. \\
Tratamento \\
periodontal \\
Cirúrgico - A \\
cirurgia \\
regenerativa \\
periodontal foi \\
realizada 3 \\
meses após o \\
tratamento do \\
canal radicular. \\
Após anestesia
\end{tabular} & SIM & $\begin{array}{l}\text { Após } 03 \\
\text { meses do } \\
\text { tratamento } \\
\text { endodôntico } \\
\text { foi realizado o } \\
\text { tratamento } \\
\text { periodontal. }\end{array}$ & \begin{tabular}{|l} 
Foram \\
prescritos \\
analgésic \\
os orais \\
(lbuprofe \\
no, 600 \\
mg, a \\
cada 8 \\
horas, \\
conforme \\
necessári \\
o) e \\
antibiótico \\
s \\
(Amoxicili \\
na / ácido \\
clavulânic \\
o, 375 \\
mg, 3 \\
vezes ao \\
dia) por 7 \\
dias, e os \\
pacientes \\
foram \\
instruídos \\
a \\
enxaguar \\
com \\
gluconato \\
de \\
clorexidin \\
a a \\
$0,12 \%, 4$ \\
vezes ao \\
dia para 3 \\
semanas.
\end{tabular} & 5 anos & SIN & $\begin{array}{l}\text { Acompan } \\
\text { hamento } \\
12 \text { meses } \\
\text { Media: IP } \\
0,74 \% \text {, } \\
\text { SS 13,78, } \\
\text { PS 2,96 } \\
\text { mm, PS } \\
\text { ponto } \\
\text { mais } \\
\text { profunda } \\
3,35 \% \text {, } \\
\text { Recessão } \\
\text { Gengival } \\
\text { 2,20, NCI } \\
\text { 5,16, NCI } \\
\text { ponto } \\
\text { mais } \\
\text { profundo } \\
5,49, \\
\text { mobilidad } \\
\text { e 10,27. } \\
\text { Observou } \\
\text {-se ganho } \\
\text { ósseo e } \\
\text { melhora } \\
\text { da PS, do } \\
\text { NCl, da } \\
\text { mobilidad } \\
\text { e, do IP e } \\
\text { do SS. } \\
\text { Não } \\
\text { houve } \\
\text { diferença } \\
\text { s } \\
\text { estatistica } \\
\text { mente } \\
\text { significati } \\
\text { vas no } \\
\text { nível de } \\
\text { inserção } \\
\text { clínica ou } \\
\text { ganho } \\
\text { ósseo } \\
\text { radiográfi } \\
\text { co entre } \\
\text { os grupos } \\
\text { com e } \\
\text { sem } \\
\text { membran } \\
\text { as. O } \\
\text { tratament } \\
\text { o } \\
\text { periodont } \\
\text { al de } \\
\text { suporte } \\
\text { dos } \\
\text { dentes }\end{array}$ & NÃO \\
\hline
\end{tabular}


TRATAMENTO DAS LESÕES ENDO-PERIODONTAIS: UMA REVISÃO DE ESCOPO

Belén Retamal-Valdes, Kamila Ribeiro do Nascimento Jabur, Silvana Felisberto Monteiro, Laryssa Macedo de Oliveira, Renata Queiroz Tavares, Cristiane Gonçalves, Magda Feres

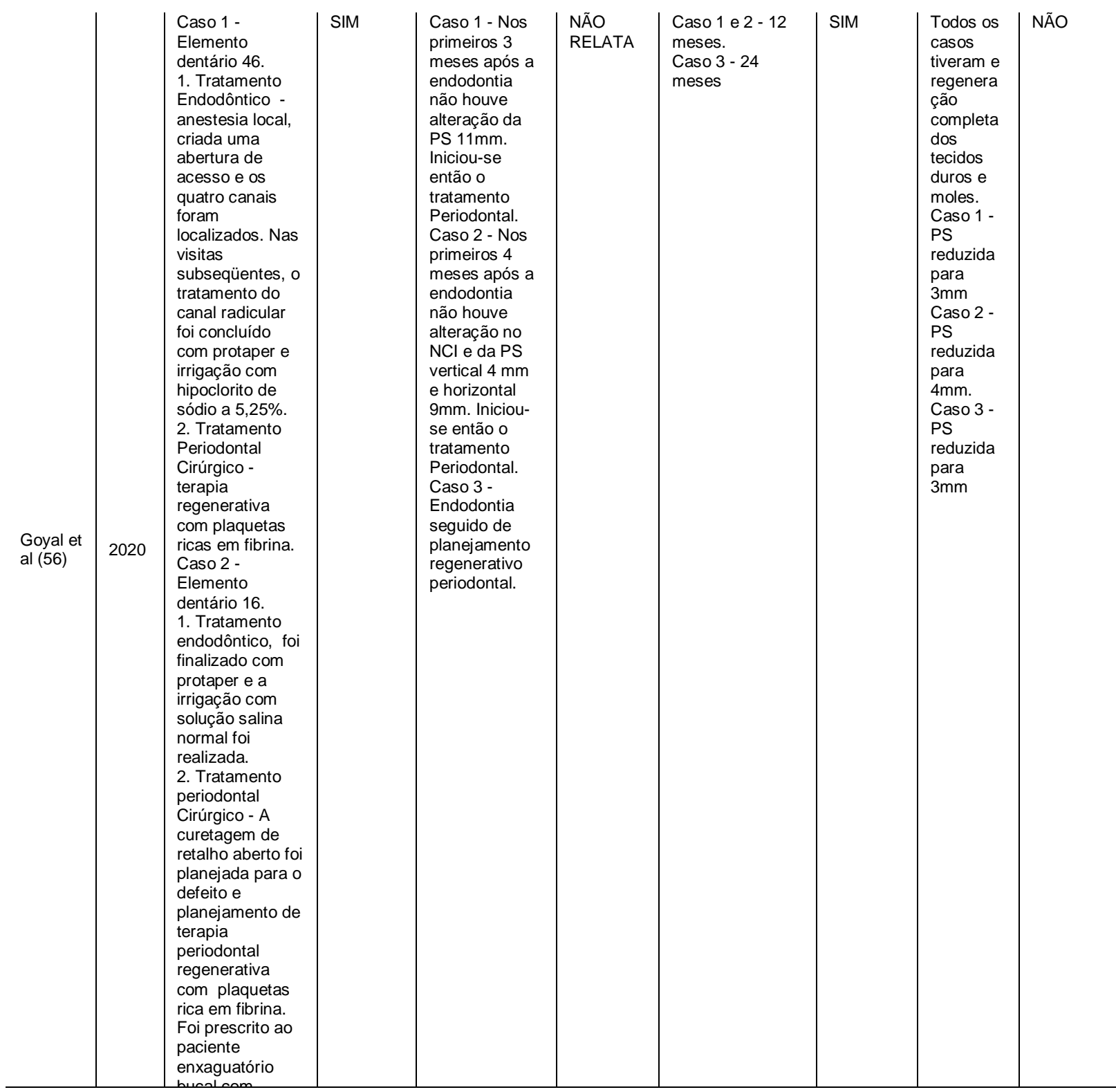


TRATAMENTO DAS LESÕES ENDO-PERIODONTAIS: UMA REVISÃO DE ESCOPO

Belén Retamal-Valdes, Kamila Ribeiro do Nascimento Jabur, Silvana Felisberto Monteiro, Laryssa Macedo de Oliveira, Renata Queiroz Tavares, Cristiane Gonçalves, Magda Feres

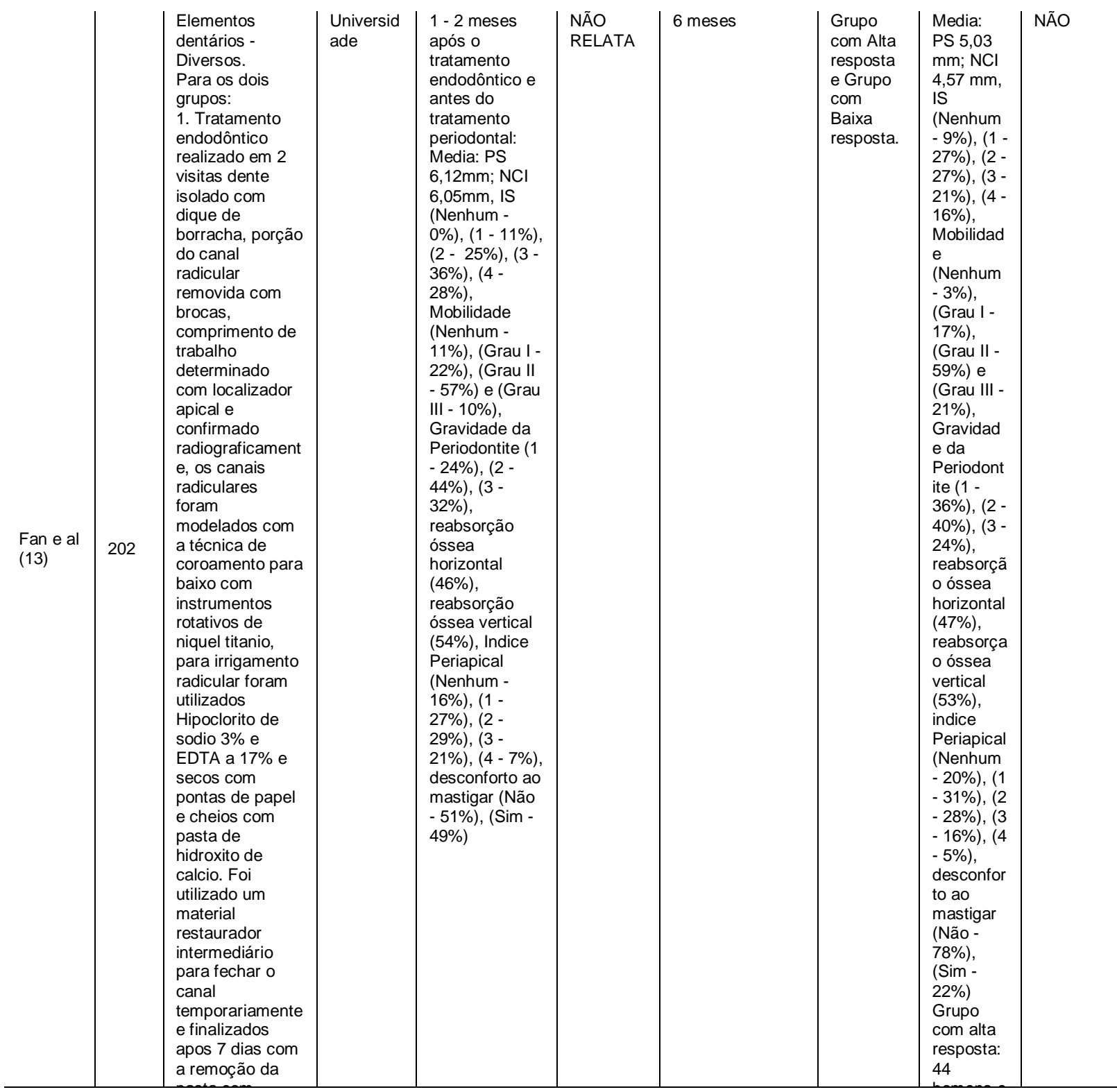

